\title{
Experience based learning : learning clinical medicine in workplaces
}

Citation for published version (APA):

Dornan, T. (2006). Experience based learning : learning clinical medicine in workplaces. [Doctoral Thesis, Maastricht University]. Universitaire Pers Maastricht. https://doi.org/10.26481/dis.20060512td

Document status and date:

Published: 01/01/2006

DOI:

10.26481/dis.20060512td

Document Version:

Publisher's PDF, also known as Version of record

\section{Please check the document version of this publication:}

- A submitted manuscript is the version of the article upon submission and before peer-review. There can be important differences between the submitted version and the official published version of record.

People interested in the research are advised to contact the author for the final version of the publication, or visit the DOI to the publisher's website.

- The final author version and the galley proof are versions of the publication after peer review.

- The final published version features the final layout of the paper including the volume, issue and page numbers.

Link to publication

\footnotetext{
General rights rights.

- You may freely distribute the URL identifying the publication in the public portal. please follow below link for the End User Agreement:

www.umlib.nl/taverne-license

Take down policy

If you believe that this document breaches copyright please contact us at:

repository@maastrichtuniversity.nl

providing details and we will investigate your claim.
}

Copyright and moral rights for the publications made accessible in the public portal are retained by the authors and/or other copyright owners and it is a condition of accessing publications that users recognise and abide by the legal requirements associated with these

- Users may download and print one copy of any publication from the public portal for the purpose of private study or research.

- You may not further distribute the material or use it for any profit-making activity or commercial gain

If the publication is distributed under the terms of Article $25 \mathrm{fa}$ of the Dutch Copyright Act, indicated by the "Taverne" license above, 
EXPERIENCE BASED LEARNING

LEARNING CLINICAL MEDICINE IN WORKPLACES 
ISBN 10:9052785228

ISBN 13: 9789052785226

Copyright (C) Tim Dornan, Manchester 2006

Lay-out and printing: Datawyse Universitaire Pers Maastricht 


\section{EXPERIENCE BASED LEARNING}

LEARNING CLINICAL MEDICINE IN WORKPLACES

\section{PROEFSCHRIFT}

ter verkrijging van de graad van doctor

aan de Universiteit Maastricht,

op gezag van de Rector Magnificus,

Prof. mr. G.P.M.F. Mols

volgens het besluit van het College van Decanen,

in het openbaar te verdedigen

op vrijdag 12 mei 2006 om 14.00 uur

door

Tim Dornan

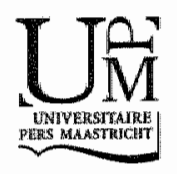




\section{PROMOTOREN}

Prof. dr. H.P.A. Boshuizen Open Universiteit Nederland Proll dr. A.J.J.A. Scherpbier

BEOORDELINGSCOMMISSIE

Prof. dr. C.P.M. van der Vleuten (voorzitter) Prof. dr. J.C.C. Borleffs, Universiteit Utrecht

Prof. dr. E. Heineman

Dr. L.W.T. Schuwirth

Prof. dr. D.L. Southgate DBE, Dsc, St. George's, University of London, UK 
To the mewory of my father, who would have approsed, and Ben, who hadn't arrived in the world when I dedicated my DM thesis to Ceri and Kate 
n 


\section{Table of contents}

1 Introduction 9

2 Early practical experience in medical education. 41

A rationale.

3 Early practical experience in medical education. 57

The evidence.

4 Learning in clinical workplaces. The teacher's perspective. 69

5 Learning in clinical workplaces. The learner's perspective. 83

6 Learning in clinical workplaces. Bringing teacher and learner together. 105

7 Measuring learning. Methodology. 121

8 Measuring learning. Conditions and outcomes. 137

9 Discussion 151

$\begin{array}{ll}\text { Summary } & 169\end{array}$

$\begin{array}{ll}\text { Samenvatting } & 175\end{array}$

Acknowledgements 181

$\begin{array}{ll}\text { Curriculum vitae } & 185\end{array}$ 
n 


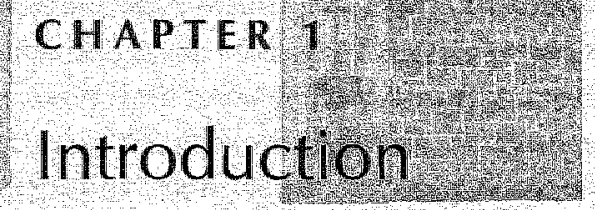


This thes is concerns the process of becoming a doctor, or "undergraduate medical education", "a misleading term given that some countries only admit graduates to medical school. True undergraduates enter fresh from secondary school or as "mature students". Medical training takes 4-6 years depending on the country and the student's prior level of education. High academic standards are required for entry to medical school and students have to be very motivated because medicine is an arduous course of study. As well as being ambitious, many medical students are altruistically motivated. In the early years, they learn biomedical sciences and, depending on the curriculum, behavioural and social sciences and perhaps humanities. In the later years, they apply theory to practice in clinical workplaces. After graduating, new doctors are able to take responsibility, under supervision, for the care of patients but they have to undergo postgraduate training before they can practice unsupervised. The aim of an undergraduate medical curriculum, then, is to produce graduates who can enter the workforce and receive a postgraduate medical training that will make them independent practitioners. Whilst those rather general statements are true, a more detailed examination of undergraduate medical education shows that its aims, structures, and processes are far from generally agreed and are in a state of change. This chapter first charts the historical origins and recent directions of change, focusing particularly on the Flexner reforms of 1910 and how preclinical education has changed in recent years. By describing how one medical school explored the strengths and weaknesses of "the new medical education", it shows that learning in clinical workplaces is also susceptible to change. It reviews what is known about clinical learning, identifies gaps in the published literature, and then introduces the research that forms the main body of the thesis.

\section{HISTORICAL PERSPECTIVE}

Medicall education as we know it today is deeply grounded in history. ${ }^{2}$ It began as a scholarly pursuit conducted in universities and untainted by practice. ${ }^{3}$ As the sciences of anatomy and physiology grew in strength, medicine became a more applied field of scholarship. ${ }^{4}$ Central to the work of a doctor was the art of bedside observation and diagnosis, which had to be learned from an established practitioner. The term "apprenticeship" is used to describe a mode of learning that was borrowed from the medieval guilds. Nineteenth and early twentieth century clinicians studied the craft of medicine at the feet of masters in the same way that young men learned a craft by serving a master craftsman, eventually entering the guild as a master. ${ }^{5}$ There, however, the similarity ends because medicine has a broader knowledge base than stonemasonry so apprentice doctors. have to master complex theory and integrate it into their practice. 


\section{ABRAHAM FLEXNER AND THE COMING TO AGE OF BIOMEDICAL SCIENCE}

The haphazard nature of medical education came to a head in late nineteenth century America, where medical degrees could be issued by any for-profit organisation on the flimsiest evidence. ${ }^{67}$ Abraham Flexner, a progressive educationalist, was hired to advise Andrew Carnegie's Foundation for the Advancement of Teaching how standards of medical teaching could be improved. This was a time when confidence in biomedical science was running high because research into infectious diseases was "rendering the baftling and terrifying world of illness .. intelligible and comprehensible" " Flexner"s landmark report was published in 1910. The American Medical Association, concemed about standards of medical education but lacking the clout of a wealthy philanthropy, teamed up with Flexner and endorsed a set of recommendations summarised in table 1.1. The key to high quality medical education was to be science. Medical schools should be research active university departments linked to teaching hospitals with full time staff. The study of medicine should have stiff entry requirements, recruiting graduates who would work towards a doctoral degree. After a preclinical grounding in the scientific disciplines, clinical education was to take place attached to clinician scientists in hospitals, using apprenticeship principles to integrate theory and practice.

Table 1.1 Key recommendations of Flexmer and the American Medical Association

- Medicine to be a umiversity study with tough entry requirements

- Smaller numbers of centres of excellence

- Active learning by enquiry and expeninent; education, not training

- Start with a grounding in science

- Clinical learning from university employed, academic practitioners

- A year of internship

Under Flexner"s influence, medical curricula around the world came to be structured into preclinical and clinical phases. Preclinical medicine was learned in the lecture theatres, teaching laboratories, dissecting rooms, and libraries of universities; clinical medicine was learned in the wards and operating theatres of university tertiary hospitals. Teaching was didactic, supplemented by one-to-one apprenticeship attachments to practitioners in the later curriculum. years. The knowledge that was taught and rested preclinically was biomedicine, moving to pathology and clinical diagnosis in the clinical years. The preclinical curriculum was explicitly "preparatory", and linked onlly conceptually to medical practice.

\section{THE FLEXNER PARADIGM UNDER PRESSURE}

As the twentieth century ran its course, the knowledge base of medicine burgeoned and science became increasingly removed from bedside practice. As in- 
terpersonal relationships; emotions, and value systems came increasingly within the ambit of medical practice, the epistemology of medicine widened to embrace humanities and social sciences. Educationalists became very critical of authority based, pedagogic methods of teaching. Learners and patients became more empowered. At the same time, changes in clinical practice put pressures on traditional apprenticeship. Table 1.2 lists conditions that favoured apprenticeship and changes that now militate against it.

Table 1.2 Conditions that Gyoured apprenticeship and modern day constraints on it

Conditions that fawoured apprenticeship Conditions in today"s healthcare systems

\section{Clinician-scholars}

Breadth of scholarship

Narrowness

Integrated practice

Specialisation

Able to supervise students continuously over long periods

Time to devote to education

Accorded education a high priority

Discontinuity

Lack of time

Education given a lower priority than service delivery, administration, and research

Experience of apprenticeship in their own

Lack of an apprenticeship tradition education

\section{Leaning enviromment}

Uniprofessional and collegial

Person-focused

Enough space for students

Staff: and students resident on-site

\section{potients}

Rich casemix "captive" for long periods on hospital wards

Lemming by practice in atuthentic clinical situation

\author{
Multiprofessional \\ Impersonal and technology-focused \\ Insufficient space \\ Staff and students resident off-site
}

More care in outpatient department and community; short stays, if hospitalised at all Patients safety not to be compromised by training

Huge expansion in numbers

In the late twentieth century, national bodies began to respond to the wind of change. The Association of American Medical Colleges published a report on "Physicians for the Twenty-first Century" recommending a stronger focus on meeting patients" needs, to be achieved through curriculum integration. ${ }^{3}$ Even more forcefully, the UK General Medical Council (GMC) mandated change in 
its set of recommendations entitled "Tomorrow's Doctors", 10 "t "The subject matter of medical curricula was to be reduced in quantity. There should be a core curriculum with defined leaming outcomes and protected time for students to pursue their own interests. Disciplines should integrate their contributions into a thematic, probably systems-based curriculum. Students should have real-life experiences in the early curriculum years. The foundation disciplines of medicine should include behavioural and social sciences and humamities as well as biomedical sciences. There should be more emphasis on people and populations, on doctor patient communication, and on ethics. The curriculum should familiarise students with modern, changing health care systems, multprofessionalism, and health care in the community. Students should understand principles rather than rote learn facts. They should learn through curiosity. Information and conmunication technology should be harnessed to support their learning. Tomorrow's Doctors suggested problem based learning (PBL) as a way of integrating students' theoretical learning but was notably silent on how to integrate workplace learaing. It offered no alternative to apprenticeship at a time when it was buckling under the aforementioned changes in academia, clinical practice, and society as a whole."

\section{CASE REPORT OF CURRICULUM CHANGE}

In the late $1980 \mathrm{~s}$, students of Manchester University Medical School were stridently critical of their curriculum, particularly the preclinical years. Relationships between staff and students were characterised, in the words of an outside consultant, by "mutual hostility". "The wind of change was already blowing in the wider world so Manchester decided to change its curriculum radically. "The Manchester experiment" is described here in some detail because it was both a test bed for the new medical education and the starting point for this thesis.

\section{RESPONDING TO THE WIND OF CHANGE}

The Dean shifted educational control from staff whose primary interest was in their own disciplines to staff whose primary interest was in learners and their learning. The School looked to Maastricht for a curriculum framework that would serve its students better and the first two curriculum years became problem based in 1995. There was no plan at that time to integrate clinical experience into the early years or carry educational reform into the clinical years but curriculum change itself became a force for change. Empowering students to be independent learners in the first two years without changing the latev years seemed very unwise so it was decided that the whole curriculum should change. What emerged was the "three turns of the spiral" curricultum within which the 
research reported in this thesis was conducted. ${ }^{2}$ The first two years - Phase 1 were to cover the biomedical, behavioural, and social science base of practice in a horizontally integrated design offering little clinical contact. The next wo years - Phase 2 - were to provide clinical experience within the same thematic structure as Phase 1 and, like it, be horizontally integrated. The last year-Phase 3 - was to be a time for students to immerse themselves in practice and make their final preparations to become a doctor.

\section{PBL IN THE CLINICAL YEARS}

There was empirical evidence and a wealth of experience that $\mathrm{PBL}$ worked and was a powerful integrating force. The revised curriculum governance structure stopped senior academic staff opposing curriculum reform to protect their own disciplines. It seemed reasonable to go beyond even the progressive schools whose curricula Manchester was modelling on and problem base Phases 2 and 3 . There would be scenario based PBL in Phase 2. Attachments to clinical disciplines would change from being the organising principle of the curriculum ${ }^{13}$ to a resource within which students would fulfil their PBL study agendas. Clinical PBL would be carried to its logical limit in Phase 3 , where students would use real situations encountered in their placements as trigger material for PBL tutorials. ${ }^{14}$ Manchester added an extra step to the Maastricht "7-jump" to formalise "clinical PBL". ${ }^{15}$ A clinical skills progranme was devised and implemented in Phases 2 and 3 . Curriculum leaders were advised that adult learning principles ${ }^{16}$ and the power of self direction ${ }^{17}$ would see to it that learners made good use of clinical learning opportunities. Clinical teaching and learning, it was hoped, could be harmonised with PBL into a rather simple pedagogic design.

\section{LESSONS LEARNED FROM CURRICULUM CHANGE}

The curriculum change was very successful in that it reduced the dropout rate from Phase 1, fostered staff-student relations that attracted favourable comment from the $\mathrm{GMC}^{18}$ established Manchester as a national leader in the rmedical education quality stakes, and prepared. graduates for practice better than the previous curriculum. 121920 Clinicians were willing to be PBL tutors and the flexibility of the new curriculum made space for specialties like anaesthetics and dermatology that were excluded from the old curiculum. But there were difficulties in Phase 2, particularly surrounding integration of disciplines, self direction, and the relationship between student and practitioner, which proved very instructive.

\section{Integration}

Clinicians wanted to be apprentice masters and teach their disciplinary expertise rather than be PBL tutors and facilitate students" integrated learning. In the Fam- 
ilies and Children Module, paediatricians and obstetricians found just one pice of conmon ground in refusing to teach breast and testicular disease because "that's surgery"."21

\section{Self direction}

Lack of self direction in students" learning behaviour was another cause for disappointment. Hospital practitioners criticised students for being unsure what they needed to learn on firms and general practitioners criticised hospital practitioners for letting students come away from PBL tutorials without objectives for their community placements. Despite four prior years' experience of PBL, Phase 3 students asked their tutors to teach them rather than help them turn clinical problems into PBL leaming objectives. ${ }^{14}$ Students and teachers seemed uncertain how to relate to one another.

\section{INTERPRETATION OF THE MANCHESTER EXPERIMENT}

At first it was hard to understand the difficulty. In accordance with adult learning principles, students had been empowered to learn independently and given choice. Teachers had been changed from apprentice masters to facilitators of integrated learning. Clinical disciplines had been changed from the organising principle of workplace learning to a resource for students" self directed learning. And yet the very same students who were empowered by those principles to learn theory through PBL seemed unsure how to behave in clinical workplaces. Worse, teachers were now disempowered too. Various interpretations had to be considered: That the new curriculum was poorly implemented (incompetence); that it was still too early to judge (impatience); that adult learning principles had not been imposed resolutely enough (incompleteness); that the clinical workplace was such a clifferent learning environment from the seminar room that different principles applied (difference); and that it was misguided to have tinkered with clinical teaching and learning in the first place. The last interpretation was hard to accept given that the philosopliy, structure, processes, roles, and outputs of Phases $2-3$ would then have been incompatible with the new Phase 1 . What published evidence there was did not suggest that Manchester had applied sound principles incompetently; several other medical schools had failed to integrate clinical learning and none had reported success. 22-27 Likewise, the one report about self directed learning in clinical settings reported difficulty implementing it. ${ }^{28}$ Regarding impatience, the field was so new that there was little empirical evidence from other schools; however, Manchester had itself published evidence that curficulum leaders were forced to regress towards disintegration rather than progress towards integration, showing that, at least, time was not on Manchester's side. ${ }^{21}$ Given the bold nature of Manchester's curriculum change, the incompleteness interpretation seemed unlikely. This thesis explores "the 
difference interpretation". Manchester had implemented PBL according to clearly articulated theory supported by empirical evidence (not reviewed here). The same principles, applied to clinical leaming, had been found wanting so there must be some important difference between the two types of learning.

\section{LEARNING CLINICAL MEDICINE IN WORKPLACES}

Table 1.3 examines some of the assumptions implicit in the trte of this thesis and in alternatives that might more conventionally have been used. It shows that the chosen title leaves the relationship between teacher and learner undefined. Unlike previous research that has been strongly bound to specific clinical contexts, the leaming environment under study is very deliberately framed by the broad term "workplace". The equally broad term "learning" is used in preference to "teaching" to avoid any presuppositions about a didactic relationship between teacher and learner.

Table 1.3 Some tems commonly used when reporting research into clinical teaching and learning

\begin{tabular}{|c|c|c|c|c|}
\hline Term & Context & Relationship & Educational focus & Dominant Role \\
\hline Preceptorship & & Mentor-mentee & Relationship & Preceptor \\
\hline Glinical teaching & & & Teaching & Teacher \\
\hline Bedside teaching & Hospital ward & & Teaching & Teacher \\
\hline Ward based teaching & Hospital ward & & Teaching & Teacher \\
\hline Ambulatory learming & $\begin{array}{l}\text { Out patient or } \\
\text { primary care }\end{array}$ & & Learning & Leamer \\
\hline Apprenticeship & & Master-apprentice & Task learning & Apprentice \\
\hline Firm & Implicitly hospital & & & $\begin{array}{l}\text { Member of community } \\
\text { of practice }\end{array}$ \\
\hline $\begin{array}{l}\text { Learning in clinical } \\
\text { workplaces }\end{array}$ & $\begin{array}{l}\text { All places where } \\
\text { patients and } \\
\text { practicioners meet }\end{array}$ & & Learming & Worker \\
\hline
\end{tabular}

The paragraphs that follow review what is already known about learning clinical inedicine in workplaces. To keep the topic as open as possible, it does so from an instructional design perspective ${ }^{29}$ under the headings: Roles and attributes of the actors; outcomes of clinical learning; the workplace as a leaming environment; curriculum design; instrumentation and media. 


\section{ROLES AND ATTRIBUTES OF THE ACTORS}

Medical education has three main actors: The student, the doctor, and the patient. According to the Hippocratic Oath, medicine is practised primarily "for the benefit of the sick", a position reaffimed by the GMC when it made the first Duty of a Doctor to "make the care of your patient your first concern". 30 Further, the Hippocratic oath calls on leamers to "hold him who has taught me this art as equal to my parents and to live my life in partnership with him" and teachers to "to give a share of precepts and oral instruction .. to pupils who have signed the covenant and taken an oath according to medical law" "31 the latter point also being reinforced by the GMC. ${ }^{32}$ So, the profession of medicine binds practitioners, students, and patients into a triadic relationship of mutual responsibility.

\section{The student}

Research into the roles and attributes of medical students is limited because the behaviourist model of clinical education that prevailed until recently was more preoccupied with how teachers "transmitted" learning than how learners responded to their learning enviromment. ${ }^{33}{ }^{34}$ Latterly, reflective learning theory has shifted attention towards learners ${ }^{35-37}$ and empirical research has shown wide differences in learners" reflective capacities and the sophistication of their personal value systems. ${ }^{38}$ It has also shown how their reflective learning can benefit from a supportive tutor. ${ }^{39}$

Socialisation into communities of practice-Contemporary, social theories of learning conceptualise expertise as residing within communities of practice and are therefore concerned with how learners absorb and are absorbed into a culture, ${ }^{40}$ and how their identity changes as a result. ${ }^{38}$ To learn, according to socio-cultural theory, is to adopt a new "way of being". 4142 Entering the medical community forces students to "rethink their constellation of values, beliefs, attitudes and dispositions" $" 43$ a process that can evoke strong emotions as they surrender their individualities and "try on" new professional idencities, which fit more or less comfortably. ${ }^{44-47}$ They may be torn between feelings of empathy towards patients and acculturation to a more impersonal professional ethic. The pressure to socialise can be so great that they surrender their individualism in favour of a "ritualised professional identity". 49 "They construct their professional identity by negotiating a role in the workplace, which allows them to participate and be recognised as junior members of a clinical team. 4150 The reflexive processes between teacher and learner constitute learning - so learning is not just facilitated by the relationship between them, but resides within that relationship. dents construct their professional identities by role modelling forms of behaviour that are held collectively within the community of practice, as well as role 
modelling on individual practitioners. ${ }^{51}$ The final result of this process of acculturation is readiness to ake on professional power and responsibility as a fully fledged member of the community. 52

Amhropological perspective - A medically tramed social anthropologist spent a year as a participant observer (in the guise of a medical student) in a UK medical school. He observed what he describes as the official and unofficial front and back stages. The curriculum on paper is "the official front stage"; many student activities in clinical workplaces are "official back stage"; activities like the annual medical student pantomime are "unofficial front stage"; and social contact among medical students is "unofficial back stage", or the hidden curriculum. Sinclair interprets medical training in terms of the interplay and transitions between the "dispositions" (attributes) of idealism, status, knowledge, experience, and responsibility. Idealism leads people to apply to medical school. Becoming a medical student gives them status. The disposition of knowledge dominates their preclinical learning. As they move into clinical settings, the disposition of experience dominates and they are motivated by the prospect of acquiring the disposition of responsibility after qualification. All this is mediated by social interaction. A short extract from the book (in which the author uses capitals to identify the dispositions) illustrates the power of his interpretation. Considering why obstetrics is, for some students, the high point of the clinical years, he notes that "they do not have to attend any conflicting lectures of Knowledge (and) the patients .. are individual women, whom they may stay with throughout their labour. During their attachment, at first they are closely supervised by midwives (but not doctors), but later it is only the delivery that is supervised, the midwife sometimes simply being present with a few words of advice or help. Students" medical Status is therefore less ambiguous than it nomally is on wards; their patients provide not only Experience but, much more importantly, an opportunity for the practice of the action of Responsibility. During the hours spent with the patient, a close relationship may be established in the practice of a less exclusively medical Co-operation than usual, in that the aims of the student (in whom, for once, personal and professional Idealism closely overlap) and the woman in labour are effectively identical." The role of the student, it seems from those observations, is to participate in very complex, value laden, social process, embedded in the world of work and acquire attributes that are culturally defined.

\section{The clivician}

Doctors who teach range in seniority from consultant to house officer. ${ }^{53}$ At its most basic, their role is to give students access to the workplace and help them interpret their experiences. ${ }^{45}$ Junior doctors can fulfil the role very effectively ${ }^{54}$ 
55 and hospitals tend to rely heavily on them. 556 Senior doctors are generally perceived as less supportive than juniors and even frankly thostile, ${ }^{\text {s3 }}$ though they can allso be very effective teachers. "A good consultant" inspires students with their personality and skill, and "charms rather than terrorises" people into efficiency and collaboration. ${ }^{57}$ Doctors are not the only practitioners students encounter in the workplace; nurses and midwives, in particular, can strongly influence their learning for better or worse ${ }^{49}$ though their role has not been well enough researched to be included in the following paragraphs.

Why doctors teach - Published research into the attributes of clinical teachers has an inherent positive bias because much of it was conducted on dinicians who chose to teach or were identified by their students and peers as excellent teachers. They are altruistically motivated. ${ }^{589}$ enjoy teaching, and want to give something back to their profession by supporting students' professional dovelopment. They also want to recruit students to their own specialty. ${ }^{58}$ They see the ethics of patient-centred practice and learner-centred education as closely intertwined and value the stimullus to reflect on practice that comes from being a teacher. 606 !

What doctors teach - They train students to perform clinical skills, often opportunistically and to no specific curriculum. ${ }^{62}$ Good teaching, whatever it covers, motivates and empowers students to continue learning relevant subject matter after the teaching has finished. ${ }^{63}$ Students crave direct observation of their workplace performance with formative feedback but receive much less of it than they would like; 4755 64-71 one author noted that students are directly observed by a supervisor and given feedback in fewer than. $10 \%$ of patient encounters, ${ }^{72}$ a shortcoming that teachers tend to deny. ${ }^{54} 73$ There are other idiosyncrasies in students' and teachers" perceptions of clinical teaching, students failing to recognise when they are being taught, and teachers believing they are teaching simply because they have students in attendance. 53

Attributes of effective teachers - Effective clinical teachers are familiar with adult learning principles, humanitarian, open-minded, and enthusiastic to teach. ${ }^{60} 74$ They are positive role models, effective supervisors, dymamic teachers, and supportive colleagues. 6075 Their clinical expertise is congruent with their educational expertise ${ }^{60}$ and they are confident in their clinical and teaching skills. ${ }^{76} 77$ Students describe them in emotional language ${ }^{63}$ as people who inspire a sense of mutual trust $\mathrm{t}^{41}$ 63 and respect. ${ }^{49} 78$ They motivate by being receptive, ${ }^{7379}$ encouraging ${ }^{49}$ and enthusiastic. ${ }^{61}$ They have time for students ${ }^{34} 73$ and give them a sense that they are nembers of the clinical team. ${ }^{4164}$ They inspire students to be confident in their own abilities. ${ }^{78}$ Effective teachers "hold the tension of opposites" 
by developing a warm relationship with students whilst maintaining a distance that is appropriate to their seniority. ${ }^{34} 4349637880$

Effective teaching behaviour - From a systematic review of measurement scales, Beckman and colleagues identified two main constructs that define effective behaviour: 81 Clinical teaching (present in two thirds of scales) and interpersonal relationships (present in half). Those constructs are represented in the Stanford Faculty Development Program's clinical teaching framework, a validated measure of teaching quality, which has seven domains of teaching effectiveness: The ability to foster an appropriate learning climate, take control of a session, communicate goals, promote understanding and retention, evaluate students' performance, give feedback, and promote self directed learning. ${ }^{82} 83$ The newer CanMEDS framework focuses less on the practitioner's teaching prowess and more broadly on their role as medicall expert, communicator, collaborator, manager, advocate, scholar, and professional.

Effective clinical teaching is clear and well organised. ${ }^{84} 85$ Teachers get better at it by reflecting on their teaching experiences ${ }^{868}$ and develop "teaching scripts", which are closely intertwined with the "illness scripts" that make them effective diagnosticians. ${ }^{868899}$ Different people have very different styles so peer reviewers find it easier to recognise that a teacher is good than define what makes them so. The best teachers tend to be older, ${ }^{6590}$ having developed through experience an ability to make a diagnosis on a patient and a learner simultaneously. They follow "a course of co-discovery with learners". ${ }^{65}$ They ask questions sensitively" and do not ask too many of them, use them to manipulate conversations, or ask them with a rigid agenda in mind. They do not show up middle grade staff in front of students. Effective clinical teachers establish a warm climate, seize opportunities to teach humanistic behaviour, role model, actively engage with learners, seek to be practical and relevant, and are adaptable to different situations and the needs of different learners. ${ }^{91}$ The clinician educator, it has been said, must be able to "undertake, demonstrate, and explain good practice". 92 The literature abounds with descriptions of teaching by humilliation, sexism, racism, delegation to students of inappropriate chores, failure to value students" individuality, and other forms of disrespectful behaviour. 45464957993 Less conspicuous, but at least as important, vices are apathy 45453 and the projection onto students of dissatisfaction, uncooperative behaviour, difficult personalities, and uncaring attitudes towards patients. ${ }^{80}$

What teachers get out of teaching - Contact with individual students is consistently described as a source of reward, even amongst clinicians who feel antagonistic towards the medical school in which the students are enrolled. ${ }^{95}$ Teachers value 
opportunities to teach climical skills and widen stadents" experience of disease. 96 Clinical teaching can offset some of the pressures of practice by rewarding practitioners with knowledge, a sense of professional growth, and a sense that they ate giving something back to the profession. ${ }^{74}$ Adding teaching responsibilities to a heavy clinical workload is more likely to alleviate than worsen stress, explained thus: "For professionals motivated by the desire to "make a difference", training young doctors to treat a condition seems more productive than simply doing that treating oneself." In the sessionally paid and therefore relatively protected enviromment of UK primary care education, one group of researchers "explicitly looked for negative effects of teaching on doctors and their practices and found very few." Through teaching, clinicians develop a new professional identity, which "often (begins) with a specific incident involving a learner and (evolves) as knowledge and expertise (increase)." They experience "ego gratifcation and personal pride", their self-identity as a teacher being intertwined with their self-identity as a physician. ${ }^{74}$ There is, however, a cost attached. 'Teaching slightly reduces clinical productivity, increases clinicians" working hours, and reduces their face-to-face contact with patients though that is more than offset by the time their learners spend with the patients. Being well organised can reduce the adverse impact of teaching on a clinician's productivity. ${ }^{90.101}$ When a clinician is dissatisfied with their teaching role, it is usually with the organizational framework within which they teach rather than the direct contact with students. ${ }^{102} 103$ Curriculum change can disenfranchise, disempower, confuse, anger and demoralise clinicians, ${ }_{y} 27$ though it can also create new opportunities for clinicians to be teachers. ${ }^{98}$ Many clinical teachers have positive attitudes towards faculty development ${ }^{56}, 77$ though few acknowledge that their teaching is below average. 95

Changing conceptions of the teaching wole - Recent publications in medical education have shown a conspicuous shift in emphasis from "teaching" to "forming relationships" with learners. The research of Mann ${ }^{60}$ and Fernald $\mathrm{d}^{63}$ into teachers" and learners" contributions to, and rewards from, clinical education deserves special mention. Both studies used rigorous exploratory methods to break away from traditional conceptions and reframe the role of teacher from a social perspective. By forming relationships, the teachers they interviewed were able to support learners' reflective learning, ${ }^{104-106}$ help them build a humanistic orientation, ${ }^{91}$ and foster a favourable educational climate. 107108

\section{The patient}

Sir William Osler, doyen of clinical workplace learning, regarded "the dissociation of student and patient (as) a legacy of the pernicious system of theoretical teaching", ${ }^{109}$ a view shared by clinicians and students today. ${ }^{110-112}$ Meeting pa- 
tients in workplaces is central to clinical learning and can help student develop, inter ali, clinical reasoning, communication and other interpersonal skills, professional attitudes, and empathy. ${ }^{12}$ Involvement in clinical education can be of direct benefit to patients, up to $90 \%$ of whom are willing to participate $40110-117$ They do so for altruistic reasons and because they believe they will receive better treatment as a result. 11511 "The experience of talking to students is often enjoyable and more likely to make patients' anxieties better than worse, 115116 just as involving patients in ward round discussions about their care can improve their mood and sense of involvement. ${ }^{18}$ Patients feel rewarded when they serve as an exemplar of and expert in the condition they suffer from. They appreciate helping medical students develop professional skills and attitudes and like to learn about their diseases and the training of doctors. 17 Patients can be active providers of medical education though their role is usually a passive one. ${ }^{117}$ Patients decline to participate in clinical teaching because they are concerned about confidentiality or have previously had a bad experience. 115 Despite those positive atcitudes, clinical teachers often fail to ask patients" consent or even tell then they are contributing to teaching. When patients give consent, they may do so under duress and their goodwill may be exploited. ${ }^{10112115119}$ Teachers sometimes put students into uncomfortable and ethically indefensible positions. ${ }^{119}$ Giving patients a role in the workplace education of students, it can be concluded, is valuable, ethically justifiable and feasible and there seems to be potential to give patients a more active role. Table 1.4 lists conditions for patients to have an effective role in clinical education.

\section{Inforrned consent}

- Patients should be informed

- They slould give consent and have an real option of declining

- The process of obtaining informed consent should rnake explicit and recognise the intrusiveness of the proposed procedure

- Paticns who are concerned about confidentiality or have had previous bad experiences of involvement in teaching nust be given every opportunity to decline

\section{The teaching exercise}

- The student and teacher should act sensitively and respectfully towards the patient, remaining aware of the patient's presence throughout the teaching exercise

- The patient should be involved as actively as circumstances permit

- Opportunities should be created to educate patients and alleviate their anxieties

- Thanks to the patient for participating should recognise their altruism and expertise

\section{Potential not yet fully explored}

- Involvenent of patients as expert instructors 
Roles and attributes; summary

Prowess in chinical practice is an important attribute of the clinician educator. Students, practitioners, and patients are ready to enter into a relationship of mutual accountability. Medical education is moving from Beckman's traditional construct of "clinical teaching" to his newer construct of "interpersonal relationships". 81 What outcomes those relationships should aim to achieve and how relationships should be forged in the world of work are the topics of the next pwo sections.

\section{OUTCOMES OF CLINICAL LEARNING}

The outcomes of clinical workplace learning are rather poorly defined ${ }^{120}$ for several reasons. First, it is difficult to distinguish learning outcomes from conditions for learning; motivation, skill, and applied knowledge, for example, are at the same time outcomes of previous learning and conditions for future learning. Second, learning processes and outcomes are tightly intertwined; student, clinician, and teacher may be clear that they have had a good or bad ancounter whilst being unclear about what made it so. Third, clinical mastery is a rich amalgam that includes such things as affects, tacit knowledge, and relationships. Complex as the clinical learning process may be, ${ }^{63}$ however, instructional design calls for outcomes to be defined.

\section{Emotional outcomes}

A very large number of publications report emotional outcomes from workplace learning. ${ }^{34} 394143-495355636470787993110121-132$ Students feel daunted at the prospect of entering the clinical environment. However, workplace experiences can leave them feeling satisfied, rewarded, motivated, and confident. Their growth in knowledge, clinical skills, and study skills is helped by those positive emotions. Growth in competence can be set back by workplace experiences that leave students disappointed, frustrated, angry, demotivated, and unselfconfident. Whilst some stress is inevitable, researchers have found a level of stress that is counterproductive, particularly when students first start medical training and enter the clinical environment. They may develop clinical arnxiety and depression and feel unsafe or powerless in the presence of practitioners and patients. They may lose their sense of identity. Students can learn to recognise and manage their emotional responses, a process that is helped by the support of a personal tutor and membership of a clinical team. PBL may be less stress inducing than a traditional curriculum. ${ }^{51} 133$

\section{Experiences of transition}

Changing "from being a predominantly pre-clinical science student .. to being an apprentice doctor on the ward" 46 gives students an experience of transition." 
4446751134135 They "shift from feelings of competence as adult lay persons to the uncertainty of beginners in the medical profession". 43 "They have to work long hours, respond to a variety of powerful personal experiences, and learn how to interact with practitioners. Then, as when they go through their next transition into the status of qualified doctor, ${ }^{135} 1^{136}$ both positive and negative emotions result. $434446 \$ 71135$

\section{Restructured knowledge and applied skills}

Through their workplace experiences, students restructure their knowledge around clinical situations rather than diseases. 44 47 They leam to apply skills previously learned in simulation to authentic situations ${ }^{4447}$ and learn new skills.

\section{Shudy skills}

Workplace experiences teach students "a different style of learning and teaching that is more diffuse, unbounded, and opportunistic than in the earlier years", 45 which calls for new study strategies. 414454750 Taking the operating theatre as an example of a workplace, one author identified three things students had to learn to manage: The demands of the working environment and its emotional impact; the educational tasks - determine the learning objectives and relevance; leaming and the social relations of the workplace. 50

\section{Fitness for practice}

Forty percent of medical graduates (varying from 20 to $73 \%$ in different medical schools) report feeling poorly prepared for practice because they have not seen a sufficient breadth of case mix, are insufficiently trained in procedures or inexperienced at performing them in authentic workplaces, and lack experience of the role of doctor. ${ }^{137-140}$ One medical graduate reported that the most essential attributes for her survival as a house officer - common sense and being able to organise and prioritise her work - had never been touched on during all her years in medical school whilst she had to releam the physiology she had spent so long acquiring to make it relevant to acutely ill patients. ${ }^{141}$ The situation can, however, be improved upon by instructional redesign. Graduates of the Manchester PBL course regarded themselves as better able to work in teams, communicate with other people, recognise the biopsychosocial nature of illness, tolerate uncertainty, call for help, and manage their learning and practice than graduates of the previous, traditional course, a perception that was shared by their supervisors. 139

\section{Outcomes; summary}

The outcomes of clinical workplace learning are also necessary conditions for further learning. They are complex and interrelated with one another and with 
the extemal conditions of the leaming environment. They include emotional outcomes, which can be negative as well as positive, a restructuring and application of knowledge and skills, and the acquisition of study skills. Many students feel deficient when it comes to the final outcone, entry to postgraduate training as a competent practitioner.

\section{THE WORKPLACE AS A LEARNING ENVIRONMENT}

\section{Context}

A student's clinical education takes place on a series of placements. In hospital, these are firms, which differ considerably from one to another in the type of learning environment they provide. ${ }^{\$} \quad 627.142 \quad 143$ There are many different workplaces within a hospital; for example, the operating theatre, a complex physical environment with very specific protocols, a distinctive working culture, and an emotional impact that can be positive or negative, ${ }^{41}$ and the day surgery unit, a novel workplace that came into existence through changes in the organisation of healthcare and has been harnessed to teach students. ${ }^{69} 14.4145$ It is only in the last four decades that clinical leaming laas extended beyond the wards, operating theatres, and post-mortem rooms of teaching hospitals. Now, students move back and forth between many different clinical environments and their medical school. ${ }^{121142146}$ As medicine has come to be practiced in more varied settings, curricula have had to offer a wider variety of workplace experiences so students can make informed career choices after qualification. ${ }^{1.47}$

\section{Climate}

Students' learning is strongly influenced by the climate of their workplace. ${ }^{45} \mathrm{~A}$ friendly climate that supports their involwement in practice, makes them feel valued as individuals, and makes clear what is expected of them, makes them feel part of the team. ${ }^{459}$ A positive social climate fosters learning through collaboration and coaching. ${ }^{39}$ However, students often encounter an unfriendly climate in which they are left hanging about, shouted at, or bumiliated. $.^{459} 579 \mathrm{Be}-$ ing well received when students first arrive on a placement predicts that they will subsequently find it a satisfactory one ${ }^{556069}$ District hospital and community placements are experienced by students as more friendly and person centred, and less technology focused than academic hospitals. ${ }^{45} 5455$ There tends also to be less peer competition for experience and better personal support in settings that are away from academic centres. ${ }^{416456}$ Especially at the start of clinical placement learning, a workplace that is particularly receptive or hostile can have a lasting impact on students' learning. ${ }^{43} 45$ Students are acutely aware of the power differential between practitioners, who are very important, and themselves, who are very umimportant; ${ }^{4145}$ so practitioners have great power over the 
leaming climate." Patients rarely have anything but a positive effect on the climate and negative interactions with peers usually arise in hierarchical and wnsupported learning environments. ${ }^{49}$

\section{The activities of the learning environment}

Meeting patients - Manchester has described how, to integrate workplace and theory learning, its Phase 2 students self directedly sought out clinical experience to fulfil their PBL learning agendas. ${ }^{146}$ Other medical schools arrange for students to meet a patient in community 121148 or tutorial room ${ }^{113121148-150}$ either as a supplement or altemative to the more typical simulated PBL trigger materials. 13151 Students tend to rate "real patient PBL" as more motivating than "simvlation $\mathrm{PBL}$ ", although their strong identification with the patient as an individwal may distract from the generalities that the patient represents. ${ }^{14}{ }^{14}$ "Simulation PBL" may have the drawback of distracting students from hands-on workplace learning. ${ }^{151}$ To build up a sufficient breadth of experience to support their future clinical expertise, ${ }^{89}$ students have to use the varied workplaces at their disposal to access a broad case mix. ${ }^{5455142-144}$ There are big differences in the depth and breadth of different students' experiences, 71137140152 and a trend in the UK towards students gaining progressively less clinical experience in recent years. ${ }^{153}$ Meeting patients motivates students to learm, 447113135149 although they may be anxious they will cause patients harm when they first put their clinical skills into practice. ${ }^{47}$

Participating in practice - Students can become involved in practice by attending business ward rounds or outpatient clinics with hospital doctors, ${ }^{142}$ or attending consulting sessions with general practitioners. ${ }^{39}$ They may be present as observers, ${ }^{127}$ or become more actively involved by clerking patients, formulating assessments, presenting on ward rounds, proposing management plans, or writing progress notes. ${ }^{154}$ On ward rounds, students value the chance to propose a management plan and receive feedback on their performance. ${ }^{70}$ Other valued experiences are "scrubbing up" and taking a place at the operating table or participating in delivery room activities. ${ }^{4} 55$ Students witli different career orientations find different types of involvement waluable. Those pursuing surgical specialties tend to favour definitive interventions with immediately tangible results, whereas those heading towards primary care specialties find personal interaction with patients most valuable. ${ }^{80}$ An absolutely consistent finding is that active involvement is more highly valued than passive involvement, and the closer the involvement comes to providing care to patients the more valued it is. 51.53636670 $78-80122125127$ Teachers can empower students to participate actively by making reasonable demands of them, introducing them to patients, providing coaching 
and constructive criticism, and being accessible. ${ }^{55} 63$ 64t $\mathrm{It}$ is inevitable that completely inexperienced students will first enter workplaces as passive observers ${ }^{79}$ but they quickly become bored, frustrated, and disappointed when, as often happens, they progress too slowly beyond the status of observer. 46.54564125127

Various processes have been described to combine education and patient care during workplace activities, the best theorised and validated of which is the "One-minute Preceptor Model" 155-158 A preceptor trained in this model uses five "microskills" to debrief a student on a clinical encounter: Get a commitment; probe for supporting evidence; teach general rulles; reinforce what was done right; correct mistakes. One-minute preceptorship is easy to learn and both efficient and effective in practice. Most important, it has been shown that preceptors using the model make diagnoses at least as well and exploit the educational potential of patient encounters better than preceptors debriefing students traditionally. ${ }^{157}$ Use of the model broadens the content of leaming encounters to include disease specific teaching as well as clinical skills. 158 Teachers' behaviour during learning encounters can also be improved by assessing them and giving feedback on five types of behaviour: Role modelling; scaffolding; coaching; collaborating; and fading. 1.59

\section{Teaching}

Workplace learning events may be planned or arise unpredictably at "teachable moments".55 106

Bedside and other forms of hospital teaching - Bedside teaching is an activity that has a hallowed place in the tradition of medical education 111160161 and is highly valued by students. ${ }^{110} 162$ Conducted for its own sake or during a business ward round, bedside teaching centres around a single, usually bedbound, patient, perhaps with their partner, relative, or friend in attendance. Several medteal students and various grades of doctor and nurse are present. The teacher is a senior clinician. The educational method may be instruction, dialogue, or interrogation. The subject matter is very often physical signs, though bedside teaching also gives teachers an opportunity to role model humane belhaviour towards patients. ${ }^{80}$ One author noted with regret that the incidence of beeside teaching on attending rounds had declined from $75 \%$ in the 1960 s to less than $16 \%$ in the 1990 s. ${ }^{161}$ That decline seems to have been caused by an increasing tension between clinical practice, education, and research. It thas become self perpetuating as fewer teachers have themselves been exposed to bedside taching. ${ }^{9}$ It may also reflect a change in the inpatient case mix away from the gross, observable pathology on which it thrives. A change away from bedside teaching to other forms of instruction may not be all for the bad given its tendency to dwell on the 
physical examination rather than the interview, and teach by demonstration rather than observation with feedback. 91191

The decline in bedside teaching and reduction in studlents' involvement in clinical care have coincided with patients staying in hospital for shorter times, doctors changing to shift working, and healthcare systems becoming increasingly preoccupied with patient safety. "Various solutions have been tried out. One is to appoint nurses as "ward based teachers" to support clinical teaching and leaming. ${ }^{163}$ Another is to establish teaching wards where students provide first-line medical care under supervision ${ }^{164}$ In one medical school, students of the warious health professions work and are educated side by side with one another: 165 Teaching win day surgical units has been another solution, though exposure to case mix and interaction with practitioners may be even more limited in day surgery than traditional surgical clerkships. ${ }^{69}$ Another trend in hospitals is to do more teaching in outpatient settings, where students can encounter a wide range of case mix through multiple short encounters. ${ }^{166}$ Some medical schools augment clinical experience with more or less high fidelity simulation training. ${ }^{1 / 7}$ Finally, hospital education is becoming increasingly devolved to district hospitals which have a more favourable ratio of student to practitioner and patient. ${ }^{168}$ Despite those various initiatives, clinical education in the hospital context is a "cause for concern"."103

Ambulatory teaching and leaning - Ambulatory education is "characterised by variability, unpredictability, immediacy, and lack of continuity."75 169170 "Two medical schools have compared the outcomes of primary care and hospital-based education. Primary care was marginally better than hospital clerkships at improving students" clinical performance in OSCE examinations, ${ }^{171}$ though each setting taught some skills better than the other. ${ }^{172}$ Students seem to have no more chance in ambulatory settings than impatient clerkships of discussing patients they have seen, being directly observed, and receiving feedback. ${ }^{75}$ Rather greater benefits of community placements were reported from Australia, albeit in a suall group of self-selected students. ${ }^{173-175}$ Whether those purported benefits would still be found if primary care had to meet the underfunded productivity pressures that are all too common in hospitals is a moot point. Within the primary care setting, placements in community hospitals are a viable alternative to general practice ${ }^{176}$ and matching students' activities and learning needs to preceptors' interests increases students' satisfaction, though not their assessment performance 177 An ambulatory care teaching centre, where expert patients with stable, chronic disorders are brought up to be seen by students, is highly valued. ${ }^{178}$ Murray's advocacy of judicious transfer of clinical skills teaching into 
general practice when conditions favour it, whilst continuning to teach some clinical skills in hospital, is well supported by published evidence: 172

\section{Relationships with teachers as a feature of the learning entwinoment}

The relationship between teacher and student has a great impact on workplace learning. ${ }^{34}$ It helps students identify emotionally with subject matter. ${ }^{46}$ The relationship has been described as a teaching-leaming alliance, ${ }^{43}$ and a dynamic, reflexive process based around approval given and received. ${ }^{41}$ Effective teachers use their interpersonal skills to involve students in workplace activities. They model good clinical practice whilst encouraging students to behave autonomously and shoulder as much responsibility as patient safety permits. ${ }^{179}$ They help students learn by explaining clinical decisions ${ }^{78}$ and asking questions. An interesting paradox noted by several authors is that intensive questioning by a senior doctor can be either an intensively positive or negative experience depending on the nature of their relationship with the student. ${ }^{53} 79$ Good teachers "coach" students and advocate their learning needs to patients. ${ }^{39}$ Students" relationships with practitioners evolve as they become more senior; at first, they want to be instructed but later they seek a more collaborative relationship. 180181

Students experience strong emotions, which teachers have the power to make positive or negative. ${ }^{53}$ Those emotions are positive when students feel valued, supported, trusted, and respected. Through their interactions with practitioners in the workplace, students are able to develop caring relationships with patients, which are a source of reward and satisfaction. Collegial interactions with practitioners help students handle difficult situations such as responding to a patient's death ${ }^{5153}$ though relationships with practitioners can also be students" greatest source of stress. ${ }^{125}$ Teachers may be apathetic towards them or, worse, humiliate them, and use other negative methods of cducation. Abuse of that sort makes students anxious and depressed. Practitioners underestimate their ability to stress students. ${ }^{126}$ Students experience discomfort if they perceive that patients' rights are being infringed. They may feel uncomfortable giving a case presentation in the presence of a patient ${ }^{12 y}$ although a sensitive senior practitioner can usually mitigate any adverse effects on the patient ${ }^{18}$ Students may experience a tension between their acculturation to the medical profession and the empathy they feel towards patients. ${ }^{48}$ They may witness insensitivity or frank abuse of patients. ${ }^{124}$ Worst of all, they may feel coerced into performing intimate examinations without knowing if the patient has given consent. ${ }^{119}$

\section{Learning environment; summary}

Students learn in al wide variety of workplaces. The main influence on the educational climate of the workplace, which has a strong influence on the quality of 
learning, is the behaviour of teachers. Students seek out patients with relevant disorders and, supported by practitioners, participate in practice. They attend bedside teaching and other leaming events but the strongest influence on their learning is the relationships they form with teachers.

\section{CURRICULUM DESIGN}

Little has been written about the design of the clinical workplace curriculum because, traditionally, a rotation through specialty attachments constituted the curriculum. Even when the subject matter is written down in an official curriculum, clinical teachers tend to be unaware of it. ${ }^{54} 63$ Teachers' indifference and a. casemix that bears little resemblance to it ${ }^{69}$ lead students to abandon the official curriculum $^{55}$ in favour of an unofficial one they pick up from junior doctors and other students. ${ }^{62}$. The resulting curriculum-in-action ${ }^{182}$ has been described as "haphazard"7l and "a mix of many unstructured educational events". 54 As was stated earlier in this chapter, the new medical education seeks to integrate students" learning around the clinical situations doctors encounter or the tasks they perform. The intended learning outcomes are made explicit because clinical disciplines no longer constitute the curriculum. ${ }^{183-185}$ However, students must also learn an "unofficial curriculum", including dress code, workload, study skills, requirenents for success, and personal welfare issues. Ignorance of such matters. is an important cause of stress, a fact of which most teachers are unaware. ${ }^{444647}$

\section{INSTRUMENTATION AND MEDIA}

Compared with the earlier stages of medical training, there is very little instrumentation of clinical workplace learning beyond the instrumentation of clinical practice itself. Clinical educators may structure their clinical workflows $186-189$ and patient encounters to strike a balance between the needs of patient, learner, and teacher. 1011.56190191 Some medical schools, traditional and integrated, make their curricula more explicit by providing course guides or logbooks, though. they do not have much impact on learning. ${ }^{62}$

\section{Curriculum design and instrumentation; summary}

It has been traditional for clinical learning to take place within the organisational structures and activities of the workplace and so little attention has been paid to curriculum design and instrumentation. The new medical education has sparked off relatively little innovation in clinical learning, leaving fundamental questions to be answered. 546371 


\section{MAIN ARGUMENT AND RESEARCH QUESTION}

So, previous research tends to support the difference interpretation proposed earlier. Unlike the relatively controlled leaming conditions created by a PBL scenario in a seminar room, clinical workplace learning take place in a relatively uncontrolled, complex, dynamic learning environment at the centre of which Thes the triadic relationship between individual patients, practitioners, and students. The outcomes of clinical workplace learning, which include emotions, contextual knowledge, and practical skills, are equally complex. It is unclear at what stage of the curriculum workplace learning should begin, how interactions within the learning environment can best achieve the desired outcomes, how those interactions evolve over time, and how they can be operationalised, instrumented, and organised into learning sequences.

Whilst the process and product of PBL are well theorised and relativelly homogeneous, clinical workplace learning is more heterogeneous and often described more in terms of specific contexts than any underpinning theory. This thesis seeks to answer the questions: What should students in today"s learner centred clinical curricula learn in workplaces and how should they learn there? Chapters $2 \& 3$ use two different methods, a consensus survey and systematic review, to identify learning outcomes that can be achieved by giving students workplace experience in the early years of medical training. Chapters 4 and 5 use qualitative surveys of stakeholders' perspectives to identify the strengths and weaknesses of workplace learning in a problem based curriculum and identify ends and means that should be included in any instructional redesign. Chapter 6 reports design based research using a novel application of information technology to explore the conditions for clinical workplace learning in the later years of medical training and how they can be instrumented. Chapters 7 and 8 use a psychometric approach to identify processes and outcomes of clinical workplace learning, and test how they relate to one another. Chapter 9 assembles the results, weighs up their strengths and limitations, considers their implications for instructional design, then considers what directions future research might take.

\section{REFERENCES}

1. United States National Library of Medicine. Medical subject headings (W eb Page]. Available at hatp://www.nln.nih.gov/mesh/meshome.html. (Accessed 9 Jully 2005).

2. Dornan $\mathbb{T}$. Osler, Flexner, Apprenticeship, and "the new medical education". JR Soc Med 2005; 98:91-5.

3. Jolly B. Historical and theoretical background. In: Jolly B, Rees L Eds. Medical education in the new millenium. Oxford: Oxford Medical Publications, 1998. 
4. Sinclair S. Making doctors. An institutional apprenticeship. Oxford: Berg, 1997.

5. Ainley $P$, Rainbird H. Apprenticeship. Towards a new paradigm of learning London: Kogan Page, 1999.

6. Bliss M. William Osler. A Life in Medicine. New York: Oxford University Press, 1999.

7. Bonner TM. Iconoclast. Abraham Flexnet and a life in learning. Baltimore: Johns Hopkins University Press, 2002.

8. Flexner A. Medical Education in the United States and Canada. A report to the Carnegie Foundation for the Advancement of Teaching. Boston: Updyke, 1910.

9. Dacre J. Clinical work and teaching. In: Jolly B, Rees L, Eds. Medical education in the milleniurn. Oxford: Oxford University Press, 1998.

10. General Medical Council. Tomorrow's Doctors. London: General Medical Council, 1993.

11. General Medical Council. Tomorrow's Doctors. Second edition. London: General Medical Council, 2002.

12. Jones A, McArdle PJ。O'Neill PA. Perceptions of how well graduates are prepared for the role of preregistration house officer: a comparison of outcomes from a traditional and an integrated PBL curriculum. Med Educ 2002; 36:16-25.

13. Posner GJ. Analyzing the curriculum. Second edition. New York: McGraw-Hill, 1995.

14. Macpherson R. Jones $A$, Whitehouse CR, O'Neill PA. Small group learning in the final year of medical degree, a quantitative and qualitative study. Med Teach 2001; 23:494-9.

15. Doman TL Baxter CM, Lee C. ParaBLe. A web-based instructional guide to problem-based learning. [Web Page]. 2000; Available at www. ParaBLeman ac.uk. (Accessed 13 October 2005).

16. Knowles MS. Self-directed learning. A guide forlearners and teachers. New York: New York Association Press, 1975.

17. David TJ, Patel L. Adult leaming theory, problem based learning, and paediatrics. Arch Dis Child 1995; 73:357-63.

18. General Medical Council Site [Web Page]. Availlable at http://www gmc-uk.org/. (Accessed 13 October 2005).

19. O'Neill PA, Jones A, Willis SC, McArdle PJ. Does a new undergraduate curriculum based on "Tomorrow" s Doctors prepare house officers better for their first post? A qualitative study of the views of pre-registration house officers using critical incidents. Med Educ 2003; $37: 1100-8$.

20. Willis $S C$, Jones $A, O^{\prime} N$ eill PA. Can undergraduate education have an effect on the ways in which pre-registration house officers conceptualise communication? Med Educ 2003; 37.603-8.

21. Patel L, Buck P, Dornan T, Sutton A. Child Health and Obstetrics-Gynaccology in a problem-based learning curriculum: accepting the limits of integration and the need for differentiation. Med Educ 2002; 36:261-71.

22. Benor DE. Interdisciplinary integration in medical education: theory and method. Med Educ 1982; 16:355-61.

23. Gale J. The Integrated Curriculum: experiences, achievements and problems. Med Teach 1984; 6:22-6.

24. Patel VL, Dauphinee WD. The clinical learning environments in medicine, paediatrics and surgery clerkships. Med Educ 1985; 19:4 60.

25. Murdocli Eaton DG, Levene MI. Comparison of two types of paediatric curricula. Med. Educ 1994; 28:534-7. 
26. Blue AV, Schwartz R. A combined third-year medicine and surgery derkship. Acad Med 1994; 69:417-8.

27. Griffith $C H$, Blue $A V$, Mainous $A G$, DeSimone $P A$. Not evarybody likes problerm-based learning in a clerkship. Acad Med 1995; 70:660.

28. Miflin BM, Carnpbell CB, Price DA. A conceptual framework to guide the development of self-directed, lifelong learning in problem-based medical curricula. Med Educ 2000; 34:299-306.

29. Gagne RM, Wager WW, Golas K, Keller JM Principles of instructional design. Fifth edition. New York: Wadsworth, 2005.

30. General Medical Council. Duties of a Doctor. London: General Medical Council, 1993.

31. Lyons AS, Petrucelli RJ. Medicine. An illustrated history. New York: Abrams, 1987.

32. General Medical Council. The doctor as teacher. London: General Medical Council, 1999.

33. Bleakley A. Pre-registration house officers and ward-based learning: a "new apprenticeship' model. Med Educ 2002; 36:9-15.

34. Tiberius $\mathrm{RG}$, Sinai J, Flak EA. The role of teacher-learner telationships in medical education. In: Norman GR, van der Vleuten CPM, Newble DI, Eds. International Handbook of research in medical education. Dordrecht: Kluwer, 2002: 463-97.

35. Kolb DA. Experiential learning. Experience as the source of learning and development. Englewood Cliffs (NJ): Prentice-Hall, 1984.

36. Schon DA. Educating the reflective practitioner. San Francisco: Jossey-Bass, 1987.

37. Moon JA. Reflection in learning and professional development. London: Kogan Page. 1999.

38. Niem PM. Medical students professional identity: self-reflection during the preclinical years. Med Educ 1997; 31:408-15.

39. Epstein RM, Cole DR, Gawinski BA, Piotrowski-Lee $S_{6}$ Ruddy NB. How students learn from community-based preceptors. Arch Fam Med 1998; 7:149-54.

40. Woolliscroft JO. Medical Student Clinical Education. In: Noman GR, van der Vleuten CPM, Newble DI, Eds. International Handbook of Research and Medical Edwcation. Dordrecht: Khluwer, 2002: 365-80.

41. Lyon P. A model of reaching and learning in the operating theatre. Med Educ 2004; 38:1278-87.

42. Swanwick 'T. Informal learning in postgraduate medical education: from cognitivism to 'culturism:. Med Educ 2005; 39:859-65.

43. Yonke AM, Lemon M. First-year medical students and longitudinal primary care. Acad Med 1993; 68:779-80.

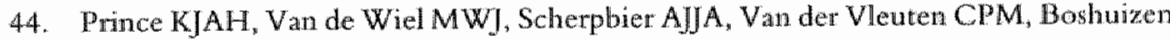
HPA. A qualitative analysis of the transition from theory to practice in undergraduate training in a PBL-medical school. Adv Health Sci Educ Theory Pract 2000; 5:105-16.

45. Seabrook MA. Clinical students initial reports of the educational climate in a single medical school. Med Educ 2004; 38:659-69.

46. Radcliffe $C_{2}$ Lester H. Perceived stress during undergraduate medical training: a qualitative study. Med Educ 2003; 37:32-8.

47. Prince KJAH, Boshuizen HPA, van der Vleuten CPM, Scherpbier AJJA. Students" opinions about their preparation for clinical practice: Med Educ 2005; 39:704-12.

48. Branch W, Pels RJ, Lawrence RS, Arky R. Becoming a doctor: critical-incident reports from third-year medical students. N Engl J Med 1993; 329:1130-1. 
49. Lempp $\mathrm{H}$, Seale $\mathrm{C}$. The hidden curriculum in undergraduate medical education: qualitative study of nedical students" perceptions of teaching. BMJ 2004; 329:770-3.

50. Lyon PMA. Making the most of leaming in the operating theatre: student strategies and curricular initiatives. Med Educ 2003; 37:680-8.

51. Ratanawongsa $N$, Teherani A, Hauer KE. Third-year Medical Students' Experiences with Dying Jatients during the Internal Medicine Clerkship: A Qualitative Study of the Informal Curriculum. Acad Med 2005; 80641-7.

52. Smith LG. First year of practice: a year of rapid leaming. Acad Med 1996; 71:580-1.

53. Stark $\mathbb{P}$. Teaching and learning in the clinical setting: a qualitative study of the perceptions of students and teachers. Med Educ 2003; 37:975-82.

54. Remmen R, Denekens J, Scherpbier AJJA et al. Evaluation of skills training during clerkships using student focus groups. Med Teach 1998; $20: 428-32$.

55. Remmen $\mathrm{R}$, Denekens J, Scherpbier $A$ et al. An evaluation study of the didactic quality of clerkships. Med Educ 2000; 34:460-4.

56. BusariJO, Scherpbier AJIA, wan der Weuten CPM, Essed GGM. The perceptions of attending doctors of the role of residents as teachers of undergraduate clinical students. Med Educ 2003; 37:241-7.

57. Newton DF. What is agood consultant? "A worm's eye view". BMJ 1987; 295:106-7.

58. Freman J, Casli C, Yonke A, Roe B, Foley R. A longitudinal primary care program in an urban public medical school: three years of experience. Acad Med 1995; 70 (Suppl 1): $\$ 64-\$ 68$.

59. Howe A. "Teaching in practice: a qualitative factor analysis of community-based teaching. Med Educ 2000; 34:762-8.

60. Mamn KV, Holmes DB, Hayes VM, Burge $\mathrm{FI}$, Weld Viscount P. Community family medicine teachers" perceptions of their teaching role. Med Educ 2001; 35:278-85.

61. Howe A. Patient-centred medicine through student-centred teaching: a student perspective on the key impacts of conmunity-based learning in undergraduate medical education. Med Educ 2001; 35:666-72.

62. Seabrook MA, Woodfield SJ, Papagrigoriadis S, Rennie JA, Atherton A, Lawson M. Consistency of teaching in parallel surgical firms: an audit of student experience at one medical school. Med Educ 2000; 34:292-8.

63. Fernald DH, Staudenmaier AC, Tressler CJ, Main DS, O'Brien-Gonzales A, Barley GE. Student perspectives on primary care preceptorships: enhancing the medical student preceptorship leaming environment. Teach Learn Medicine 2001; 13:13-20.

64. Price DA, Miflin BM, Mudge PR, Jackson CL. The quality of teaching and learning in rural settings: the learner's perspective. Med Educ 1994; $28: 239-51$.

65. Becknan T. Lessons learned from a peer review of bedside teaching. Acad Med 2004; $79.343-6$.

66. Kernan WN, O'Connor PG. Site accommodations and preceptor behawiours valued by third-year students in ambulatory internal medicine clerkships. Teach Learn Med 1997; 9:96-102.

67. Dolmans D, Schmidt A, van der Beek J, Beintema M, Gerver WJ. Does a student log provide a means to better structure clinical education. Med Educ 1999; 33:89-94.

68. Daelmans HEM, Hoogenboom RJI, Donker AJM, Scherpbier AJJA, Stehouwer CDA, van der Vleuten CPPM. Effectiveness of clinical rotations as a learning environment for achieving competences: Med Teach 2004; 26:305-12.

69. Seabrook MA, Lawson M, Woodfield S, Baskerville PA. Undergraduate teaching in at day surgery unit: A 2-year evaluation. Med Educ 1998; 32:298-303. 
70. Torre DM, Sebastian JL, Simpson DE. Learning activities and high-quality teaching: perceptions of third-year IM clerkship students. Acad Med 2003; 78:812-4.

71. van dex Hem-Stokroos $\mathrm{HH}$, Scherpbier AJA, van der Vleuten CPPM, de Vries $H$, Haarman HJTHM. How effective is a clerkship as a llearning enviromment. Med Teach 2001; 23:609-13.

72. Jolly B. Clinical logbooks: recording clinical experiences may not be enough. Med Educ 1999; 33:86-8.

73. Qualters DM, Regan MB, O'Brien MC, Stone SL. Comparing ambulatory preceptors and students' perceptions of educational planning. I Gen Intern Med 1999; 14:196-9.

74. Stone S, Ellers B, Holmes D, Orgren R, Qualters D, Thompson JU. Identifying oneself as a teacher: the perceptions of preceptors. Med Educ 2002; 36:180-5.

75. Irby DM. Teaching and learning in ambulatory care settings: a thematic review of the literature. Acad Medl 1995; 70:898-931.

76. Ramani $S$, Orlander JD, Strunin L, Barber TW. Whither bedside teaching? $A$ focus-group study of clinical teachers. Acad Med 2003; 78:384-90.

77. Busari JO, Scherpbier AJJA, van der Vleuten CPM., Essed GE. Residents' perception of their role in teaching undergraduate students in the dinical setting. Med 'Teach 2000; 22:348-353.

78. Elnicki DM, Kolarik R, Bardella I. Third year medical students' perceptions of effective teaching belhaviours in a multidisciplinary ambulatory clerkship. Acad Med 2003; 78:815-9.

79. van der Hem-Stokroos HH, Daelmans HEM, van der Vleuten CPM, Harman HJThM, Scherpbier AJIA. A qualitative study of constructive clinical learning experiences. Med Teach 2003; 25:120-6.

80. Mutha S, Takayama JI, O'Neil EH. Insights into medical students' career choices based on third-and fourth-year student focus group discussions. Acad Med 1997; 72:635-40.

81. Beckman TJ, Ghosh AK, Cook DA, Erwin PJ, Mandrekar JN. How reliable are assessments of clinical teaching? A review of the published instruments. J Gen Intem Med $2004 ; 19: 971-7$.

82. Litzelman DK, Stratos GA, Marriott DJ Skeff KM. Factorial walidation of a widely disseminated educational framework for evaluating clinical teachers. Acad Med 1998; 73:688-95.

83. Litzelman DK, Westmoreland GR, Skeff KM, Stratos GA. Student and resident evaluattions of faculty - how dependable are they? Acad Med 1999; 74 (Suppl):s25-s27.

84. Irby DM. Clinical teacher effectiveness in medicine J Med Educ 1978; 53:808-15.

85. Beckman TJ, Lee MC, Rohren CH. Evaluating an instrument for the peet review of inpatient teaching. Med Teach 2003; 25:131-5.

86. Irby DM. How attending physicians make instructional decisions when conducting teaching rounds. Acad Med 1992; 67:630-8.

87. Pinsky LE, Monson D, Irby DM. How excellent teachers are made: reflecting on success to improve teaching. Adw Health Sei Edwc Theory lract 1998; 3:207-15.

88. Irby DM. What clinical teachers in medicine need to know. Acad Med 1994; $69: 333-342$.

89. Sichmidt HG, Norman $G R$, Boshuizen HPA. A cognitive perspective on medical expertise: theory and implications. Acad Med 1990; 65:61:-21.

90. Mattern WD, Weinholtz D, Friedman CP. The attending physician as teacher. N EnglJ Med $1983 ; 308: 1129-32$. 
91. Branch WT, Kem D. Haidet $P$ at Teaching the haman dimension of care in dinical setrings. JAMA 2001;286:1067-74.

92. Wrideaux D, Alexander $\mathrm{H}, \mathrm{B}$ ower A et al. Clinical teaching: maintaining an educational role for doctors in the new health care envomment. Med Educ 2000; 34:820-6.

93. Metcalfe DH, Matharu MV. Students" perceptions of good and bad teaching: report of at critical incident study. Med Educ 1995; 29:193 7 .

94. Rushtorth B. Teaching medical students: The student's perspective. The Clinical Teacher 2004; 1:46-8.

95. Finucane P, Allery $\mathbb{L}$ A, Hayes TM. Comparison of teachers at a "traditional" and an "innovative" medica: school. Med Educ 1995; 29:104-9.

96. O'Malley PG, Kromke KK, Ritter J, Dy N, Pangaro L. What leatners and teachers value most in anbulatory educational encounters: a prospective, qualitative study. Acad Med $1999 ; 74,186-191$.

97. Rutter H, Herzberg J, Paice E. Stress in doctors and dentists who teach. Med Educ $2002 ; 36: 543-9$.

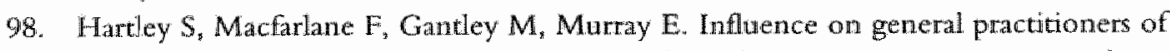
teaching undergraduates. Qualitative study of London general practitioner teachers. BNIJ 1999; 319:1168-71.

99. Vinson $\mathrm{DC}$, Paden $\mathrm{C}$. Devera-Sales $\mathrm{A}$. Impact of medical student teaching on family physicians use of time. I Fam Pract 1996; 42:243-9.

100. Usatine RP, Nguyen $\mathbb{K}$, Randail $J$, Irby DM. Four exemplary preceptors' strategies for efficient teaching in mamged care settings. Acad Med 1997; 72:766-9.

101. Usatine RP, Tremoulet PT, Inby D. Time-afficient preceptors in ambulatory care settings. Acad Med 2000; 75:639.42.

102. Seabrook MA. Medical teachers" concerns about the clinical teaching context. Med Educ 2003; 37:213-22.

103. Spencer J. The clinical teaching context: a cause for comcem. Med Educ 2003; $37: 182-3$

104. Smith CS, Irby DM. The roles of expentence and reflection in ambulatory care educarion. Acad Med 1997; 72:32-5.

105. Lipsky MS, Taylor CA, Schnuth R. Microskills for students: twelve tips for inuproving latring in the moulatory setting. Med Teach 1999; 21.469.72.

H06. Branch WT, Paranjape A. Feedback and teflection: teaching methods for clinioal settings. Acad Med 2002; 77:1185-8.

107. Roff S, MrAleer S, Harden RM et al Development and validation of the linde Ready Education Enviroment Measure (DREEM). Med Teach 1997; 19:295-9

108. Rof S. The Dundec Ready Educational Environment Measure (DREEM)-a generic instrument for measuring students" perceptions of undergraduate health professions curricula. Med Teach $2005 ; 27: 322-5$.

109. Silverman ME, Murray T], Bryan CS. The Quotable Osler. Philadelpha: Anerican College of Physicians, 2003.

110. Nair BR, Coughan JL, Henshey MJ. Student and patient perspect wes on bedside teaching. Med Educ 1997; 3:341-6.

11.1. Thibault GE. Bedside rounds revisited. N Engl J Med 1997; 336:1174-5.

112. Spencer J. Blacknore D, Heard S et al Patient-oniented leaming a review of the role of the patient in the education of medical students. Med Educ 2000; 34:851-7.

113. Aspigren $K$, Blomqvist $P$, Borgstrom A. Live patients and problem-based learning. Med Teach 1998; 20:417-20. 
114. Jagsi R, Lehmann LS. The ethics of medical education. BMJ 2004; 329:332 4.

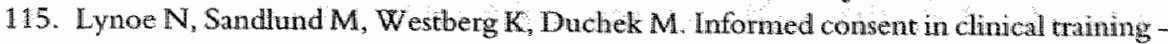
patient experiences and motives for participating. Med Educ 1998; 32:465-71.

116. Thomas EJ, Haffler JP, Woo B. The patient's expenence of being interviewed by first-year medical students. Med Teach 1999; 21:311-4.

117. Stacy R, Spencer J. Patients as teachers: a qualitative study of patients" views on their role in a community-based undergraduate project. Med Educ 1999; 33:688-94.

118. Lehmann LS, Brancati FL, Chen M-C, Roter D, Dobs AS. The effect of bedside case presentations on patients" perceptions of their medical care. N Engl J Med 1997; 336:1150-5.

119. Coldicott $Y$, Pope $C$, Roberts $C$. The ethics of intimate examination-teaching tomorrow's doctors. BMJ 2003; 326:97-9.

120. Bordage G, Burack JH, Irby DM, Stritter FT. Education in ambulatory settings: developing walid measures of educational outcomes; and other research prionities. Acad Med $1998 ; 73: 743-50$

121. McGrew MC, Skipper B, Palley T, Kaufman A. Student and faculty perceptions of problem-based learning on a family medicine clerkship. Fam Med 1999; 31:171-6.

122. Harrell PL, Kearl GW, Reed EL, Grigsby DG, Caudill TS. Medical students' confidence and the characteristics of their clinical experiences in a primary care clerkship. Acad Med 1993; 68:577-9.

123. Rogers HD, Carline J, Paaw DS. Examination room presentation in general intermal medicine clinic: patients and students perceptions. Acad Med 2003; 78:945-9.

124. Brewster A. A student's view of a medical teaching exercise. N Engl J Med 1993; 329:1971-2.

125. Firth J. Levels and sources of stress in medical students. BMJ 1986; 292:1177-80.

126. Moss F, McManus IC. The anxieties of new clinical students. Med Educ 1992; $26: 17-20$.

127. Kachur EK. Observation during early clinical exposure - an effective instructional tool or a bore? Med Educ 2003; 37:88-9.

128. Adans J. Straining to describe and tackle stress in medical students. Med Educ 2004; 38:463-4.

129. Guthrie EA, Black D, Shaw CM, Hamilton J, Creed FH, Tomenson B. Enabarking upon a medical career: psychological morbidity in first year medical students. Med Educ $1995 ; 29: 337-41$.

130. Stewart SM, Betson C, Marshall I, Wong CM, Lee PWH, Lam TH. Seress and vulnera bility in medical students. Med Educ 1995; 29:119-27.

131. Moffat KJ, McConnachie A, Ross S, Morrison JM. First-year medical students' stress and coping in a problem-based learning medical curricujum. Med Educ 2004; $38 \cdot 482-91$.

132. Stecker T. Well-being in an academic environment. Med Educ 2004; 38:465-78.

133. Kiessling C, Schubert B, Scheffling D, Burger W. First year medical students' perceptions of stress and support: a comparison between reformed and traditional track curricula. Med Educ 2004; 38:504-9.

134. O'Neill PA, Morris J, Baxter C-M. Evaluation of an integrated curriculum using problem-based leaming in a clinical enviromment: the Manchester experience. Med Educ $2000 ; 34: 222-130$.

135. Valentino J, Bluc AV, Donnelly MB, Stratton TD. The most waluable critical incidents in a 4th-year acting internship in surgery. Teach Learn Med 1999; 11:75-9. 
136. Fith-Cozens J. Enotional distress in junior house officers. BMJ 1987; 295:533-6.

137. McManas IC Richards $P$, Winder BC. Clinical experience of UK medical students Lancet $1998 ; 351.802-3$.

138. English WA, Nguyen-yan-Tam JS, Pearson JCG, Madeley RJ. Deficiencies in the undergraduate and pre-registration medical training in prescribing for pain control. Med Teach 1995; 17:215-8.

139. Jones $A$, McArdle PJ, ONeill PA. How well prepared are graduates for the role of pre-regristration house officer? A comparison of the perceptions of new graduates and edicational supervisors. Med Educ 2001; 35:578-84.

140. Goldacre MJ , Lambert " $T$, Evans J, Turner G. Preregistration house officers" views on whether their experience at medical school prepared them well for their jobs: national questionnaire survey. BMJ 2003; 326:1011-12.

141. Cooper N. Medical training did not teach me what I really needed to know. BMI 2003; $327: 3190$.

142. Davis MHE, Dent JA. Comparison of student learning in the out-patient clinic and ward round. Med Educ 1994; 28:208-12.

143. Rattner SL, Louis DL, Rabinowitch $\mathrm{C}$ et al. Documenting and comparing medical students' clinical experiences. JAMA 2001; 286:1035-40.

144. Seabrook MA, Lawson M, Malster M, Solly J, Rennie J, Baskerville PA. Teaching medical students in a day surgery unit: adapting medical education to changes in chnical practice. Med Teach 1998; 20:222-6.

145. Seabrook MA, Lawson M, Baskerville $P A$. Teaching and learning in day surgery units: a UK survey. Med Educ 1997; 31:105-8.

146. O'Neill PA, Willis SC, Jones A. A model of how students link problem-based learning with clinical experience through "elaboration". Acad Med 2002; 77:552-61.

147. Nordgren R, Hantman JA The effect of managed care on undergraduate medical education. JAMA 1996; 275:1053-8.

148. Dammers J, Spencer J, Thomas $M$. Using real patients in problem-based learning: stum dents" comments on the vallue of using real, as opposed to paper cases, in a problem-based learning module in general practice. Med Educ 2001; 35:27-34.

149. van de Wiel MWJ. Schaper NC, Scherpbier AJJA, van der Vleuten CPM, Boshuizen HPA. Students' experiences with real-patient tutorials in a problem-based curriculum. Teach Lean Med 1999; 11:12-20,

150. Whitehouse $C R, O$ Neill P, Dornan T. Butlding confidence for work as house officers. Student experience in the final year of a new problem-based curriculum. Med Educ $2002 ; 36: 718-27$.

151. Blosser A, Jones B. Problem-based learning in a surgery clerkship. Med Teach 1991; 13:289-93.

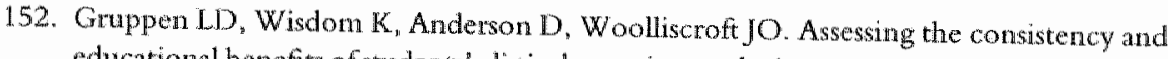
educational benefits of students' clinical experiences during an ambulatory core internal medicine totation. Acad Med 1993; 68:674-80.

153. McManus I.C, Richards P, Winder BC, Sproston KA, Vincent CA. The changing clinical experience of British medical students. Lancet 1993; 34:941-4.

154. Vieira JE, Nunes MAPT, Martins MdA. Directing student response to early patient contact by questionnaire. Med Educ 2003; 37:1 19-25.

155. NeberJO, Gordon KC. Meyer B, Stevens N. A five-step "microskilis" model of clinical teaching. J Am Board Fam Pract 1992; 5:419-24. 
156. Ferenchick G, Simpson D, Blackman J, DaRosa D, Dunnington C. Strategies for Effcient and Effective Teaching in the Ambulatory Care Setting. Acad Med 1997; $72: 277-280$.

157. Aagaard E, Teluerani A, Irby DM. Eftectiveness of the one-minute preceptor model for diagnosing the patient and the learner: proof of concept. Acad Med 2004; 79:42-9.

158. Irby DM, Aagaard E, Teherani A. Teaching points identified by preceptors observing one-minute preceptor and traditional preceptor encounters. Acad Med 2004; 79.50-5.

159. Dolmans DHJM, Walfhagen HAP, Gerwer WJ, de Grave W, Scherpbier AJIA. Providing physicians with feedback on how they supervise students during patient contacts. Med Teach 2004; 26:409-14

160. Siegler M. A legacy of Osler: teaching clinical ethics at the bedside. JAMA 1978; 239:951-6.

161. LaCombe MA. On bedside teaching. Ann Intern Med 1997; 126:217-20.

162. Ward $B$ "Moody $G$, Mayberry JF. The views of jumior doctors and medical students on pre-graduate clinical teaching. Postgrad Med J 1997; 73:723-5.

163. Kilminster SM, Delmotte A, Frith H, Jolly BC, Stark P. Howdle PD. Teaching in the new NHS: the specialised ward based teacher. Med Educ 2001; 35:437-43.

164. Goldstein DA, Hoffman KI, Bethune J. The role of the student ward in the medical clerkships. J Med Educ 1985; 60:524-9.

165. Wahlstrom $\mathrm{O}$, Sanden $\mathbb{I}$, Hammar M. Multiprofessional education in the medical curriculun. Med Educ 1997; 31:425-9.

166. Grum CM, Richards PJN, Woolliscroft JO. Consequences of shifting medical scudent education to the outpatient setting: Effects on performance and experiences. Acad Med $1996 ; 71: 599-101$.

167. Sullivan ME, Ault GT, Hood DB et al. The standardized vascular clinic: an alternative to the traditional ambulatory setting. Am J Surg 2000; 179:243-6.

168. Parry J, Mathers J, Al-Fares A, Mohammad M, Nandakumar M, Tsivos D. Hostile teaching hospitals and friendly district general hospitals: final-year students' views on clinical attachments locations. Med Educ 2002; 36:1131-41.

169. Lynch DC, Whitley TW, Basnight LL, Patselas T. Comparison of ambulatory and inpatient experiences in five specialties. Med Teach 1999; 21:594 6.

170. Dent JA, Davis MH. Role of ambulatory care for studert-patient interaction: the EPIT OME model. Med Educ 1995; 29:58-60.

171. Murray E, Jolly B, Modell M. Can students learn clinical method in general practice? A randomised crossover trial based on objective structured clinical examinations. BMJ $1997 ; 315: 920-3$.

172. Murray E, Jolly B, Modell M. A comparison of the educational opportunities on junior medical attachments in general practice and in a teaching hospital: A questionnaire survey. Med Educ 1999; 33:170-6.

173. Worley P, Sillagy C, Prideaux D, Newble D, Jones A. The parallel rural community curriculum: an integrated dinical curriculum based in rural general practice. Med Educ $2000 ; 34: 558-65$.

174. Worley P, Prideaux D, Strasser R, March R, Worley E. What do medical students actually do on clinical rotations? Med Teach 2004; $26.594-8$.

175. Worley $P_{0}$ Esteman A, Prideaux D. Cohort study of examination performance of undergraduate medical students learning in community settings. BMJ 2004; 328:207-9.

176. Grant J, Ramsay A, Bain J. Community hospitals and general practice extended attachments for medical students. Med Educ 1997; 31:364-8. 
177. Wade $W$, Silagy C, Mahoney S. A prospective tandomised trial of an urban general practice attachment for medical students: Med Educ 1998; 32:289-93.

178. Dent J, Angell-Preece HM, Ball HM-L, KerJS. Using the Ambulatory Care Teaching Centice to develop opportunities for integrated learning. Med Teach 2001; 23:171-5.

179. Irby DM, Ransey PG, Gillmore GM, Schaad D. Characteristics of effective climical teachers of ambulatory care medicine. Acad Med 1991; 66:54-55.

180. Paukert $J \mathrm{~L}$, Richards BF. How medical students and residents describe the roles and characteristics of their influential clinical teachers. Acad Med 2000; 75:843-5.

181. Kilminster $\mathrm{SM}$, Jolly $\mathrm{BC}$. Effective supervision in clinical practice settings: a literature review. Med Educ 2000; 34:827-40.

182. Coles C. How students learn. In: Jolly B, Rees L, Eds. Medical education in the millenitum. Oxford: Oxford University Press, 1998.

183. O'Neill PA, Metcalfe D, David TJ. The core content of the undergraduate curriculun in Mancluester. Med Educ 1999; 33:121-9.

184. Harden RM, Crosby J, Davis MH, Howie PW, Struthers AD. Task-based learning: the answer to integration and problem based learning in the clinical years. Med Educ 2000; 34:391-7.

185. Race P. Task-based learning. Med Educ 2000; 34:335-6.

186. Regan-Smith M, Young WW, Keller AM. An effective and efficient teaching model for ambulatory education. Acad Med 2002; 77:593-9.

187. Murdoch Eaton D, Cottrell D. Maximising the effectiveness of undergaduate teaching in the clinical setting. Arch Dis Child 1998; 79:365-7.

188. Mires GJ, Howie PW, Harden RM. A "topical" approach to planned teaching and learning using a topic-based study guide. Med Teach 1998; 20:438-41.

189. DaRosa DA, Dunnington GL, Stearns J, Ferenchick G, Bowen JL, Simpson DE. Ambulatory teaching 'lite': less clinic time, more educationally fulfilling. Acad Med 1997; $72: 358-61$.

190. Kurth RJ, Irigoyen M, Schmidt HJ. A Model to Structure Student Learning in Ambulatory Care Settings. Acad Med 1997; 72:601-606.

191. Rolfe I, Sanson-Fisher RW. Translating leaming principles into practice: a mew strategy for learning skills. Med Educ 2002; 36:342-52. 
CH A P T R 2

\section{Early practical experience in medical education. A rationale}

This full text version was published on bmi.com. An abbreviated version of it was published in the British Medical lournal 2004, 329:834-7 What can experience add to early medical education? Consensus study Tim Dornan and Chris Bundy 
Objective: To provide a rationale for integrating experience into early medical education ("early experience").

Design: Small group discussions to obtain stakeholders' wews. Grounded theory analysis with respondent, internal, and external validation.

Setting: Problem based, undergraduate medical curriculum that is not vertically integrated.

Participants: A purposive sample of 64 students, staff, and curriculum leaders from three university medical schools in the United Kingdom.

Results: Without early experience, the curriculum was socially isolating and divorced from clinical practice. The abruptness of students' transition to the clinical enviromment in year 3 generated positive and negative emotions. The rationale for early experience would be to ease the transition; orientate the curriculum towards the social context of practice; make students more confident to approach patients; motivate them; increase their awareness of themselves and others; strengthen, deepen, and contextualise their theoretical knowledge; teach intellectual skills; strengthen learning of behavioural and social sciences; and teach them about the role of health professionals.

Conclusion: A rationale for early experience would be to strengthen and deepen cognitively, broaden affectively, contextualise, and integrate medical education. This is partly a process of professional socialisation that should start earlier to avoid an abrupt transition. "Experience" can be defined as "authentic human contact in a social or clinical context that enhances learning of health, illness or disease, and the role of the health professional." 


\section{INTRODUCTION}

It is nearly a century since Abraham Flexner began to direct massive endowments from North American philanthropists towards reforming medical education. 'So great was Flexner's influence that his model of preclinical education in science preceding apprenticeship to clinical scientists employed by universities became an assumption of 20 th century medical education. However, 21 st century conceptions of professionalism are much broader. ${ }^{2}$ Doctors must communicate well, respect their patients" wishes and needs, and be accountable to society. In their education, "insufficient weight has been given to the ethical, attitudinal, and interpersonal features of medical practice."3 Modern medical education must therefore lay affective and social as well as scientific foundations. ${ }^{4-6}$ At the same time, Flexner's preclinical to clinical sequence is being challenged by early clinical exposure ${ }^{7-9}$ To explore the rationale, interrelations with professionalism, and learning outcomes of "early experience," we framed the research question: "What can experience add to early medical education?" Our theoretical orientation was that an answer given by a community of practice $^{710}$ would be valid, so we should develop a theory grounded in the experiences of students and staff.

\section{METHODS}

\section{ORIGIN OF THE RESEARCH QUESTION}

The University of Manchester's medical curriculum (www medicine.man.ac. uk) is problem based, community oriented, and fully horizontally integrated, ${ }^{\text {it }}$ but it provides little early clinical experience. We decided to consult widely with stakeholders, including St Andrews University, whose medical science graduates enter Manchester phase 2, and two new partner organisations, Keele University and Preston and Chorley Hospitals. We framed the topic as "learning from early experience," to avoid preconceptions associated with the tems "early clinical experience", "teaching", "community based", and "professionalism", which pervade the literature on vertical integration.

\section{METHOD}

A qualitative, grounded theory approach ${ }^{12}$ best matched our research context, question, and theoretical orientation.

\section{SAMPLING STRATEGY AND PARTICIPANTS}

We purposively recruited 33 students and 31 staff to represent all years of the curriculum; teachers of behavioural and biomedical science; a spread of primary, 
community, and specialist clinical disciplines; and the deans and associate deans of all three medical schools.

DISCUSSIONS

Leaders of the Medical Students' Representative Council met the researchers to set a research agenda. Then staff and students attended semistructured group discussions, five including only staff and three including only students. Staff and students attended separately to encourage free expression of opinions. Staff from related disciplines and students from the same curriculum phase attended together to identify shared wiews. Each was facilitated by the first author and at least one other researcher. The template had four questions: "Why should we prowide early experience?" "What disadvantages could you foresee?" "What is happening at present?" and "How should we do it?" We explored participants" responses openly in early discussions and guided by the evolving theory in later ones.

\section{ANALYSIS}

Each discussion was audiotaped, transcribed verbatim, and open coded by one researcher using NUD*IST 4 and, later, NVivo software (QSR, Doncaster, Australia) promptly, so it could inform subsequent discussions. A second researcher compared the coding with the original transcript. A series of subsequent validation procedures is summarised in box $\mathbb{1}$.

\section{RESULTS}

\section{MEDICAL EDUCATION WITHOUT EARLY EXPERIENCE}

\section{Sense of vocation}

Students entered medical school "just itching to be a doctor." The destination was distant yet "what [we] are doing it for." But their early medical education was not vocational (box 2 ; section 1 , subsection $A$, participant i). Without experience, students could not judge if medicine was right for them. Contact with pationts and "feeling medicalish rather than sitting with your textbooks for six hours" would be exciting and "keep your learning online." No respondent dissented from the vocational view, but teachers rarely voiced it.

\section{Emorional challenges}

"Coming from school where everyone was nomal" and meeting seriously ill people challenged students. To be first insulated from it and then "dumped into a hospital environment ... might be too much for you," "scar you," and teach 


\section{VALIDATION PROCEDURES}

\section{TRESPONDENT VALIDATION"}

We agree with Barbour, who argues that respondents can refune intergretations, al though not stictly "validhte" dhen. 13 Once the first and second researdhers had agreed on ar open coding and descriptive inter pretation of a transcipt, they emailed it to the participants, unviting connient Criticisms led to review and nodification of the inter. pretation; new comments were handled os additional" raw dath" Seven people replied. supporting Barbour's opwinon that respondent validation una y be relativel y umproducive 13

\section{SCRUTHNY WITHIN THE \\ RESEARCH TEAM}

After respondenf validation, a third re searcher reviewed each transenipr, respondents' commient, and the find analysis, searching for bias in the evolving integrretation and statements that negated it. The first researcher combined all eompleted inreypre tations in a single grounded theory analysis. He constantly compared the evolving intert pretation with the primary and secondary naterials, and the two other researchers critiqued it At his stage we forinulated a definition of experience as 4 atherntie freal as opposed to smuliated hunan contact in a social or dinical context that enharices lean ing of hieal h, illness, and disease, and whe role of the health professional?

\section{WORKSHOP INCLUDING LAY PEOPLE}

The next validation stage was 10 invite 73 stadents and staf, again purposively recruted to balance disciplines and cumculum Jears, and frue lay people who support our education programme as standardised patients, to attend a one day workshop deding with the same quettions as the focus groups. Few workshop participants had 1 o contributed to die focus sroups. in faclitated dis cussion groups, staf, stidents, and lay people (now nixed, to accentuate differences of perspective) considered (What sont of doctors do we want to produce?" and How could early expenence help produce hen? Group outputs were synthesised in a plenary session to provide collective answers to "Why provide early experience?" At thrs point, the antenin grominded theors analysis was revealed so particip ints could conpare and contrast the two (very simular) set of conclusions, before considering "What $\mathrm{ex}$ periences showld we offer, and whrt sliould we guard against?' A final, plenary session anrived at a synihesis of die day's findings. The proceeding were not nudto recordled but the reserrchers pirticlpated actwely, and transcribed and analysed contents of flip charts to test the accuracy of theit evolving interpretation.

\section{VALIDATION WITHINTHE MEDLAL SCHOOL}

We used the grounded theory malysis, now refined by the workshop, as a rationile for dhanging the Minchester clirriculluin, as $r$ quested by the General Medieal Gouncil So the interpretation wis entingued and debated in all higl level ciniculum cominitees

\section{TNT ER NATIONAL PERSPECTIVE}

We presented a near final data arialysis to 30 people representing seven Etropedi coun tries, Malaysia, South Africa, and North America, who were atending an interachve worksliop it in interiational confinetice on medical cdication. They spent a lialf day in small groups, critiguing the evolving theory and inventory of leaning outconnes. Their imumite paper't evaluations were transcribed (by TD), and again test the alcuracy of the evolving interpretation.

\section{FINAL REPORT}

We prepared this teport by reorganising the existing codes aind adding extra le wels of deail to the coding Jierarchy We teport the data in language as close as possille to the respondents in the main text, referenced to verbatin quotations in box 2 , to remian faithifl to the onginal daca 


\section{EXTRACTS OF TEXT}

\section{MEDICAL EDUCATION \\ WITHOUT EARLY EXPERIENCE}

\section{A Sense of pocations}

i FY1 768 Jomior sudent: "it"s like we"re here and it's not happening."

\section{$B$ Enotional challenges}

is $Y 1493$ Junior student" "You might lear the cut-off tactor, which I wnderstand... a lot of people think you've got to get as a doctor. You just go home and forger about things, but then mayb you'd not become as good a doctor if you can cut off that easily." ii TFF 26 Senior student: "one of the diffculties that faces a student going from the scond to the thind yoar is the change from Jarning from textbooks and resources provided within lectures. . . to actually leaming from people... And, so some people can go running away back to their textbooks when you should really be leaming how to learn. from people themselves."

iii $\mathrm{FY} 1744$ Junior student: "you have come straight from school, you are 18, and you have just come away from home, and you are trying to manage a life, and . . is it going to be too much?" Junior sundent: "But, if we are taking a medical degree, we expect that to some extent."

\section{WHAT EARLV EXPERUENCE COULD ADD}

\section{A. Expertere as "Wroadener"}

i FY 1975 Jumior student: "I think that is a ranlly good idea. I think it is a good point to go out and meet people who maty not necessarily be ill or have anything wrong with dnem, but just to meet people from lots of different backgrounds becatuse coming to madical school, you don't really meet that diverse ange of people, most people who come here are neally quite well off."

ii FX1 350 Junior student: "The idea of hawing clinical sessions through years 1 and 2 .. is about being . = all round, learning psychosocial things, learaing how to do skil], and various things rather than just parient contact."

jin CPH 733 Staff member." "I would . . see this early experience as a sort of counterbalance to say: "They, stand back for a moment. let's see where this firs into the broader picture, what is it that doctors do, what are pam tients, what are populations, what is society?

\section{B Experience to achiente affective ow tomtes Confidence}

i SY 1651 Junior student: "Starting tearly, as well. . Would help you in how to act around patients, because I know we do work experience in hospitals, but we ve never really been in the position where we are medcal students and a bit more, not authoritative."

\section{Motivation}

\#S $S$ 1 1260 Junior student: "I think the most important thing I draw from this whole discussion is the enthusiasm and the motivation it would bring to you."

iil FYI 802 Junior student: "And we had a kidney transplant guy come to talk to us, and it was really good because he was talking all about himself and where he trained, and what he did, and what he enjoyed, and wat he didn't enjoy. How many hours per week lie does, just stuff like that, and it made it all so much more real, and you could just inagine yourself doing it, and it whis just really good."

iv SY1 1041 Junior student: "I would want it to make mic think one day you can be a doctor, because some way along the line in the furst and second year, you forget, you can easily forget that you are going to be a doctor at the end of this course","

v FY1 1245 Jumor student: "Jast being with someone who is qualified and just watching what they do on a day to day basis, and just seeing what it is like to be a proper, qualified doctor doing whing because 1 can't at this moment in time, irnagine nyself doing that, to be honest. Situing and struggling with textbooks and not understanding, and wed- 
ing throught everything, I can't ever imagine being able to go "all right, that is what is wrong with that patient, "with a team of people. I think that would be a really good idea."

\section{Self antureness}

vi KPM 595 Staff member: "To look at under what conditions do they study best, what subject do they like best, and why, what does this contribute to their personal motivations and so on? I think all of those things are really helpful for students to get to know themselves better, to prepare themselves better for a career in medicine, and I would argue the sooner we do it the better."

\section{Awareness of others}

viu BSD 225 Staff member: "Understanding other people's lifestyles and value systems before moving to understanding those people, then, as patients."

\section{Experience to support cognitive procosses}

Strength and depth of learning

i FY1 108 Junior student: "It is very much easier to link what you have learnt if you can say: "Oh yes, well I saw somebody with that," and then that creates a picture in your mind, and it actually helps you to remember why things are linked that way and what the conditions are, and how they work."

ii STA 604 Staff member: "What I'm quite keen to do is to give students experience of the things that there is evidence of. So, rather than just learning in a lecture that men die younger, they should go out and talk to people about when people die and bring back the evidence."

\section{Contextisalising leaming}

iii FY1 396 Jumior student: "It will be interesting to see how the physiological things that we learn about week in and week out affect patients, and what the tests that everyone does, what that shows you in real life." iv TFF 693 Senior student: "I remember after having read lots about the nervous system and then seeing it demonstrated, we saw someone with hyperreflexic knee reflexes, everyone's face just lit up, it was so satisfying to see what really happened, and then there was a woman with diabetes who told a hilarious story about having a hypoglycaemic attack, and she was weeing in the wardrobe. It was hillarions, but it was also relevant."

Developing intellectual skills

v SY 151 Jumior student:" "I think it would be a good thing to see their train of thought as they go through seeing a patient, because that would help you in the way you approach PBL if you could see how somebody who is qualified structures their questions and their thought processes."

\section{$D$ Experience to teach subject matier \\ Foundation sciences}

i TFF 305 Senior student: "It emerges really. really well when you speak to a patient. You do use non-verbal cues and everyching that we read about when you speak to a patient, and you also have to have your knowledge of anatomy ... I think the problem in the first two years is that we are only doing the psychology part, and not really applying it, so we become a bit "is this worth it at all?" whereas it does have its use, but . . . we don't see it."

ii CPH 146 Staff member: "But we also need them to broaden out into their understanding of the sciences of the whole person, of society, of the population. And, there is an anxiety that students are much less good at doing that throughout the course, and I think the question we have to address is what kind of experience of any kind outside the lecture theatre, the book, the PBL case will actually enable them to broaden, to develop their understanding in those particular sciences."

ii KPM 154 Staff member: "So, I think there is something to be said for saying "Where can intellectual disciplines that are necessary in the early years and the ground work be built up?', and we may need to look wider than (the medical school) and the libraries."

iv STA 643 Staff member: "We can deninonstrate to them that people will have a state- 
Inert of what they think is important to their healt b whilst innultaneously telling you that what they do to their health is different It's important to mininuse stress, but they say that they don't It's important to give up snoking, but they dont. We can also denonstrate to then things that are quite theoreticilly based, like, that people's belief, not Whe medical evidence, will influence their behaviour And so rather than w just reaching that in a lecture our students are going out and finding out that this is true of the famidy thit they interview?

\section{Conmunitation}

WFY 376 Junior student. "What we are doing is a gentle introdliction . [having]. . a chat with patiens, is something that is really difficult Going and caking a history is one thing, but rctual, y just going and having a chat with somebody is nuch more diffcult. The history 1 quite a nice logical process, and you can lean diat, and it is like rote learning really, but going and talking to somebody, making conversation witl them, that is almost a first step.

VI KPM 800 Staff menber 1 think people are not very good at finding out what people feel, you know the subjectrity of things; and there is a hgour to funding out that, which could be helpfuil:

Oiher dinical skills

vii TFF 228 Senior student Although some clinical skills are important, th is having that fundanental knowledge of the bioschences, it is so much easier to look at it clincally in the hospital if you have a sound knowledge of the system."

Professional roles

wiil KPM 32 Staff nember: We showld. aim to socialise them on a wder basis thati the nodel of the profession that is still rather predoninant?

1x STA 1560 Staf member "experiencing the other health professions . . in order. to get a fel for how they fit in with every thing else? 
you to "cut off" (box 2;1, B, i). Both jumior and senior students described entering the clinical environment as "being thrown in at the deep end," where "you might sink or swim," but it was also exciting. They might experience as much excitement with less stress if they were "titred into it" and might "more or less understand the stress it might cause you, and [learn to] . . deal with it better." Supportive teachers and a positive experience, such as following a mother through pregnancy, would "break them in gently." As a counter argument, some students had found overcoming their reactions to human dissection motivating.

Staff saw encountering serious illness as "traumatic" but did not recognise the method of learning could also be traumatic. Students feared being made to feel inadequate in professional settings. A specific example was "going into surgery and being taken apart for our lack of anatomy knowledge." Others were not knowing how to approach patients, having to get used to being in hospital, "wearing a white coat and being seen as a medic," and not knowing practical things. Another aspect was switching their method of learning from textbooks to patients (box 2; 1, B, ii). Students were divided on how fast they should face the challenge of learning in clinical situations. Some felt that junior students had enough challenges without adding early experience (box $2 ; 1, \mathrm{~B}$, iii). Taken as a whole, students" narratives portrayed medical education as vocationally driven, emotionally laden, and involving an abrupt switch in the method of learning from inanimate resources to practitioners and ill people in practice settings. Staff narratives had little to say on these issues.

\section{WHAT EARLY EXPERIENCE COULD ADD}

\section{Experience as a "broadener"}

Staff and students agreed that early experience could fill a gap, but their gaps differed. For staff, it was in students' prior life experiences. For students, it was in the course. Staff saw students as having generally limited prior life experience, "coming from a sheltered, protected school environment," needing to encounter social diversity and develop social awareness, and needing time for intellectual and emotional development. Early experience would give them a better understanding of "the human condition," so they came out "reasonably rounded doctors, both socially, in egalitarian terms, and in terms of their knowledge," with "improved people skills" and awareness of how illness affects families. Students agreed (box 2; 2, A, i), but, for them, the gap was "being put away in this academic building," "surrounded by the brightest people from schools all over the country" and needing to be "reminded ... there is an outside world." Interacting with people would relieve their "tunnel vision" in a way problem 
based learning did not. The agenda should be broad (box $2 ; 2, A$, ii), a wiew echoed by one community clinical teacher who saw the science base as "very, very narrow" (box $2 ; 2, \mathrm{~A}$, iii) Common ground between the perspectives of students and staff was a need to educate whole people and keep them in touch with society and its needs.

\section{Experience to achieve affective outcomes}

Confidence - Students spoke of needing to build confidence to talk with patients and act appropriately in their presence "as medical students rather than friends" (box $2 ; 2, B, i)$.

Motivation - Early experience would be "exciting," "amazing," "terrific," "incredibly positive," "excellent," and "lovely," and give students "zest for the course" (box $2,2, \mathrm{~B}$, ii), although it might be "difficult" and "frustrating if the emphasis went too far into spending ... time in hospitals." A junior student who had "got a buzz" out of work experience and come into medicine for people contact found it "cut out totally" from the course. Learning theory without practice was demotivating because students "lost the .. greater scheme of things." Early experience could motivate by adding interest and variety, helping students feel less "bewildered by the background" (including healthcare systems and contexts) and connecting them with realities to which they could aspire (box $2 ; 2, B$, iii and iv). Students recognised their need to develop a professional identity and saw contact with doctors as a highly motivating way of doing so (box $2 ; 2, \mathrm{~B}$, w). Staff recognised the motivating effect of experience but warned against providing it out of "tokenism."

Self awareness - According to staff, providing experience at such a critical time in the development of students' value systems could build an awareness of their professional status and future responsibilities, encourage humility, and help integrate personal and professional development (box $2 ; 2, \mathrm{~B}$, vi).

Awarenes of others - Staff felt that experience could help students understand more about people (box $2 ; 2, B$, vii). It could teach them "what it is like to feel unwell.," to recognise and value diversity, acknowledge patients" expertise, and respect confidentiality. This would occur through socialisation and role modelling. Students agreed that " $\mathbb{t}$ is very good for medical students to be on the other side of the fence" and suggested that meeting people who misuse drugs or alcohol on their own ground rather than in a healthcare setting would prevent students from developing judgmental attitudes.

Overall - The narratives contained rich affective content with different but very complementary perspectives. Students wanted to build confidence and a sense of identity and sustain their motivation; staff wanted students to become mone aware of themselves and others. 


\section{Experience to support cognitive processes}

Here, the perspectives of staff and students were concordant.

Strength and depth of learning - Information that was linked to visual inages, particularly of patients, would be easier to recall, linked with other information, and understood rather than memorised by rote (box 2; 2, C, i). Experience could make information more believable (box $2 ; 2, \mathrm{C}$, ii) and help students understand diffacult subject matter such as epidemiology and ethics.

Contextualising leaming - Seeing theory put into practice, contact with patients and doctors, and recalling or coding information in "real" situations would contextualise knowledge, strengthen it, put it into perspective, and prepare students to apply it in practical situations (box 2; 2, C, iii and iv).

Developing intellectual skills - Experience could stimulate students' intellectual development, encourage them to evaluate the way they learnt (box $2 ; 2, \mathrm{~B}$, vi) and teach study skills that would be useful later. It could develop a questioning attitude by exposing students to uncertainty and link the intellectual skills of problem based learning (PBL) with those of practice (box 2; 2, C, v).

\section{Experience to teach subject matter}

Foundation sciences - Although biological sciences were scarcely mentioned, staff and students argued strongly that experience could strengthen learning of behavioural and social sciences by showing their importance and integrating them into the curriculum. Reciprocally, behavioural and social sciences would provide a theoretical framework for interpreting experience (box $2 ; 2, \mathrm{D}$, ii). One teacher described "the wider community" as a "laboratory where students could ground their learning of behavioural and social sciences" (box 2; 2, D, iii). Another gave specific examples of how experience could teach those sciences (box $2 ; 2, D, i v)$.

Communication - Learning interpersonal communication ("people skills") through early experience was seen as important by staff and students, on the grounds that good communication "is the most important thing," takes a long time to develop, and is difficult. Early experience could show students that they needed to develop an ability to communicate well and identify people who would struggle later in their education through lack of it (box $2 ; 2, \mathrm{D}, \mathrm{v}$ ). It could help students strike the right balance between social and professional skills in their communication with patients (box $2 ; 2, \mathrm{D}, \mathrm{v}$; and 2, B, i). Whereas students stated their goals for early communication learning in general terms, staff had more specific goals, such as learning the appropriate use of open and closed questions, and finding out what people feel (box 2; 2, D, vi). One theme brought up repeatedly by students and scarcely apparent in staff transcripts was learning to communicate as a way of building confidence, "knowing what they 
were doing," feeling "less useless" in clinical settings, and starting to act in a professional capacity.

Other dinical skills - Staff saw value in learning "living anatomy" and laying a basic science foundation for climical procedures. Students felt that they would be better equipped to go on to wards if they had learnt some skills. To record an electrocardiogram by using modern machines on patients in a hospital rather than "ancient" machines on peers in the medical school would "put everything more into perspective:" Overall, skills were more a vehicle for patient contact, and part of an "all round" training (box $2 ; 2, \mathrm{~A}$, ii) than an end in their own right. Neither staff nor students wanted then to be learnt at the expense of basic sciences (box $2 ; 2, \mathrm{D}$, vii).

Public health - Staff, only, discussed public health. Their opinions were sharply divided as to whether it could be learnt experientially at all, let alone early. One respondent regarded disease encountered experientially as "anecdote"; another argued that specific instances of disease could teach generalities by showing how "people as human beings fit into a population view" (box $2 ; 2, \mathrm{C}$, ii). Experience could show that diseases have environmental determinants, and resources for treating them are not limitless.

Profescional roles - Staff felt that experience could teach students about their future role as a doctor, although it must not channel them into stereotypical behaviour (box $2 ; 2, D$, viii). It could teach them how doctors interrelate with other health professionals (box $2 ; 2, \mathrm{D}$, ix). Finding out through experience what career options exist within the profession would motivate students to study.

\section{DISCUSSION}

\section{PRINCIPAL FINDINGS AND MEANING}

Respondents generally favoured early experience, provided it did not weaken the learning of bioscience. Staff had additional concerns about cost and logistics. Our theory is that experience could strengthen, deepen, broaden, contextualise, and integrate early medical education: strengthen and deepen, cognitively, by complenenting existing teaching and learning and helping students develop intellectual skills; broaden, by accentuating affective dimensions of learning; contextualise, by linking theoretical learning to the settings, roles, and responsibilities of practice; and integrate, by at once stimulating students" intellects, motivating them, and encouraging them to reflect on their progress towards professional roles and responsibilities. These benefits, we think, would be complementary to any contextualising and integrating effect of problem based learning. 
The narratives depict medical education as a process of socialisation into a profession. Students were disappointed to enter medical school and not to meet patients and doctors. Two to three years later, without any preparation in the interim, they had to make an abrupt social transition. Their sense of vocation was a source of positive emotions; the abruptness of the transition a source of both positive and negative ones. A more gradual entry to the clinical environment, students suggested, would achieve a better balance of positives and negatives. Staff, who can provide positive or negative role models and be more or less sensitive to students' needs, showed little awareness of the social dimension. Such an ill defined, composite educational process and outcome as "professional socialisation" could easily be squeezed out by the modern pressure to frame curriculums in terms of explicit, measurable, short term methods and outcomes. We contend that it should not be forgotten. Flexner was able to put his emphasis on science because he could entrust professional socialisation to the apprenticeship education of his day.

\section{STRENGTHS AND LUMITATIONS OF THE STUDY}

The qualitative nature of the study is both a strength and a limitation. A strength, because theoretically oriented, rigorously performed, qualitative research that uses an appropriate sampling strategy can generate valid theories. A limitation, because it cannot test hypotheses or claim generalisability beyond the study conditions. Our respondents were numerous and varied, which allowed us to draw out differences in student and staff experiences. We do not know if our findings apply to non-problem based curriculums. We cannot say what experiences individual medical schools should choose, but box 3 offers a definition of "experience" arising from this study that may guide them.

\section{RELATION TO OTHER PUBLICATIONS}

Publications on early experience can be categorised into opinion statements, empirical research, and theories. Consonance with opinion statements about both early experience ${ }^{7}$ and professionalism ${ }^{24}$ supports the validity of our findings. Our cognitive, social, and affective reasons for experience correspond well to Hamilton's call for medical education to have wide, long, and deep outcomes. ${ }^{15}$ We are systematically reviewing empirical research on the impact of early experience. Our preliminary analysis of 104 publications between 1992 and 2001 showed the evidence base to be poorly grounded in theory, methodologically weak, and more often at the level of opinion rather than learning outcomes. ${ }^{16}$ However, it supports our respondents' view that awareness of professional roles, preparedness for clerkships, and early detection of students with difficulties are probable benefits of early experience. Students and staft in the 
Huthenuc (real as opposed to simulated) human contact in a social or clinical context that enhance leaming of heallh, ilness and disease, and the role of the health professional

vertically integrated Linkoping curriculum are very satisfied with a cognitive approach that fits the principles articulated by our respondents. ${ }^{8} 17$ Two recent qualitative studies have, like ours, characterised medical education as developing a professional identity. ${ }^{18} 19$ One described how meeting patients built students' confidence to interact with clinicians. ${ }^{18}$ The other described how transition into the clinical environment and unfeeling behaviour on the part of teachers could pose an emotional threat to professional socialisation. ${ }^{19}$

The blend of cognitive, social, and affective learning fits well with social cognitive theory, a widely accepted explanatory framework for human behaviour and its development (see, for example, Bandura ${ }^{20}$ ). Our students" wish to build up mental images of patients fits both with Bandura's concept of "symbolisation" and another theory, according to which "illness scripts" are foundations of clinical expertise. ${ }^{21}$ Our respondents" wish for role modelling fits with Bandura's "vicarious learning"; anticipation of future professional roles with "forethought"; awareness of future goals with "self regulation"; and self awareness with "self reflection." Our results also fit well with new conceptualisations of apprenticeship, according to which an important part of professional learning is developing a sense of identity within a community of practice. ${ }^{10}$

\section{FUTURE RESEARCH}

ten Cate et al have developed a model of medical education that could translate our results into educational practice, 22 and Kachur has suggested an approach that makes fieldwork more active, fits it to the theoretical framework of the curriculum, and supports laming through reflection. Medical education is too complex and the pace of change too fast, we think, for those approaches to be subjected to controlled experiment. The challenge is for educators to base their interventions on theory and evaluate them tigorously enough to advance knowledge through implementation. ${ }^{2.3}$

Acknowledgenent: We thank our many colleagues who gave freely of their time to participate.

Contributors: TD conceived of the study, conducted it, analysed the data, and wrote the paper. CB co-facilitated many of the groups, participated throughout the data analysis, and commented on all drafts of the paper. John Humpherson 
helped conceive the study, co-facilitated most of the groups and helped the early stages of data analysis. TD is guarantor.

Funding: The University of Manchester Faculty of Medicine, Dentistry, Nursing and Pharmacy Academic Standards Committee funded the Manchester workshop. The international workshop took place under the auspices of the Association for Medical Education in Europe. Other expenses were met from TD's endowment funds.

Competing interests: None declared.

Ethical approval: Two ethics review committees considered this progranme of investigation not to need approval; an NHS ethics committee because the research did not involve patients, and a university ethics committee because its primary purpose was curriculum development.

\section{REFERENCES}

1. Bonner TM. Iconoclast. Abraham Flexner and a life in learning. Baltimore: Johns Hopkins University Press, 2002.

2. Medical Professionalism Project. Medical professionalism in the new nillennium. Clin Med JR.CPL 2002; 2:116-8.

3. Irvine D. The performance of doctors: new professionalism. Lancet 1999;353:1174-7.

4. General Medical Council. Tomorrow's doctors. 2nd ed. London: GMC, 2002.

5. Howe A. Professional clevelopment in undergraduate medical curricula-the key to the door of a new culture? Med Educ 2002;36:353-9.

6. Gordon J. Fostering students ${ }^{\circ}$ personal and professional development in medicine: a new framework for PPD. Med Educ 2003;37:341-9.

7. Gordon J, Hazlett C, ten Cate O, Mann K, Kilminster S, Prince K, et al. Strategic planning in medical education: enhancing the learning environment in clinical setrings. Med Educ 2000;34:841-50.

8. Dahle LO, Brynhildsen J, Berbohm Fallsberg M, Rundquist I, Hammar M. Pros and cons of vertical integration between clinical medicine and basic science within a problem-based undergraduate medical curriculum: examples and experiences from Linkoping, Sweden. Med Teach 2002;24:280-5.

9. Kachur EK. Observation during early clinical exposure-an effective instructional tool or a bore? Med Educ 2003;37:88-9.

10. Wenger $\mathrm{E}$. Communities of practice. Learning, meaning and identity. Cambridge: Cambridge University Press, 1998.

11. O'Neill PA. Problem-based learning alongside clinical experience: reform of the Manchester curriculum. Educ Health 1998;11:37-48.

12. Strauss A, Corbin J. Basics of qualitative research. Techniques and procedures for developing grounded theory. 2 nd ed. Thousand Oaks: Sage, 1998.

13. Barbour RS. Checklists for improving rigour in qualitative research: a case of the tail wagging the dog? BMI 2001;322:1115-7.

14. Angelo TA, Cross K. . Classroonn assessment techniques: a handbook for college teachers. 2nd ed. San Francisco: Jossey-Bass, 1993. 
15. Hamilton $\mathrm{JD}$. Outcomes in medical education must be wide, long and deep. Med Teach 1999:21:125-6.

16. Littewood SL. What are the benefits of early clinical experience to healthcare students? July 2002. www.bemecollaboration.ong/reports/Earlyclinicalexperiencereport pdf (accessed 20 Sep 2004).

17. Brynhildsen J, Dahle LO, Berbohm Fallsberg M, Rundquist 1 , Hammar M. Attitudes amongstudents and teachers on wertical integration between clinicall medicine and basic science within a problem-based undergraduate medicall curriculum. Med Teach $2002 ; 24: 286-8$.

18. Pikkala KH, Mantyranta T. Professional socialization revised: medical students' own conceptions related to adoption of the future physician's role- a qualitative study. Med Teach 2003;25:155-60.

19. Radcliffe C, Lester H. Perceived stress during undergraduate medical training: a qualitative study. Med Educ 2003;37:32-8.

20. Bandura A. Social foundations of thought and action. Englewood Cliffs: Prentice-Hall, 1986.

21. Schmidt HG, Noman GR, Bashuizen HPA. A cognitive perspective on medical expertise: theory and implications. Acad Med 1990;65:611-21.

22. ten Catte $\mathrm{O}$, Snell L, Mann K, Vermunt J. Orienting teaching towards the learning process. Acad Med 2004;79:219-28.

23. The Design-Based Research Collective. Design-based research: an emerging paradigm for educational inquiry. Educ Res 2003;32:5-8. 


\section{CHAPTER 3}

\section{Early practical experience in medical education. The evidence}

British Medical Journal 2005; 331: 387-91

Early Practical Experience and the Social Responsiveness of

Clinical Education. Systematic Review

Sonia Littlewood, Valmae Ypinazar, Stephen A Margolis, Albert Scherpbier, John Spencer, Tim Dornan

The full version of this research was published at www.bemecollaboration.org/EarlyExperienceReview.pdf, and is in press; Medical Teacher as:

How can experience in clinical and community settings contribute to early medical education?

Tim Dornan, Stephen A Margolis, Sonia Littlewood, Aibert Scherpbier, Valmae Ypinazar, John Spencer 


\section{ABSTRACT}

Objectives: To find how early experience in clinical and community settings ("early experience") affects medical education, and identify strengths and limitations of the available evidence.

Design: A systematic review rating, by consensus, the strength and importance of outcomes reported in the decade 1.992-2001.

Data sources: Bibliographical databases and journals were searched for publications on the topic and reviewed under the auspices of the recently formed Best Evidence Medical Education (BEME) collaboration.

Selection of studies: All empirical studies (verifiable, observational data) were included, whatever their design, method, or language of publicatior.

Results: Early experience was most commonly provided in community settings, aiming to recruit primary care practitioners for underserved populations. It increased the popularity of primary care residencies, albeit among self selected. students. It fostered self awareness and empathic attitudes towards ill people, boosted students' confidence, motivated them, gave them satisfaction, and helped then develop a professional identity. By helping develop interpersonal skills, it made entering clerkships a less stressful experience. Early experience helped students learn about professional roles and responsibilities, healthcare systems, and health needs of a population. It made biomedical, behavioural, and social sciences more relevant and easier to learn. It motivated and rewarded teachers and patients and enriched curriculums. In some countries, junior students provided preventive health care directly to underserved populations.

Conclusion: Early experience helps medical students leam, helps them develop appropriate attitudes towards their studies and future practice, and orientates medical curricullums towards society's needs. Experimental evidence of its benefit is unlikely to be forthcoming and yet more medical schools are likely to provide it. Effort could usefully be concentrated on evaluating the methods and outcomes of early experience provided within non-experimental research designs, and using that evaluation to improve the quality of curriculums. 


\section{INTRODUCTION}

The nom for the past century has been for medical students to leam theory for two to three years before seeing it applied in practice. Encouraged by professional bodies such as the UK General Medical Council, many medical schools are "vertically integrating" various types of practical experience into the early years, ${ }^{1-3}$ yet exponents of wertical integration have not clearly argued the case for it, let alone presented evidence in its favour. We developed a theory, grounded in consensus, that early practical experience ("early experience") could orient medical curriculums towards the social context of practice, and strengthen students' affective and cognitive learning. ${ }^{4}$ We have now extended this research by systematically reviewing publications on the topic ${ }^{5}$ under the auspices of the recently formed Best Evidence Medical Education (BEME) collaboration. "This paper summarises the review and interprets its main findings in relation to contemporary trends in medicall education.

\section{METHODS}

Methods are reported in full elsewhere. 5 We have not completed the QUOROM statement since this is not a systematic review of clinical trials. The topic review group (all of whose members are authors) was recruited to be international, experienced in innovative clinical education, representative of community and hospital perspectives, familiar with horizontal and vertical integration, and conversant with evidence based practice. A medical student was a lead nember.

\section{REVIEW QUESTION, DEFINITIONS, AND INCLUSION CRITERIA}

The review question was: "How can experience in clinical and community settings contribute to early medical education?" Early was defined as "what would traditionally have been regarded as the preclinical phase; usually the first two years" and experience as "authentic (real as opposed to simulated) human contact in a social or clinical context that enhances learning of health, illness and/or disease, and the role of the health professional." All tmpirical studies (verifiable, observational data) were included, whatever their design, method, or language of publication. Although the search was directed towards medicall education, evidence from other health professions was not excluded if it could be applied to medicine. 
Bibliographical databases screened electronically

Britisly Education Index (BED)

Education Resources Information Center (ERIC)

Medline

CINAHL

Embase

PsychINRO

"TimeLIT

EBM rewiews

SIGLE

Cochrane databases

\section{Journals hand screened}

Acadernic Medicine

Advances in Health Sciences Education

Joumal of Educational Psychology

Medical Education

Medical Teacher

Teaching and Leaming in Medicine

\section{SEARCH STRATEGY AND REFERENCE HANDLING}

The review covered the decade 1992-2001. After a scoping search, the research group ran a main search across seven major bibliographical databases (Table 1), searched three other databases by keywords, handsearched six journals, and screened the reference lists of all informative articles. We used EndNote bibliographical software (Thomson, Philadelphia, USA) to handle the citations, of which there were 6981 after elimination of duplicates.

\section{ARTICLE SELECTION, CODING OF OUTCOMES, AND SYNTHESIS OF RESULTS}

All articles presenting empirical evidence on the effect of experience on early education in the health professions, according to the definitions above, went to two members of a coding pair, who independently identified all outcomes and coded them for their strength (on the 1-5 scale described in box 1) and educational importance (using Kirkpatrick's hierarchy for educational outcomes, which is also included in box 2). The researchers resolved disagreements by consensus and entered the outcomes and their metadata into a database. The review yielded 277 educational outcomes from 73 studies. This report is based on the 116 of those outcomes from 38 studies, which the review group judged admissible as evidence because their strength was rated 3 or higher and their Kirkpatrick level was 2 a or higher. The group divided the studies into positive outcomes 
(evidence of benefit), negative outcomes (no benefit or harm) and adverse outcomes, and coded them as coming from a descriptive or comparative study. The theory previously developed by consensus ${ }^{4}$ provided an interpretive structure. One author then re-read the original papers and wrote this narrative; the other five authors did a critique of it:

\section{RESULTS}

\section{NATURE, STRENGTH, AND IMPORTANCE OF THE EVIDENCE}

Sixty nine per cent of studies were from North America, $23 \%$ from Europe, and $8 \%$ from other parts of the world. Ninety three per cent were in medicine and the remainder in pharmacy $(6 \%)$ or nursing (1\%). Seventy two per cent of interventions were in primary care, family medicine, or community settings; and $28 \%$ in hospital, hospice, or medical school. Sixty nine per cent were clinical placements, ranging from a single half day session to half day clinical visits through both preclinical years; $8 \%$ were skills training events; $7 \%$ were placements in "lay" community settings; $7 \%$ were attachments to a single patient or family; and $9 \%$ were combinations. The number of learners ranged from six to 1081. Most evidence was from descriptive studies ( $72 \%$ descriptive v $28 \%$ comparative) with evidence of positive publication bias ( $91 \%$ of outcomes positive), more so in descriptive studies ( $99 \%$ of outcomes positive) than comparative studies ( $70 \%$ of outcomes positive).

\section{EFFECT ON CAREER CHOICE}

Recruitment of doctors to underserved, rural communities is a major public health issue in the United States, whose publications dominated the evidence base. We found strong evidence from comparative studies with long follow-up that students who had early experience were more likely than controls to choose residencies in prinary care, ${ }^{8-12}$ and show positive attitudes towards rural practice. ${ }^{13-16}$ However, the students in those studies often chose to have early experience and may have had more positive attitudes from the outset. Moreover, their early experience was in rural communities, usually as part of a recruitment drive. ${ }^{17}$ 

STRECTH AND INPORTANCE OF EVIOENCE AS APPLIED TO THIS RELEW

\section{sitength}

It would be possilsle to have a strong study winl low inpact, and nice versa.

Sitrength equates with critical ap prais al and is a statement of your confidonce that the tesults of dhe stady are credible. Having conphdered he study destgn, the way the stuidy was performed, and the data analygis, we wited the ontcomine.

N No clear conclusions can be drawn, not strongs

2 Results anbuguovi, here seemas to be a trond

3 Conditions can probably be based on the resultes

4 Results are clear and yery $14 k$ ly to be thue

9 Resuls are une quwocal

\section{mportance}

Level 1. Participation - cover learners: news on the learning experience, its organsation, presentation, content, teaching nethods and aspects of the instructional or ganisation, materials, and quality of instructrion

Level $2 a$ Modification of attitudes or perceptions - outcomes here elate to changes in the reciprocal attitudes or perceptions between participant groups towards intervention or simmlation

Level 2 b. Modification of knowledge and kills for knowledge, this relates to the acquisition of concepts, procedures, and principles for skills this relates to the acquisition of thiniking and problem solving prychomotor and social skills

Level 3 . Behaviental change - documents the transfer of learning to the workplace or willingness of leaners to apply new knowledge and skills

Level 4 a. Change in organisational practiceWider changes in the organination or delivery of care, attributable to an educational progranme

Level 4 b Benefits to patient of clients - any improvenent in the fiealth and wellibeing of patients and clients as a direct result of an educational programme

Note: The use of the term importance to describe the Rirkpatrick hierarchy of educational evidence is the authors, not the BEMU: callaboration: 


\section{EFFECT ON STUDENTS' LEARNING}

Early experience influenced students in several ways.

\section{Attitudes}

Attitudes are notoriously hard to quantify, and it is hard to compare without quantifying, so only $16 \%$ of attitudinal outcones were from comparative studies. However, descriptive methods are well suited to exploring students' complex emotional reactions and the factors that trigger them. Early experience motivated students in numerous ways. ${ }^{16-21}$ It reminded them of their vocation to be a doctor. It showed the practical relevance of the theory they were studying and made it easier to learn. It motivated them by giving welcome respite from the discipline of preclinical studies and exposing them to patients they could empathise with and doctors they could strive to emulate. It also made students more confident to meet and interview patients. ${ }^{131519-25}$ Students who chose to have early experience were more satisfied with their studies 26 because it gave them insight into the social and psychological problems of "real people." 23 It helped build self awareness, including the ability to recognise and respond to feelings of uncertainty and inadequacy. ${ }^{18}$ Early experience helped students develop empathic responses to ill patients. 1827 Some of the evidence concerned students' socialisation to their role as a clinical learner and future health professional. Two comparative studies found no association between early experience and the outcomes examined, ${ }^{22} 26$ although six descriptive studies found positive effects, 41517192728 including becoming more mature, acclimatising to professional settings, and identifying with doctor role models. Looking back on their education, graduates felt that early experience had reduced the stress they experienced when they first met patients during clerkships. ${ }^{27}$

\section{Understanding of subject matter}

These findings were almost all positive and from descriptive studies, reporting qualitative changes in intellectual perspectives and patterns of thought. Early experience made students more confident in their knowledge, taught them things "that could not be learned from books," 1420242527 brought diseases to life, and made medical science more comprehensible. ${ }^{13} 172029$ It provided a framework to explain clinical practice, showed students how professionals viewed their interactions with patients, and helped develop "clinical ways of thinking." 77 It also taught students how people live, how their living conditions affect their health, and how important it is that health services are readily accessible to them. ${ }^{14} .3031$ It helped them appreciate the impact of illness 182830 and strengthened their knowledge of healthcare delivery systems, ${ }^{14} 16.32$ health professional roles and responsibilities, and the importance of good interprofessional communication and multidisciplinary working. ${ }^{18} 193031$ It helped students learn biomedical sci- 
ences, ${ }^{19}$ behavioural and social sciences, and the ethical dimension of patient care. 1823

\section{Clinical skills}

Again, much of the research explored the quality rather than quantity of educational benefit, though nearly half the outcomes came from comparative studies. Early experience improved students' ability to relate to patients and communicate empathy. ${ }^{2022}$ It helped them understand the doctor-patient relationship and the importance of listening to patients, carers, and other professionals. ${ }^{19} 30 \mathrm{Stu}-$ dents valued exploring social and psychological determinants of health and disease through contact with real patients ${ }^{23}$ and were able to deliver preventive healthcare. ${ }^{33}$ They appreciated learning to take diagnostic histories $13222328.34-36$ and performing simple physical examinations. ${ }^{13} 24$ 35-37 Equipped with those skills, they felt better able to approach patients. ${ }^{27}$

\section{Sindy skills}

Qualitative analysis of learning logs showed early experience to uncover differences in students' ability to learn reflectively. ${ }^{38}$

\section{Performance in exaninations}

It was concluded from several comparative studies that early experience improved performance in examinations, but the data were often sketchy, the study methods weak, the effect sizes small, and the benefits inconsistent. ${ }^{15} 20$ 39-42 Experience in hospital had comparable effects to experience in community. ${ }^{43}$

\section{Effects on teachers, organisations, populations, and patients}

Descriptive studies reported that students were not the only beneficiaries of early experience, which could motivate and reward teachers ${ }^{44}$ and patients in hospital ${ }^{45}$ increase the breadth of placements that organisations provided, ${ }^{13}$ and bring health care to underserved populations. ${ }^{37}$

\section{DISCUSSION}

As part of a complex curriculum intervention, ${ }^{* 6}$ early experience helped recruit residents to rural primary care in the US. Many countries need urgently to recruit health professionals to deliver primary care to underserved populations. The nature of the research, however, makes it unsafe to conclude that the benefit is restricted to rural practice, or even primary care. The students who opted for rural primary care had opted to have early experience, which was often provided within rural primary care. Early experience in an urban setting or second- 
tion. They also support the view that avoiding an abrupt transition into the clinical environment would give students an easier passage through medical education. ${ }^{4}$

Acknowledgements: We thank Liz Asbridge, Lucy Coxon, Rhona Dalton, Kate Dornan, Alex Haig, Gwyn Hodgson, Debbie Leadbetter, Pat Lilley, Pat McArdle, and Dan Powley for their help. Diana Wood, Jill Morrison, and lain Chalmers made helpful comments on the manuscript.

Conntwitors: SL did the literature search, validated the methods, selected the arricles, piloted the analysis and second-coded half the articles in the funal analysis. TD conceived of the study, supervised SL's medical student project, convened the topic review group, validated the methods, second-coded half the articles, analysed the results, wrote the paper, and revised it after peer review. VY, SAM, $A S$, and JS helped validate the article selection, first coded papers, and participated actively throughout the conduct, analysis and writing of the study. TD is its guarantor.

Funding: None, except that minor expenses were met from TD's endowment funds:

Competing interests: None declared.

Ethical approval: Because it did not involve human subjects, the study was not submitted to ethical scrutiny.

\section{REFERENCES}

1. General Medical Council. Tomorrow"s doctors. 2nd ed. London: GMC, 2002.

2. Harden RM. Integrated teaching-what do we mean? A proposed taxonomy. Med Educ 1998;32:216-7.

3. Dahle LO, Brynhildsen J, Berbohm Fallsberg M, Rundquist 1, Hammar M. Pros and cons of vertical integration between clinical medicine and basic science within a problem-based undergraduate medical curriculum: examples and experiences from Linkoping, Sweden: Med Teach 2002;24:280-5.

4. Dornan 'T, Bundy $\mathrm{C}$. What can experience add to early medical education? Consensus survey. BMJ 2004;329:834-7.

5. Dornan T, Margolis SA, Y pinazar V, Scherpbier A, Spencer J. How can experience in clinical and community settings contribute to early medical education? www.bemecollaboration.org/topics.hm (accessed 19 Jul 2005).

6. Albanese $M$, Norcini J. Systematic reviews: what are they and why should we care? Adv Health Sci Educ Theory Pract 2002;7:147-51.

7. Kirkpatrick DL. Evaluation of training. In: Craig $\mathbb{R}$, Bittel L, eds. Training and development handbook. New York: McGraw-Hill, 1967:87-112.

8. Lynch DC, Teplin SE, Willis SE; Pathman DE, Larsen LC, Steiner BD, et al. Interim evaluation of the rural health scholars program. Teach Learn Med 2001;13:36-42. 
9. Grayson MS, Klein MP, Franke KB. Impact of a first-year primary care experience on residency choice. J Gen Intern Med 2001;16:860-3.

10. Levy BT, Hartz A, Merchant $\mathrm{ML}_{\text {, }}$ Schroeder BT. Quality of a family medicine preceptorship is significantly associated with matching into family practice. Fam Med 2001;33:683-90.

11. Mengel MB, Davis $\mathrm{AB}$. Required first-year generalist clinical experience courses and their relationship to career choice: the critical effect of family medicine involvement. Firm Med 1995;27:652-7.

12. Dobie SA, Carline JD, Laskowski MB. An early preceptorship and medical students" beliefs, values, and career choices. Adv Health Sci Educ Theory Pract 1996:2:35-47.

13. Quinby PM, Papp KK. Adopt-a-student, early mentoring in family medicine. Med Teach $1995 ; 17: 47-53$.

14. Vaz $R$, Gona $O$. Undergraduate education in rural primary health care: evaluation of a first-year field attachment. Med Educ 1992;26:27-34.

15. Barley $G, O^{\prime}$ Brien-Gonzales A, Hughes $\mathbb{E}$. What did we learn about the impact on students" clinical education? Acad Med 2001;76(4 suppl): s68-71.

16. Riley $\mathrm{K}$, Myers W, Gordon MJ, Laskowski M, Kriebel S, Dobie S. A collabotative approach to a primary care preclinical preceptorship for underserved settings. Acad Med $1991: 66: 776$

17. Mann MP. A light at the end of the tunnel: the impact of early clinical experiences on medical students. Presented at the annual meeting of the American Educational Research Association, New Orleans, LA, 4-8 April, 1994.

18. Kent GC. Medical student's reactions to a nursing attachnent scheme. Med Educ $1991 ; 25: 23-32$.

19. Hampshire A. Providing early clinical experience in primary care. Med Educ 1998;32:495-501.

20. Rooks L, Watson RT, Harris JO. A primary care preceptorship for first-year medical students coordinated by an area health education center program: a six-year review. Acad Med 2001;76:489-92.

21. Steele D, Susman J, McCurdy F, O'Dell. D, Paulman P, Stott J. The Interdisciplinary Generalist Project at the University of Nebraska Medical Center. Acad Med 2001;76(4 suppl): $: 121-6$.

22. Nowack DH, Dube $C_{s}$ Goldstein MG. Teaching medical interviewing. A basic course on interviewing and the physicianmpatient relationship. Arch Intern Med. $1992 ; 152: 1814-20$.

23. Orbell $\mathrm{S}$, Abraham $\mathrm{C}$. Behavioural sciences and the real world: Report of a community interwiew scheme for medical students. Med Educ 1993;27:218-29.

24. Fernald DH, Staudenmaier AC, Tressler CJ, Main DS, O'Brien-Gonzales A, Barley GE. Student perspectives on primary care preceptorships: Einhancing the medical student preceptorship learning environment. Teach Learn Med 2001;13:13-20.

25. Alford $C$, Miles $T$, Palmer A, Espino D. An introduction to geriatrics for first-year medical students. J Am Geriatrics Soc 2001:49:782-7.

26. Johnson AK, Scott CS. Relationship between early clinical exposure and first-year students' attitudes toward medical education. Acad Med 1998;73:430-2.

27. Friedberg M, Glick S. Graduates' perspective of early clinical exposure. Educ Health $1997 ; 10: 205-11$.

28. Frank D. An integrated curriculum for teaching preparatory clinical skills at a traditional medical school. Teach Learn Med 1996;8:4-9. 
29. Chisholm MA, MCCall CY, Francisco GEJ, Poinier S. Situdent Exposure to Actulal Patients in the Classroom. An J Pharm Educ 1997;61:364-70.

30. Cooper HC, Gibbs TI, Brown L. Communiry-orientated medical education: extending the boundaries. Med Teach 2001;23:295-9.

31. Waddell RF, Dawidson RA. The role of the community in educating medical students: Imitial impressions from a new program. Educ Health $2000 ; 13: 69-76$.

32. Bucci KK, Maddox RW, Holmes TJ, Broadhead WE, Tse C-KJ. Implententation and evaluation of a shadow program for PharmD students. Am J Pharm Educ 1993;57:44-9.

33. Nieman LZ, Hoxhall LE, GroffJ, Cheng L. Applying practical preventive skills in a prechnical preceptorship. Acad Med 2001,76:478-83.

34. Madray H, Pfeiffer CA, Ardolino A. Teaching patient wellness to first-year medical students: the impact on future ability to perform the history of present illness. Med Educ 2000;34:404-8.

35. Allen SS, Bland CJ, Harris IB, Anderson D, Poland G, Satran L, et all. Structured clinical teaching strategy. Med Teach 1991;13:177-84.

36. Rogers JC, Dains JE. Can first year students master dinical skills? Acad Med $2001 ; 76: 1065-6$.

37. Linder BM, Saha A, Heseltine GF. Teaching clinical skills to new medical students: the Oman experience. Med Educ 1992;26:282-4.

38. Nieni PM. Medical student's professional identity: self-reflection during the precilnical years. Med Educ 1997;31:408-15.

39. Elnicki DM, Halbritter KA, Antonelli MA, Linger B. Educational and career outcomes of a medicine preceptorship for first-year students. I Gen Intern Med 1999; 14:341 -6.

40. Rogers JC, Swee DE, Ulian JA. Teaching medical decision making and students " clinical problem solving skills. Med Teach 1991;13:157-64.

41. Pamies RJ, Herold AH, Roetzheim RG, Woodard LJ, Micceri T. Does early clinical exposure enhance perfomance during third-year derkship? I Nat Med Assoc 1994;86:594-6.

42. Carney P, Baron ME, Grayson MS, Klein M, Cochran N, Eliassen MS, et al. The impact of early clinical training in medical education: A multi institutional assessment. Acad Med 1999;74(1 suppl):s59-s67.

43. Satran L, Harris IB, Allen S, Anderson DC, Poland GA, Miller WL. Hospital-based versur community-based clinical education: Comparing performances and course evaluations by students in their second-year pediatrics rotation. Acad Med 1993,68:380-2.

44. Freeman J, Cash $C$, Yonke A, Roe B, Foley $\mathbb{R}$. A longitudinal primary care progran in an urban public medical school: Three years of experience. Acad Med 1995;70(11 suppl) $: 564-568$

45. Thomas $\mathbb{E} J$, Hafler $J \mathrm{P}$, Woo B. The patient's experience of being interviewed by first-year medical students. Med Teach 1999;21:311-4.

46. Murray E. Challenges in educational research. Med Educ 2002;36:110-2.

47. Dornan T. Osler, Flexner, apprenticeship, and "the new medical education." J $\mathbb{R}$ Soc Med 2005; 98: 91-5

48. Irvine $\mathrm{D}$. The performance of doctors: new professionalism. Lancet 1999;353:1174-7.

49. Medical Professionalism Project. Medical professionalism in the new millennimin: a physicians' charter. Lancet 2002;359:520. 
CHAPTER

\section{Learning in clinical workplaces. The teacher's perspective}

Published in Medical Education 2005, 39:163-170

Clinical teachers and problem-based learning: A phenomenological study. Tim Dornan, Albert Scherpbier, Nigel King, and Henny Boshuizen 


\section{ABSTRACT}

Aim: To explore how clinicians perceive their roles in problem-based medical education, and how closely those perceptions link to the curriculum they teach. Method: All 14 general physicians in a teaching hospital took part in 6 semistructured discussions, which were analysed phenomenologically.

Results: Third year clinical teaching was described in terms that bore little relation to problem-based learning (PBL). Teachers placed great importance on the social dimension of professional learning. They expressed strongly positive af fects towards learners and their learning that they found hard to express as PBL tutors: Their narratives of education were remarkably divorced from modern day clinical practice.

Conclusions: Problem-based method lacked some important conditions for professional teaching and learning. Traditional apprenticeship is unsustamable under present day conditions of practice. There is a need for new educational methods that help the learner to build a professional identity through social interaction with practitioners. 


\section{INTRODUCTION}

Since the time of Hippocrates, medical students have learned practice by working with and assimilating the artistry of master clinicians. The "curriculum" consisted of whatever the masters did. Now, educational objectives are to be explicit, integrative and not determined by the interests of "masters". "Learners are to be 'self directed'; in other words, they should organise and manage their own learning activities and needs ${ }^{1}$ rather than await a master"s directions. ${ }^{2}$ Problem-based learning (PBL) is a prominent feature of contemporary medical education. ${ }^{3}$ Grounded in cognitive psychology, it sets out to stimulate curiosity, define the limits of a student's knowledge and build durable understanding. It contextualises learning to practical situations, and integrates it across disciplinary boundaries, ${ }^{3}$ It takes place in early medical training, often giving way to traditional clerkships in the later years.

There are important differences between PBL and traditional clinical teaching, summarised in Table 1. Despite those differences, some teachers regard clinical teaching as intrinsically problem-based, and curriculum leaders assume that problem-based methods will carry across to clinical learning. To that end, our own School extended PBL into clerkships. ${ }^{4}$ We detected dissatisfaction among clinicians because being a PBL tutor provided little outlet for their mastery. Yet mastery is as important as ever to good clinical practice, and tutelage by a clinician remains an important way of developing it. 5.6 This raised the following questions:

- How do clinicians perceive their roles in problem based medical education?

- How closely do those perceptions match the curriculum they teach?

\section{METHODS}

\section{SETTING}

The University of Manchester School of Medicine lends itself to the research question because it has introduced PBL into all curriculum years, including clerkships. ${ }^{4}$ It did so successfully according to external review by the General Medical Council (GMC) (http://www.gncmuk.org) and the Quality Assurance Agency (htrp://www.qaa.ac.uk/). Hope Hospital, one of its 3 major teaching hospitals, was chosen because its senior staff had been very supportive of the curriculum, and the researchers had ready access to them. 
Differences in emphasis berween PBL and taditional clinical reaching

\begin{tabular}{|c|c|c|}
\hline & PBC & Traditional \\
\hline Context & Seminar room & Practice setting \\
\hline Direction & Learner & Teacher \pm learner \\
\hline Style of turoring & Facilitative & Didactic \pm authoritarian \\
\hline Curriculum & $\begin{array}{l}\text { Systematic; prescribed by } \\
\text { curriculum committee; common or } \\
\text { 'exemplar' clinical situations }\end{array}$ & $\begin{array}{l}\text { Unoystematic; dictated by } \\
\text { casemix and teacher }\end{array}$ \\
\hline "Triggers" for learning & $\begin{array}{l}\text { Sinculated, controlled and } \\
\text { integrative }\end{array}$ & $\begin{array}{l}\text { Authentic, uncontrolled and } \\
\text { situation-specific }\end{array}$ \\
\hline Subject matter & $\begin{array}{l}\text { Knowledge and skills } \\
\text { Integrative }\end{array}$ & $\begin{array}{l}\text { Professional tasks and roles } \\
\text { Discipline-specific }\end{array}$ \\
\hline Source of information & Private study and peers & Teacher \pm private study \\
\hline Expertise in the subject muatter & Preferable, but not essential & $\begin{array}{l}\text { Essential, and determines subject } \\
\text { matter }\end{array}$ \\
\hline
\end{tabular}

\section{RESEARCHERS}

Of the authors, TD is a general physician and teacher, who, as former Hospital Dean, implemented the curriculum at Hope Hospital. AS is a nonpractising doctor who heads the curriculum in a problem-based Dutch medical school. NK is an academic psychologist and phenomenologist. HB is a cognitive psychologist who researches expertise development in a Dutch university. This team brought together theoretical, contextual and methodological knowledge.

\section{RESEARCH PARTICIPANTS}

We chose general physicians as a relatively coherent community of practice ${ }^{6}$ with major commitments to the old and new curricula. They had responsibilities in acute internal medicine as well as subspecialties, inpatient as well as outpatient medicine, and research and administration beside education and practice. A minority of them were Manchester graduates. All 14 general physicians involved in teaching firms (TD being the 15th) agreed to take part. Two had subspecialty interests in respiratory medicine, 1 in cardiology, 4 in renal medicine, 3 in gastroenterology and 4 in diabetes / endocrinology.

\section{INTERVIEWS}

All participants gave informed consent to participate in 1 of 6 semistructured discussions lasting 30-60 minutes. In all but one, the participants were from a single subspecialty. TD, who facilitated, asked them how successful third year 
students were at 'learning from clinical experience', what factors help and hinder them, how their learning might be improved, and about the clinical teacher's role. He asked for their views on 2 specific topics: directed (as opposed to opportunistic) clinical learning, and outpatient learning. He allowed their narratives about the clinical teacher's role to unfold, departing whenever necessary from the interview template. The interviews were audiotaped and transcribed verbatim.

\section{PHENOMENOLOGICAL METHOD}

Phenomenology holds that rigorous interpretation of peoples" narratives (the phenomena) leads to valid knowledge. ${ }^{7}$ Central to it is 'bracketing', or making a deliberate effort to interpret materials naively. All the researchers read and reread the transcripts. TD drew up a written inventory of preconceptions, suppositions and biases that might affect his interpretation, and maintained this throughout the analysis. He performed a preliminary analysis and developed a comprehensive coding framework. The other 3 researchers read TD's inventory and, through discussion, identified further biases and distortions such as: forcing dichotomies; 'setting up straw men in order to knock them down'; a strongly humanist view of medicine; defensiveness towards the new curriculum; a bias towards directed, and outpatient, learning, and a bias towards students versus teachers. Then came 'phenomenological reduction' Redundant/overlapping phrases were identified, the coding structure simplified, and each of the 14 narratives reduced to a thematic description in the respondent's phraseology. The researchers discussed the descriptions and agreed some provisional interpretations. The data were coded for a third time, the individual narratives further reduced, and a thematic synthesis agreed upon. Individual statements and the evolving interpretation were referred back to the original, complete transcripts. Respondents reviewed the final interpretation and unanimously supported publication. The 'Results' and 'Discussion' sections were edited to take account of their comments. NUD*IST 4 and NVivo software (QSR; Qualitative Solutions and Research, Doncaster, VIC, Australia) assisted the analysis.

\section{RESULTS}

\section{PROBLEM-BASED LEARNING}

Problem-based learning was described as "the main part of the course' in both content and method. Paper PBL scenarios defined the core of the curriculum and the move to a problem-based curriculum had rekindled enthusiasm for education. Some respondents spoke enthusiastically about it. Others resented its preferred status over clinical teaching: 
Think there is a very stouctured approach to ... PBL, that they discuss cases and they develoy skills to be able to communicate as a group and to look at the sources, extrad information and relate that to a medical case scenario and wse it in the analysis of that scenario. That I believe is well structured ... there's a supportive network of lectures, thitorials that agan assist in then acquing knowledge. What is left unstrutured and almost ... well it's up to you to sont that ont ... is actually the dinical bedside teading.' (B132)

I think it needs to be ... the profile of it and the importance of it needs to be upped. They get a book for PBL, you know, there's a book and a folderand a map and we have twronals and we lean how to do it. I think the enthasis and the importance of dinical bedside reaching need to be uplifted in the teachers' and in the stadents' minds... it's wot an additional add-on." (P7O)

The second statement shows how, in 1 respondent's words, "clinical focus had been lost". Students were too busy to be on wards. They attended tutorials but not clinical teaching. Clinical teachers itched to give structure when students were 'behaving like headless chickens' in tutorials. Problem-based learning could be "a waste of their [teachers'] time". Consultants, it was suggested, were not good at sitting back and facilitating. Students were more self-directed in PBL than in practical clinical learning.

\section{CLUNICAL LEARNUNG: PROCESS}

\section{Direction}

Teachers fostered a supportive, if directive, culture. The most common way of directing learning was to call on students to present cases for group discussion:

'Yeah, wy tendency ... is to shawe them into having enongh cases to present, which weans they've clerked then." (Y561)

It was felt important to set quotas and to check how many patients students had clerked.

\section{Seeing patients}

As in the preceding example, clerking dominated the narratives:

'We say to the students ... al the stam of each atrachment ... we've got a lot of clinical material ... it's up to you to go and derk the patients and find some material ... and pwesent it.' (Z13)

Teachers expected students to 'be around on wards', both for general experience and to see acute presentations of disease. Students were to pick their own patients, and not expect medicine to be 'comparmentalised' in the same way as their curriculum. 
Students were seen as variable in their motivation and success in overcoming the obstacles that stood between them and seeing patients. One teacher found it 'richly rewarding' when students brought clinical problems to discuss.

\section{Participation in practice}

As distinguished from 'learning as a voyeur', concrete examples of participation included filling in blood forms, taking blood (which no longer applied because a phlebotomy service was provided) and attending case discussions at the end of clinics. Students, it was thought, would complain if called on to contribute routinely to care:

'So are you really saying that inwolvement of Year 3 students in the practical day-to-day management of patients is an acidental outcome that sometimes happers?' (Q) 'Yes, that's a fair summary, there's no programme that they have to be inwolved in the care of a patient.' (Y395)

\section{Teaching}

Teaching should be active and relevant, some carried out by seniors, and some by juniors, who are 'less intimidating'. Bedside teaching was seen as important:

'To my mind ... the most enjoyable ... aspect of teaching is definitely still ward-based cinical teaching, and you can see their cyes light up ... when they feel ... a large kidney or ... listen to a murmur and can actually realise it's not a bee on the stethostope.' (RZ231)

Although 1 respondent had:

"... come to the conclusion that ... traditional bedside teaching is a waste of time." (C86)

Demonstration of abnormal signs, feedback on clinical skills, teaching ward rounds and case discussions came in for favourable comment. Several respondents described enthusiasm as a feature of good teachers, but modelling, as described below, was generally absent from teachers' narratives:

'Consultants [are/ generically not just the person who's planning the attadiment fbut they should be] displaying attitudes and prowiding [a] sort of role model behaviour... in front of patients.' (Z129)

\section{CLINICAL LEARNING: CONTENT}

\section{Attitudes}

Affective outcomes should include:

- feeling welcome and comfortable on wards;

- overcoming a novice's fear of exposure;

- being comfortable talking to people who are ill, and 
- the rewards of mastering skills, and feeling one is a help rather than a hindrance.

\section{Study skills}

Students should learn to learn, including:

- how to find out what sort of case a patient represents;

- how to access one;

- how to learn by interviewing and examining;

- how to generate problems as a result;

- how to adjust to the reality of learning;

- learning to continue learning, and

- being prepared for future experiences.

\section{Experiences}

These were generally equated with what general medical inpatients had to offer, including:

- Surprise:

"Opportunistic, go and find patients and find the whexpected, you go to see the angina case awd it will tum out that the main problem isn't angina, it's chest paindue to something they've never heard of. 'Tietze's syndrome, or whatever.' (Y481)

- Complexity:

'They start with a textbook... case of asthma, and they end wp with a case of dizziness but the $y^{\prime v e}$ also got transiewt ischaemic attack, dysarthria, prolonged QT interwals, or the patient with idiopathic pulmonary fibrosis who also has mastocystosis.' (Y513)

- Interesting signs:

"... somebody with very good Vwaves." (X133)

Acute illwess:

"If you are going to lean about acute illness and acute medical clinical signs... then the wast majority of those will be opporturistic." (D120)

- Chronic disease:

"If you leam some things about those (chronic diseases) you don't necessarily need to know a lor abour oner chronic diseases.' (H28)

\section{SUBJECT MATTER}

Through seeing patients, students should learn:

- interpersonal communication;

- information gathering;

- plysical interaction;

- to detect abnormal signs;

- to integrate theoretical knowledge with knowledge of the patient;

- skill in practical procedures; 
- to develop a diagnosis and treatment plan, and

- to apply evidence.

A key design concept of the curriculum - that clinicians should provide access to patients with problems relevant to a student's current PBL case-received scant mention, mostly negative:

'And I think there is an important part of what $L$ says about ... telling students that you can't just go onto the wards and see $A, B, C$ and $D$ that's relevant to what you are going to be doing this week in your systematic course." (C48)

\section{CLINICAL LEARNING: CONTEXT}

\section{Wards}

There was a pervasive assumption that learning occurs on hospital wards, with frequent references to respondents' own experiences as ward-based students. There was enthusiasm for the rich and suitable learning opportunities wards could offer:

'You are seeing diseases unt their natural frequency ... and in their natural twild state.' (Z87) 'Could I ask from ignorance how suitable your inpatient case mix is?' $Q(R 70)$ 'Oh, very.' (R) 'For signs, absolutely.' (G) 'Signis, histories, you know, a vange of medicine, we'te got the lot.' $G(R 77)$

One respondent spoke empathically about how hostile an environment the hospital ward could be for clinical learning:

'More reticent members of the group feel nore pushed out and perhaps less able to ... go and particularly batte on the wards to get what they want.' (O93)

Falling numbers of beds, shorter lengths of stay, changing work patterns, pressure on staff and a narrower range of 'material' were seen as constraints. However, the presence of students in places other than wards was noted with regret rather than as a solution:

'Clinics are full of students, even the operating theatres on occasions, Everywhere are students except the ward.' (F28)

\section{Outpatients}

It usually required a prompt from the interviewer for respondents to talk about the outpatient setting. In contrast to the variety and relevance of case mix on wards, the narratives dwelt on:

- space constraints;

- work pressure;

- productivity targets;

- patient expectations , and

- the time-cost of teaching. 
The narrative that follows shows a respondent moving backwards and forwards between his conceptualisations of teaching and outpatient practice:

'Oupatients is wonderful for cardrology but also ... quite busy ... you've got to see so many people, they might have wurnurs but... you might not be getting then on and off the bed all the time, particularly if the 'we just had their echocardiogram done the week before, and therefore if you are going to use thew as teaching cases, you are dong additional hings to the patient.' (A352)

Not all comments about outpatients were negative. One respondent felt that clinical learning needed to shift from wards to clinics. Others described how students had put theoretical leaming into context whilst observing outpatient practice. Bringing exemplar or expert patients to specially established teaching clinics was suggested as a solution to the tension between education and practice.

\section{AFFECTS}

There was strong affective content in the narratives.

\section{Perceived affects of students}

Students were represented as:

- wanting to be good doctors;

- mostly eager to learn;

- keen to be useful;

- easily delighted by success, and

- capable of working dynamically in groups.

Feeling they belonged to a team and involvement in clinical care could be richly rewarding to students. However, starting on the wards was intinidating for seweral reasons:

'There's an element of sort of getting into the cold swiwning baths, going to introduce yourself to the patient, sit down and start talking to them, you inght come away and think I'pegot quite a lot owt of that, you might think I want to derk patients, but when it actually comes fo doing it I think there's a natwral tendency to shy away. (Z29)

$\therefore$ fear of the patients and the unknown I think is a great one... they are shy, menows ... not wery confident at approading strangers and asking them to whdress ... and ask them a lot of personal questrons.' $(1347)$

"... the students often, wnfortwnately, can be made to feel in the way, that they are not wanted on the firm, that they're always hanging around looking for people. " (A58) As a result, enthusiasm could quickly wane. 


\section{Affects of staff}

Senior staff should be welcoming and willing to relate to students at a personal level. Teaching was 'something we all love', and 'fun'. Junior staff related well to students because they understood their position and were not intimidating. A consultant's job was to 'get juniors fired up with teaching'. Teaching had been less enjoyable as attachments were shortened, but far more important reasons for unhappiness were the conflict between teaching and service, and lack of structure and role clarity:

II don't think the house physicians understand what role they should be playing if any; I think that the SHOS may be a bit unsure ... as to what role the house physicians play and yice versa, and I think it all goes up the ladder, so the end result is you've got a lot of people there, many of whom would be very good cinically, they play a very useful role, but they are unsure how to fit into the team structure as far as education is concemed." (B220)

\section{Affects towards clinical material}

Physical signs were often coupled with positive expressions of affect:

"... there was a tinte when ... we tried ... having a ... system a week, whereby we would say that this week is going to be the nervous system, we are going to grab a case off the ward and they are going to clerk it, and it fell down because the case mix just didn't fall neatly into that, and sod's law you'd get a brilliant neurological case on your cardiovascular week.' (B180)

There were graphic descriptions of hearing your first mitral stenosis, feeling your first spleen, feeling large kidneys, and seeing a wonderful hernia or fantastic $V$ waves. Failure of students to share the same sense of excitement caused disillusionment:

'We get very few real kind of buzzes out of teaching them ... there don't seem to be all that wany that seem to get, and I may be doing them a disservice here, but ... you look for a bit of sparkle sometimes, and a bit of excitement about the clinical problem.' (P156)

\section{DISCUSSION}

There was a remarkable lack of crossover between PBL and clinical teaching. Problem-based learning tutoring was, for some teachers, a frustrating drain on time that did not fit their educational style and distracted from clinical learning. Clinical teaching retained most or all of the "traditional" attributes shown in "Table 1 . Respondents reported in authoritarian language that learners had to be directed because they lacked motivation, contradictory to their view of students as eager and capable learners. There were no descriptions of collaborative group 
learning; other than PBL tutorials. The curriculum was unsystematic and determined by case mix and their own interests. They functioned as content experts more than facilitators of learning. Active participation in practice had little place in the teachers' curriculum in action. However, acclimatisation to the workplace and acquisition of clinical sklls (including learning skills) were prominemt. Interest and excitement ranked higher than relevance in the choice of subject matter, although the affects associated with exotic lumps and bumps seemed to pertain to teachers at least as much as students. Apart from those differences from the official curriculum, the narratives were notable for teachers' positive attitudes towards learners and their learning.

What explanations night there be? The interviewer's complex position as researcher, former hospital dean and current colleague might have introduced systenatic bias. However, every effort was made to exclude it. The spread of contradictions across 14 respondents and 6 separate discussions suggests they were authentic. It is unlikely they signify an outright rejection of PBI. Respondents were chosen because they had positive attitudes towards PBL and most had not just served as group tutors, but had been highly rated by their students. Teachers were as likely to blame themselves as students for whatever difficulties they encotantered, which argues against a fundamental unsuitability to teach. However, they were right to say they were trained as PBL tutors but not retrained as clinical teachers when the curriculum changed. There was no 'modern' method of clinical teaching analogous to PBL. We had to trust the reputed power of self-direction ${ }^{2}$ and hope problem-based method would simply carry across to clinical learning.

It would be easy to write off our teachers as Luddites who had refused to buy into the new medical education. However, it may be that problem-based nethod was itself part of the problem. The concepts of notivation and direction underpinning PBL were developed within a cognitive theoretical framework, ${ }^{8}$ whereas our teachers" narratives were more notable for their affective and social features. They referred time and again to the personal relationship between teacher and leamer, the workplace as a context for learning, the affective barriers to entering it, and the rich traditions of the medical profession. Teachers sought opportunities to pass on their enthusiasm and mastery. They became confused and disempowered when they found few such opportunities in their roles as PBL tutors.

Whilst this might explain why the conduct of clinical teaching was so far removed from that of problem-based method, it does not explain why conceptualisations of the content and context of learning were so divorced from 
current clinical practice. Even within the memory of respondents, clinical practice was conducted in a way that treated medical students as apprentices and trained them 'on the job'. Increasing student numbers, specialisation, the pace of practice and consumer expectations have changed medical training. Perhaps that is why respondents' own experiences as students on wards were such a strong point of reference, and why education and practice seemed so far apart. The absence from the narratives of a holistic view of patients as people may be further evidence. Any clinician might have an occasional lapse in their patient-centredness, but a whole set of narratives that considered patients as exotic physical signs and diseases, making almost no mention of holistic care and role modelling, is so plainly at odds with the behaviour of committed clinicians as to require explanation.

What is the way forward for problem-based medical curricula? A study in the Netherlands found that experienced teachers were slow to change from 'transmitter of knowledge" to "coach of learning activities' because they were so strongly conditioned by their prior experiences. ${ }^{9}$ The situation could be improved by changing the instructional design. ${ }^{10}$ One solution, suggested by some of our respondents, is for students to turn their experiences with patients into the problems to which they apply their study skills. Already, our students link clinical experiences to their discussions of hypothetical problems (see http://www parable.man.ac.uk). ${ }^{11}$ Tutorial discussions that use real patients as their starting point have shown promise in 2 phases of our curriculum. ${ }^{12,13}$ However, real situations too easily take teachers and learners across the theory-practice divide, so they concentrate on problem solving - or clinical expertise - at the expense of theoretical understanding. Teacher training seems an obvious solution, but not all teachers 'yearn to learn' (van Eekelen IM, Vermunt JD, Boshuizen HPA. Exploring teachers' will to learn, submitted). Few of our clinical teachers attend staff development when offered it.

A return to traditional apprenticeship is not an option. However, there are new models of apprenticeship. Now, the role of masters is to accept learners into their community of practice and help them construct a professional identity through social interaction with practitioners, peers and patients. ${ }^{6}$ For humanistically oriented practitioners who have survived the culture shock of PBL that should not be too hard a role to adopt.

Contributors: TD conceived the study, interviewed the participants, analysed the transcripts and wrote the paper. AS read the narratives, criticised and helped form their interpretation at every stage, critiqued each draft of the manuscript and checked its fidelity to the transcripts. NK read the narratives, advised on a 
qualitative approach to their interpretation, supervised the phenomenological analysis and reviewed the later drafts of the manuscript. HB participated in all stages of the research conjointly with and similarly to AS. She supervised TD's Masters thesis, of which this research was part.

Acknowledgements: we thank the physicians of Hope Hospital for participating in the study, reading this paper and allowing us to publish their narratives. We acknowledge the unfailing support of the Undergraduate Medical Education Department, Christine Bundy for commenting helpfully on the manuscript and Sonia Littlewood for helping to prepare the transcripts for analysis.

Futiding: this study was funded by education endowment funds.

Ethical approval: the Institutional Ethics Committee did not wish to consider a submission. All subjects saw the manuscript and approved publication.

\section{REFERENCES}

1. General Medical Council. Tomorrow's Doctors. 2nd edn: London: GMC 2002

2. Knowles MS. Self Directed Learring. A Guide for Learners and Teachers. New York: New York Association Press 1975.

3. Schmidt HG. Foundations of problem based learning: some explanatory notes. Med Educ 1993;27:422-32.

4. ONeill PA. Problem-based learning alongside clinical experience: reform of the Manchester curriculum. Educ Health 1998;11:37-48.

5. Ainley P. Rainbird H. Apprenticeship. Towards a New Paradigm of Learning. London: Kogan Page 1999.

6. Wenger E. Communities of Practice. Learning, Meaning and Identity. Cambridge: Cambridge University Press 1998.

7. Moustakas C. Phenomenological Research Methods. Thousand Oaks, California: Sage 1994.

8. Schmidt HG. Problem-based learning: rationale and description. Med Educ $1983 ; 17 ; 11-6$.

9. Hoogveld AWM, Paas F, Jochems WMG, van Merienboer JG. Exploning teachers" insuctional design practices from a systems design perspective. Instructional So $2002 ; 30: 291-305$

10. Hoogveld AWM, Paas F, Jochems WMG, van Merrienboer JJG. The effects of a web-based training in an instructional design approach on teachers' instructional design behaviour. Computer Human Behav 2001;17:363-71.

11. ONeill PA, Willis SC, Jones A. A model of how students link problem-based learning with dinical experience through 'elaboration'. Acad Med 2002;77:552-61.

12. Macpluerson R, Jones A, Whitehouse CR, ONeill PA. Small group learning in the final year of a medical degree: a quantitative and qualitative study. Med Teacher $2001 ; 23: 494-9$.

13. Whitehouse $C R, O$ Neill $P$, Dornan $T$. Building confidence for work as house officers. Student experience in the final year of a new problem-based curriculum. Med Educ $2002 ; 36: 718-27$ 
CHAPTER 5

Learning in clinical workplaces.

The learner's perspective

Submitted for publication

Medical students' learning in clinical workplaces. Grounded theory analysis.

Tim Dornan, Henny Boshuizen, Nigel King, Albert Scherpbier 


\section{ABSTRACT}

Objective: To examine what medical students learn in workplaces and how they learn it.

Design: A grounded theory analysis of focus group discussions with junior and senior medical students and a complex educational intervention to broaden their workplace experiences.

Setting: Problem based, predominantly undergraduate entry, clinical curriculum with little early workplace experience.

Participants: 24 jumior and 12 senior medical students.

Results: Clinical learning was a complex and dynamic process, which evolved as respondents became more experienced. They wanted to help patients. To do so, they needed to develop certain emotions and practical competences. The emotions included motivation, confidence, a sense of professional identity, and a sense of reward. The competences included knowledge, clinical skills, and the study skills that could help them become more sophisticated learners. They developed those attributes by participating in practice. Doctors and nurses helped them participate by coupling support with appropriate demands. Developing some attributes made it easier to develop others, a circle that could be virtuous or vicious.

Conclusion: These findings are concordant with new theories of apprenticeship, according to which "learning" entails "developing a professional identity" by accommodating the values and protocols of workplaces. Maintaining one's individuality and adapting it to the culture of the profession is an emotionally exacting process. This social interpretation of learning provides not just educational strategies but a system of values that constitute a positive educational climate. 


\section{INTRODUCTION}

Contrary to the way in which today's doctors learned their craft, Tomorrow's Doctors" 2 are to have a "learner centred" education, leaving many clinician educators feeling confused about their role and disenfranchised ${ }^{3}$. In order to reconstruct workplace clinical teaching, then, we need to understand what medical students learn, how they learn it, and how those processes and outcomes interlink ${ }^{4}$. To be informative, research needs to be student focused, exploratory, broad enough in its scope to reflect the many workplaces students are exposed to, and open to changes that occur as they progress through the curriculum. Recent researchers have rigorously explored learning outcomes and processes from a medical student perspective; however, much of their effort was bound to particular contexts (primary care in particular), restricted to students at just one stage in their training, or concerned just with the process or outcome rather than the link between the two ${ }^{6-13}$. To develop a more generalisable model of workplace learning, we set out to collect a suitably broad set of narratives of learning and then use the power of grounded theory analysis ${ }^{14}$ to examine the interactions between process and outcome and develop a model that could inform clinical learning and teaching.

\section{METHODS}

\section{CONTEXT}

The context was the Salford Sector of the University of Manchester Medical School. The curriculum was a contemporary one with a spiral, fully horizontally integrated design that used problem based method through all five years. After little clinical exposure in Years 1-2 (Y1-Y2), students continued thematic learning in Y3-4 but now with clinical skills training and simultaneous community and hospital attachments to provide access to a breadth of clinical problems and contexts ${ }^{15}$. In $\mathrm{Y} 5$, they had one-to-one attachments to clinicians and continued attending group tutorials, now using real patients as the "trigger" for problem based learning ${ }^{16}$.

\section{STUDY DESIGN}

Students at the end of $\mathrm{Y} 3$ were chosen as index respondents because they had nearly a year's clinical experience but were still junior. A tutorial group of eight students on a 7-week attachment to one firm took part in a semi structured group discussion. Following the interview template used in our previous staff study ${ }^{3}$, they discussed how successfully they had learned from clinical experience, what factors helped or hindered their learning, ways their experience 
could have been improved, and the roles of their teachers. Then clinically naive students were recruted at the very start of 3 . Eight of them who had been non purposively allocated to the firn gave informed, verbal consent to take part ina complex intervention ${ }^{17}$. Their real patient learning was maximised through individual mentoring, briefing, increased use of the outpatient setting, and teflective group debriefing, as described in more detail elsewhere. After seven weeks, they took part in a group discussion. Next, a group of nine $Y 5$ students gave a senior student retrospect and a mixed group of three $\mathrm{Y} 5$ and eight $\mathrm{Y} 3$ students compared perspectives on clinical learming.

\section{ROLES OF THE RESEARCHERS}

Having gained experience of acting as a "participant observer" 318 , the first author conducted the index discussion and complex intervention with students on this own firm. He kept dailly field notes on the intervention and students kept daily written records of their learning. His co-researchers helped him identify preconceptions and biases that might colour his interpretation ${ }^{3}$, supervised the study to identify: bias in its conduct, and compared his evolving interpretation against the original narratives. A second author and a clinical academic who was not an author observed the discussion with intervention group students to identify undue influence on their opinions. In contrast to the $Y 3$ students, who were all taught by the first author, few of the $Y 5$ students had been attached to his firm and some had never met him. A third author, who never met the students, supervised the study. A fourth author, naive to the conduct of the study, critiqued a provisional interpretation against the original transcripts.

\section{ANALYTICAL METHODS}

Each discussion was analysed in enough detal to inform the next one but the grounded theory analysis was "abbreviated" in the sense that definitive analysis took place after data collection had finished. All discussions were transcribed verbatim. They and the feld notes on the intervention were entered into nVivo software (QSR. Doncaster, Australia) and analysed using the procedures proposed by Strauss and Corbin to identify causally related "actions and interactions" "The index discussion was coded and the interpretation critiqued. A core theme and coding structure we re agreed, the transcript was recoded again, and the coding structure was applied to the other transcripts and field notes. $A$ theory and graphical model were developed and the authors agreed that theoretical saturation had been reached "Results" adheres to the model, following a narrative sequence that was chosen to make the concepts and relationships as clear as possible. Verbatim extracts are cross-referenced between the text and table 1 , which identifies the source of each extract. 


\section{Extracts of text}

Each extragt has a unque identifer (eg $1 \mathrm{a} 1$ ), a label indicating which transcript it cane from (Index -index focus group, Interven tion =debriefing focus group on the intervention study, $Y 583$-Mixed focus group of Y 8 Y 3 students, Y 5 - Focus group of Y 5 students alowe), and an alentifier for the student"s curriculun year and gender.

$0,1 \mathrm{Y} 583 \mathrm{Y} 5 \mathrm{M}$ : I remember in third year its very danuting going on the wards the first fime but then after a while you become much more confident and people get to know your face as well so that, you beconne much nore relaxed abour it.

1. The nature of participation

La Observation as participation

1.al Y $583 \mathrm{Y3F}$. almost everyone that comes in has got something different and you've never seen these things in a clinical situation You might haye read bout some of them but. it's quite a lot to take on at the beginning, its quite oxerwhelining, the amount of new information and new expe. riences

1 a 2 Intervention Y $3 \mathrm{M}$, you can go to a dinic and you can just sit in the cornet and do nothing. and. that's when a dinic is not worthwhile 1 's not worth you being there because you're just a spectator whereas if you're allowed to actually do somethings erom, perform examunation, wnder supervision, then your confidence grows and, your clinical skills . get better.

193 Index Y $3 F$, We went into theatre, oh hello, I na a thrid year nedical stadent, is it all right if I watch you? Yes, fine, stand in the conner Or, if you' re nery lucky you can stand and peer over my shoulder Great But its not the same as having your hands in and doing thing

1 b Acting as participation

IbI Intervention Y $3 F$, I think it's ntal that the doctors that are on the elinic are willing to have you there and if they're busy and they can't teach you letting you do some- thrng like taking a blood pressure once or twice or taking blood, that's, somethung that will make the clinic worthwhile if you know that you're welcone.

162 Y $5 \mathrm{Gp}$ Y $5 \mathrm{M}$, in the third yeat you re told the diagnosis and then youre told to take the history which is always very boning and you he never allowed to exanune the patrenr because they re fired or for wharever reason:

163 Intervention Y 3 F. I lad to take a paGent: blood and I , felt that 1 was actually just for once useful be cause I was able to take the history, present it to the doctor and then rake the patient's blood.

164 Intervention $>3 F$. if you go and get the notes for the next patient, your are getting a kind of feel of things And then going and calling the patient, you feel as though you are doing something

2. Patients, practitioners, peers and participation 2a linteraction with patients

$2 \pi$ Index $Y 3 F$, part of the renson why people go to do nedicine is because they think it's a worthwhile thing to do , if: sonnebody doesin th appreciate it then. that's sort of basically against the reason that you went into medicine.

2,2 Y 583 Y 5 F lnwading a patient's priwey turt haxing so nawy people round the bed and even though a lot of them say they don $\mathrm{t}$ nind you can tell that they really do. You know, they dont want all these people round the bed and when I ve been w smaller groups it has inade a lot of difference.

223 Y 5 G P $Y 5 \mathrm{M} / \mathrm{l}$ 's like doing an examing tion on patient, they've got a slight brit of pain and you re frightened of causing then pain. By the time you get to the fourth year you realise you can roll them backwards, folwhards and anywhere in order to blict your clinicalsign.

2 intervention X $3 \mathrm{~F}$ / I was sent to a room. to take a history, then the doctor would 
conve in (and) examine the patient ... I learned so much from that. Just because, you just brilt up a relationship with the patient.. $2 \mathrm{~b}$ Interaction with doctors

2b1 Doctors" behaviour towards students 2b1.1 Undex Y3M: After battling and batthing to get teaching sessions just any or even just an hour a week, you know.. by the end of the fourth week everyone was just like. what's the point ... and the first day for someone to even send a note saying, welcome to the firm, here's a timetable, that wasn't even done. No-one was aware that we were actually there and, well, that was just, you know, the worst.

261.2 Y5Gp Y5M: they've just swapped over the $\mathrm{SHO}$.. the $\mathrm{SHO}$ before every time you walk on to the ward, "is there anytling I can do"? "No". Clunge the SHO, "anything I can do"? "Yes, do this blood, do this discharge". Work"s no different so why does one person have jobs and the other person doesn't

$2 \mathrm{~b} 11.3$ Y5Gp Y5M: He .. would stop the ward round and say, "listen to this." Such a nice thing for someone just to take the interest and say "listen to this, can you hear it?" "No." "Tity harder."

$2 \mathrm{~b} 1.4$ Y5Gp Y5F: 1 think some of them genuirely care about you and your education and notice that you're keen, so they"re willing to let you loose as far as you feel comfortable to be let loose.

$2 b 1.5$ Y5\&3 Y YF: I think there are some people who are natural teachers, who are very good at teaching and they just have a natural skill and way that they involve you and, you know, really go out of their way ... involve you with the patient and there's a total interaction goes on and the patients ats well do try their best to involve you as the student sat there.

$2 \mathrm{~b} 1.6$ Y5Gp Y5M: $\mathbb{1}$.. asked a question about why he'd started such a treatment and the registrar said don't you know I need you to be quiet because otherwise l'in not going to get through the clinic? .. that's very winhelphul and you'we wasted your moming, haven't you?

2b1.7 Index Y 3M: 1 mean genuinelly you actially felt as if you were .. doing a worthwhile job because the SHO went can you do this because. . l'm quite busy so if .... you "re competent at it, they will let you do it and they"d be happy and you'd be happy.

2b18: Y5\&Y3 Y5M A \& E is a classic example .. you .. tum up .. and you can see the SHO sort of trying not to make eye contact with you .so they can get on with their work and then . you go up to people and say "would you mind if I spent the afternoon with you and I'll just help out, I can do some bloods and things for you if you like?" And after a while. . they warm to you and by the end of the afternoon they're dragging you away from things to show you other things because .. they've enjoyed the experience

$2 b 1.9$ Interviewer: So the firm that would make every day a good day would be relentless in it's demands?

Index Y3F: Probably.

Y3M: Yes.

$Y 3 F:$ It's a firm that uses you.

Y $3 \mathrm{M}$ : Not unattainable expectations, you know, not sort of like, by the end of the week, you know, you should be able to put in a central line or whatever.

Y3F: Because we all sit there and make our own excuses, if you'we got someone else making them for you as well theri you just ..

Interviewer: So you want someone who doesn't make excuses for you?

Y3F: Yes, absolutely, makes you do something rather than just say sut there and let you get away with it.

2bl.10 Index Y3M. Personally I quite like. the old-fashioned, consultant humiliation. It's horrible at the time but at the end of the day, er, it doesn't really matter becalse you know you ve learnt something and every. one else in the group will think right, I'm not going to get that wrong ever, either. 
no-one can be rude to you and you'll feel you have to go away because you just think, well, this is mine as well.

\section{Students' emotions}

4.1 Index Y3F: We came in never having done aryything clinical and you turn up ... in your whire coats with your new stethoscope, all excited, and (nurses) like to say can you do anything? And you' re like, er, no, we $\operatorname{can}^{\prime \prime} t$ do anything .. we've never done anything before, we haven't, a clue. And so, you can just sort of see them thinking, oh well, you"te just going to hang around, get in our way, you're not going to be able to help us very much.

4a Sense of identity

4all Intervention Y3F: Il think (it's) important to feel .. you have the right to be there .. (and) we have the right to be taught .. and if someone drives that point home to you, you .. become more confident.

4a2 Intervention Y3 F: simple little things just to make you feel like you are doing something even naking a cup of tea snything, just feeling .. you belong ". and .. have the right to be there.

4a3 Index Y3F: I just thought the attitude was so much better.. Students were new and exciting and people were really pleased to see you and, 'oh, come and see this' and 'oh, you're a student, oh ?' really encouraging and everywhere you went everyone used to say "hello" to you and it made you feel as thought you weren"t, like, something that they"d scraped of the bottom of their shoe.

4a4 Y5Gp Y5 F: Maybe feeling important goes along with the responsibility that you re given and in the third year nobody really gives you any responsibility and therefore you don't feel important and you don't feel that you've got anything valuable to contribute.

425 Index $Y 3 M$ It does feel difficult sometimes if you're in a huge group and you know that in a way you're sort of interfering writh like the general nunning of the ward al- though you should be, like, an integral part of it, you are getting underfoot..

$4 a 6$ Index Y $3 F$ : I think there's a real stigma attached to medical students that we are the absolute lowest of the low and we shouldn't be.

4a7 Index Y3F: It was .. always your job to put in a veriflon and they really did involve you .. you're attached on your own to a department or a team and you become part of that team because you're there for four wreeks .. nine to Give.

488 Index Y3F: But the recognition and the acknowledgement is when the consultant walks past you in the corridor and says, "Oh, hello, you're $\mathrm{x}$ and your friend says "Oh"! $4 b$ Confidence

$4 \mathrm{~b} 1$ Intervention $\mathrm{Y} 3 \mathrm{~F}$. If you walk in really confident ... and aren't scared of being wrong .. and not scared of asking questions ... it s far more helpful than if you're just sat there.

Intervention Y3F: (Yes) definitelly it's up to you .. I"mot notraid to ask questions which is good but it works both ways. If the attitude is right it's $O K$.

$4 b 2$ Y5Gp Y5F: I think that"s where confidence comes in actually.. As a third year it can be .. really difficult to have (the) confidence to .. say, listen I really want to do this, I want to do that.. As af fifth year we're in a better situation to have the confidence to say I know I can do this. It's hard when you start off

4b3 Index Y3F: Feedback on how you're dong..

Y3M . . just gives you the confidence (to) look into the eye of your patient

4c. Motivation

$4 c 1$ Index $Y 3 F$. 1 think it very nuelh .. depends on the student, how much you put in. You need to be motivated yourself to be there in the first place.

402 Intervention $\mathrm{Y} 3 \mathrm{M}$. Some of them are surprised that you ask them questions; oh, I didn't realise you were interested in that ${ }^{3{ }^{3}}$ 
2b1.11 Y5\&3 Y3F: I was on a clinic (and) 1 got the pleasure of learning how to make him a cup of tea four times in an aftemoon and that was it

$2 \mathrm{~b} 2$ The climate of the medical team

$2 \mathrm{~b} 2.1$ Index Y $3 \mathrm{M}$ : 1 just think it comes from the consultant's expectations of his own staft .. he should demand that teaching is happening, teaching is on time, teaching is good

$2 \mathrm{~b} 2.2$ Index Y3F: One of the problens with our last firm was that .. the House Officer .. put in so much effort but, because the consulant didn't make an effort... I think in order for it to work like that an example has to be set higher up the chain.

$2 b 3$ Doctors' knowledge of the curriculum 2b3.1 Y5Gp Y5M: (Some consultants) .. think .. "I don't need to teach the people that are attached to me because they learn everything from PBL".

Y5F: I think they sort of say you don't learn on the wards any more, do you? You do PBL.

Y5F: Yes.. it's almost like they think that they shouldn't teach you any nore because it's PBL .. when we went to Obs. and Gynae. the registrar said to us, well apparently I'm not meant to teach you, you're meant to go and look it up my book and come back and tell me about it and he said well, you know, I'n nor going to do that, if you want me to teach you I"ll teach you. And they have this conception that PBL means I don"t trell you anything. You look it up.

Y5M: That is so true. I've heard that so many times.

YSF: And you ask a question and (they say) you go .. read that and.. rell me why. Which is fair enough but not all the time. You know, you want to be able to ask a question and get a straight answer.

$2 c$ Interaction with nurses

2c1 Index Y3F: .. the way the nursing staff are to you can kind of nould and shape your .. experience in a hospital just as much as the doctors can .. Nurses could absolutely rnake your life hell for you. It just doesn't matter how good teaching you get from the doctors. At the end of the day, hke, you're going to be groing on the wards, day in, day out and nurses are going to be there..

202 Intervention $Y 3$ F"I think the nurses are very important. I mean, yesterday I went to a dinic and theard that one of the doctors that was on, he was quite scary, but the nurses are lovely.

2 c3 Y5Gp Y5M: There seems a whole different attitude from the nursing staff as soon as you become afth year. Third yeari, as you walk on the ward in a group of you and it"s oh no, here come the students "let"s not look up, let's not talk and let's not be halpful at all. In fifth year you walk onto the ward on your first day on that firm, it"s like oh there's the coffee room, there's the notes, there's the blood bottles, can I get you a coffee, can you do these TTOs, you're my hero.

$2 d$ Interaction with peers

2d1 Intervention Y YF: .. the discussions .. put quite a lot of pressure on me and not necessarily in a helpful way.. l'll do the ostrich thing and bury my head to aroid it.

Y3F: I'm with $A, I$ (found) it really useful.

2 d2 Interviewer: Can you think of a winy in which firms could make every day a lucky day?

Index Y3F: It would definitely be .. one-to-one with the doctors because .. next day when he sees you, he's asked you to do that so he's going to diseuss that with you or whatever. And you build up more of a rapport

$2 d 3$ Index Y3F: Like I was silying before.. about feeling like a spare part ... it just didn't happen. there. You felt as though you tre actually a useful part of the tean .. you felt welcome .. because it was one on one .. you learnt so much; because I was basically with nyy consultant the whole timse and if 1 wasn't with him I was with the SHO or somebody.

3. Curriculum factors that affected participaltion

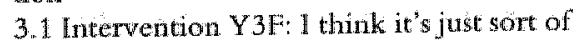
knowing that you've got a place that's yours and no-one can tell you to go away or 
$4 c 3$ Index Y3F: Being motivated depends on the .. enthusiasm of the people around you...

$4 c 4$ Interviewer: So you want someone who doesn't make excuses for you?

Index Y3F: Yes, absolutely, makes you do something rather than just say sit there and let you get away with it.

$4 d$ Sense of reward

4dI Index $Y 3 F:$ The people that are .. best .. say "right, off you go and .. do this", you go and clerk the patient and you come back and tell them what's going on, and you nearly always go, ol, God, but then you do it, but then you go back at the end of the day and say yeh! I had a really good day and got a lot out of it, whereas if you just sit quietly in a clinic and listen you don't get a lot out of it.

$4 \mathrm{~d} 2$ Index Y3M: Getting recogniition .. For .. making an effort and stuff for the hospital. There are so many people, so many doctors on a firm ..

4d3 Y5Gp Y5M: (1f) you're not getting positive vibes you're not going to go back again. In my third year group we used to dread going on to the ward, we'd go on to a ward for an hour on a Friday and we were relieved when we got off after the hour and we'd go home and celebrate that was the week. And that was not a pleasant experience.

5. Students competences

5 a Study skills

5all Intervention $\times 3 \mathrm{M}$ : Initially when we were faced with how to use, clinics as a way oflearning I just thought . "I'Il put down for general surgery because l'm scared of that" and it wasn"t actually focused. I was meant to go to clinic yesterday and I thought well aictually I'd covered that ground .. I've .. met that consultant and I think l've used it to its full extent and therefore I was .. conscious I could cancel it in the same way as with a good conseience I could pick up a different linic.

$5 \mathrm{a} 2$ Y5Gp Y $5 \mathrm{~F}$ : There must have been a point .. where I went from being taken to see patients and being very directed by people what to do, who to go and see and not (being) very proactive in my learning .. to where I .. now .. go and see someone and (am) pro-active

5 3 Index Y3F: You'll see something on the ward that's completely different to the PBL case your doing that week. When you ger home you have to get out the books. Which books do you get out? "The PBL books or the stuff that you saw in clinic?

$5 a 4$ Intervention Y3F: You have to reflect; I've been to this clinic, has it been helpfill, . would 1 go again, is there any reason and it's that whole attitude that I think I have learnt a lot about ..because it would have been very easy to be wery scatterbrained and go for a bit of this and a bit of that and really not be certain what l'd learnt at the end of the week or why I was going to that clinic.

5a5 Index Y3M: It's the only way you can learn, by pitching in and you know, sort of, helping. Just sort of helping out.

$5 a 6$ Intervention $Y 3 F$, I think it 's triall and error as well. It's just sort of try something and if it works out then do it again.

Y $3 F$. It depends what other people do as well.

5 7 Intervention Y $3 F$ : There's a girl in our house and she doesn't have any support really in the clitical environment. She doesn"t know what to go to .. and it just seems so kind of up in the air in comparison to what we have.

Interviewer: What have you got that she hasn'?

Y3F: Suppoit, I think.

5 b Knowledge

561 Y 583 Y YM: You think that you don"t have much knowledge .. as a third year bue.. you've alleady spent two years or three years, you know, and you know a lot about a lot of things and you forget that and .. to stant with its .. trying to pull information where you've never pulled it from before but after a while it all comes second nature 
ary or tertiary care might have led to very different career choices. It is reasonable to conclude, however, that early experience has a strong formative influence that can be used to foster a socially responsive career orientation. In line with our previous consensus survey, biomedical science had only a small place in the rationale for early experience. ${ }^{4}$ One of us has argued elsewhere that "the new medical education" is not forsaking biomedical science but putting it in a broader, social context. ${ }^{47}$ We view the move to offer early experience as a sign of that paradigm shift because it adds professional socialisation, the development of appropriate attitudes, interpersonal skills and study skills, and familiarity with the healthcare system, to the benefits of a grounding in basic science. In making the curriculum more socially responsive, it aligns medical education with contemporary concepts of professionalism, which emphasise doctors' accountability to the society they serve. ${ }^{48} 49$

\section{STRENGTHS AND LIMITATIONS OF THE STUDY}

This review is one of the early products of the BEME collaboration, which seeks to bring medical education into the "evidence era." 6 ducational interventions are often complex and educational outcomes can be hard to measure, so education systematic review has to accommodate different research methodologies. Nowhere is Einstein's epithet that "not everything that can be counted counts, and not everything that counts can be counted" truer than of educational outcomes. The evidence reviewed here includes comparative and descriptive stud-m ies, and qualitative and quantitative methods, weak and strong. Some of the studies that yielded the most robust causal inferences were qualitative and non-comparative. The review group has striven to present this very varied evidence base in a way that will help curriculum planners draw their own conclusions. The strength of this review is in the rigour of its methods, which evaluated complex evidence by consensus between a heterogeneous, multinational group of reviewers. They entered the review with open minds and communicated solely through the internet, keeping decision making relatively objective. The limitations are the lack of rigour in many of the studies reviewed and the inherent subjectivity of exploratory research. A predominance of underpowered and poorly designed studies, coupled with positive publication bias, would tend to exaggerate the effect of early experience. However, qualitative analysis of the benefits of a complex intervention should only bias the opinions of uncritical readers, while informing critical ones. Any readers wishing to review the evidence for themselves can trace each conclusion back to its primnary source from a summary table in the detailed report. ${ }^{5}$

These findings do not prove, but are consistent with, the theory reported in our previous publication that early experience could strengthen and deepen cognitively, broaden affectively, contextualise, and integrate medical educat 
$5 b 2$ Jindex Y $3 F$, Students, tend to anderestimate the amount of knowledge, they' ve. taken, I think if we. look back at this year then well say, we leamt, not quite as much as we wanted to whereas in effect we probably learnt so much but you just donit: realise at

$5 \mathrm{~b} 3$ Y $5 i \times$ Y 3 Y5M, You need to have the ba sic theoretich knowledge behind before you go into a clinical experience so that you can understand the principles. and then undertand just how to put them into practice

$5 b 4$ Y 583 Y $5 \mathrm{~F}$ You go into dinic, gou've done your theory and you come out and think well where are ny gaps again, and there are sone things that cant be futtilled by use staying in clinie

565 Y583 Y5M. Until you're asked the question you don't know whether you know the answer , you don't know really whether you know the answer, so by being asked you find little holes in your knowledge

$5 \mathrm{~b} 6$ Y5\&3 Y5M If they involve you in an active role, for example, in a climic, if you go and see patients on your own and have to present what you found and then discuss the pros and cons of whit decisions you've decided to make, I think you certainly remember the things rather than if you just sit and watcli someone take I history and do examhations and tell you what they see and what they te goning to do about it.

5. Clinical kills

$5 \mathrm{c} / \mathrm{lodex}$ Y $3 \mathrm{M}$. Our first fin they threw us In the deep end, didn't they, because we were doing all thit kind of thing, even after the first week, catheterisation.

5.2 hidex Y 31 . We' ye been ar one GP practice where the nurse has been our main teacher and she's been brilliant and we ve learnt a lot frow her, especially in terms of skills like injections, taking blood and things like thit: 


\section{RESULTS}

Respondents leamed by participating in practice, though it was hard for junior students to be participants. Despite their weekly visits to general practice, hospital experiences dominated their narratives $(0.1)$.

\section{THE NATURE OF PARTICIPATION}

\section{1a Observation as participation}

When they first entered workplaces, respondents had to familiarise themselves with the places, people, and methods of practice (1a1). Passive observation allowed them to glean knowledge and encounter realities they had learned about in theory but gave, at best, a transient sense of participation. Interaction with doctors and nurses made observation more participatory and instructive (1a2) and respondents became frustrated when helpful interaction was lacking (1a3).

\section{6 "Acting" as participation}

To act was to perform a clinical task (1b1). Clerking a patient who had already been clerked by a doctor was rehearsal (1b2). An act became performance, when the task contributed to patient care ( $1 \mathrm{~b} 3$ ). There were some tasks that had to be rehearsed before respondents could perform them but there were simple ones, such as calling a patient into a consulting room or completing a request form (1b4), that gave junior respondents an immediate sense of participation.

\section{PATIENTS, PRACTITIONERS, PEERS AND PARTICIPATION}

It was a wish to benefit patients that had led many respondents to study medicine in the first place but doctors and nurses had a lot of power over the quality of their interactions with patients.

\section{$2 a$ Interaction with patients}

Doctors could increase the sense of participation of respondents who were too junior to perform by recognising the quality of their rehearsal (2a1). Being taken to the bedside in a large group gave respondents a sense of non-participation because they were not just passively observing, but collectively invading a patient's privacy (2a2). Respondents were afraid of harming patients in their early one-to-one rehearsals but became bolder with time (2a3). They needed self-confidence to approach patients and found it helpful when a doctor introduced them (particularly as a "doctor-to-be"). Successful interactions increased their confidence and sense of participation. They could compensate for their inexperience and increase their sense of participation by building social relationships with patients (2a4). 
Table 2

Ways in which doctors helped medical students participate

\section{Support}

Being:

- Welcoming

- Accessibie

- Friendly

- Enthusiastic

Helping a student express their learning needs

Having a student beside them while they worked

Guving a student some of their time

Explaining

Allowing a student to rehearse or perform tasks

Brokering a student's relationship with a patient

Shiaring their expertise

Briefing

Observing

Giving a student feedback

Involving a student in their practice

\section{Demand}

Asking questions, particularly ones rellated to patient management

Allocating a task the student could realistically accomplish

\section{Interaction with doctors}

\section{Doctors' behaviour towards students}

Doctors varied in their willingness to support participation. Some, who were completely unwilling, did not greet respondents when they arrived, provided no timetable, cancelled teaching or did not turn up, and allowed themselves to be bleeped away (2b1.1). Others actively supported participation by helping respondents have access to their practice (2b1.2), making observation active, sharing their clinical expertise ( $2 \mathrm{~b} 1.3$ ), and creating tasks for them to perform (2b1.4, 2b1.5). Table 2 shows how teachers could promote participation by being supportive and making demands. The pressures of practice amplified doctors' (un)willingness to support students' participation, some becoming unfriendly and relegating them to the role of passive observer (2b1.6), others keeping respondents actively involved and even asking them to help out (2b1.7). There was a dynamic between doctor and respondent such that students who were clear what they wanted to learn, unafraid to ask questions, and practically competent had the best chance of participating (2b1.8). Making demands of respondents increased their participation provided the demand was appropri- 
ate to their level of experience and the doctor supportive (2b1.9). Teachers could strike a good balance between support and demand by anuicably "grilling" respondents or having them perform clinical tasks (2b1.10). Asking questions in a belittling way or using respondents as a mental pair of hands were examples of unsupportive demands (2b1.11). Respondents were particularly sensitive to doctors' behaviour when they were very junior and became better able to judge and respond to it as they becarne more experienced.

\section{The climate of the medical team}

The personalities of doctors had a pervasive influence on the learning climate of a firm. Some senior doctors helped respondents participate by increasing their juniors' interest in teaching ( $2 \mathrm{~b} 2.1)$; others made participation difficult by leaving their juniors unsupported, unaccountable and unrewarded (2b2.2).

\section{Doctors' knowledge of the curriculum}

Doctors' familiarity with the curriculum also affected respondents" sense of participation. A common misunderstanding, which stood in the way of participation, was that teachers in a problem based curriculum should not divulge answers or share their expertise (2b3.1).

\section{C INTERACTION WITH NURSES}

Nurses had a powerful influence for good or ill on respondents' participation (2c1). They could deny access to the workplace or leave respondents feeling passive, unskilled, and unconfident by claining they had arrived unannounced. At the other extreme, they could be welcoming, supportive, willing to share their expertise, and able to offset the "scariness" of doctors (2c2). Respondents" experiences with nurses were more positive in outpatient than ward settings, in district than teaching hospitals; with specialist than generalist nurses, and as senior rather than junior medical students. Respondents contrasted their situation unfavourably with student surses, who wore a uniform, had a one-to-one relationship with trained nurses, had their own patients, had defined responsibilities, were a useful part of the workforce, and "were training to be nurses rather than pass exams". Returning to a ward where they had found it hard to participate, senior respondents described being welcomed because they could now be useful (2c3).

\section{$2 d$ Interaction with peers}

Depending on their individual personalities and the climate of the peer group, respondents could be spurred into active participation or rendered passive by peer interaction (2d1). One of the greatest effects of peers, particularly in the junior years, was to dilute respondents' experiences. Greater numbers of students 
on firms and shorter, more discontinuous attachments reduced participation by making respondents' interaction with doctors less personal $(2 \mathrm{~d} 2,2 \mathrm{~d} 3)$.

\section{CURRICULUM FACTORS THAT AFFECTED PARTICIPATION}

A well structured curriculum with a clear timetable, defined leaming objectives, and space in the hospital they could call their own (3.1) helped respondents participate, particularly when they were most junior and vulnerable.

\section{STUDENTS' EMOTIONS}

Participation was influenced by, and influenced, respondents' emotions, which reached high peaks and low troughs through interaction with practitioners in the earlier years of the curriculum $(4.1)$.

\section{4 a Sense of identity}

Junior respondents grappled with whether or not they had any right to be in the workplace (4a1). Something as simple as making tea for a friendly registrar (4a2) or having a safe haven where they could write up notes without being in the way (3.1) made them more confident and helped them learn. Being in workplaces where students were "new and exciting" increased their sense of identity (4a3). However, much of the time they felt like "spare wheels" because they were unskilled, had no responsibilities (4a4), and were anonymous nembers of large groups that got underfoot (4a5). A jumior respondent described feeling stigmatised by ward nurses as "the lowest of the low" (4a6). Students could, however, build rapport with doctors and nurses and develop the identity of "member of the team" when they interacted one-to-one, preferably continuously over a period of time, felt confident in their clinical skills, and contributed to patient care (2d3, 4a 7), all of which became easier as they became more senior. For a nurse from their ward or senior doctor to recognise a junior student and address them by nane when they passed in the corridor boosted their sense of identity ( $4 a 8)$.

\section{4b Confidence}

Respondents became more confident by participating (1.a2). Some were naturally more self-confident than others ( 461 ) and it was easier to be confident if they were clear what and how they were expected to learn but their confidence was very sensitive to how doctors responded to them. It was hard for junior students to communicate their learning needs to doctors though doing so helped make their learning participative (4b2). Respondents confidence was easily dented by a failed performance, and bolstered by a doctor or nurse giving supportive feedback (4b3). 


\section{$4 c$ Motivation}

Respondents had variable degrees of intrinsic motivation, (4c1) which workplace experiences could strengthen or weaken. Sometimes, doctors and nurses demotivated respondents by refusing to interact with them (2b1.1), keeping them as passive observers (1a3), or expecting them to be poorly motivated ( $4 \mathrm{c} 2$ ). At other times, doctors' and nurses' enthusiasm ( $4 \mathrm{c} 3)$ and accessibility and the demands they made ( $4 c 4$ ) were powerful motivators. Thus motivated, respondents could "make things happen".

\section{4d Sense of reward}

Respondents' sense of reward was highest when their level of participation was relatively high for their stage of training (4d1). It was demoralising to be completely ignored (2b1.1). They got little out of being passive observers (1a3). They got more out of acting. They felt they were doing a worthwhile job when they performed (1b1, 2b1.7). A doctor's recognition made their hard work worthwhile $(2 a 1,4 d 2)$, strengthened their sense of vocation to be a doctor, and motivated them (4d3). For a senior student to teach junior students on behalf of a doctor was very rewarding.

\section{STUDENTS: COMPETENCES}

\section{5 a Study skills}

Respondents spoke articulately about how their study skills had evolved. They had learned what to learn, what activities to attend (5a1), how to access those activities, how to behave in sometimes hostile and unfamiliar workplaces, what expectations to have of doctors and nurses, how to manage their time proactively $(5 \mathrm{a} 2)$, how to balance time spent on book-learning against time in the workplace (5a3), and how to identify reflectively what they had learned (5a4). They had to be willing to "pitch in" (5a5) and devellop study skills through their own and their peers" experiences (5a6), but supportive doctors and nurses could help them become better learners ( $5 \mathrm{a} 7)$.

\section{Knowledge}

Respondients" experience of entering workplaces was oflosing confidence in the knowledge they had spent so long acquiring (5b1) and having to devote a lot of time to a very intangible new type of learning (5b2). Private study made them more confident to participate ( $5 \mathrm{~b} 3$ ), while participation made their learning more tangible and increased their confidence in their knowledge (5b4). Doctors could help them apply their knowledge by asking questions relating practice to theory $(5 b 5,5 b 6)$. 


\section{Sic Clinical skills}

Respondents acquired clinical skills through action, not observation (122). At the outset, doctors and nurses could help by "throwing them in at the deep end" (5c1), training them, supervising them, giving them feedback, expecting them to achieve quotas of particular skills, and ensuring they had opportunities to do só (5c2). Developing clinical skills buit respondents" confidence, motivation, reward, and sense of identity, which in turn made it easier for them to participate.

\section{DISCUSSION}

\section{PRINCIPAL FINDINGS}

Figure 1 assembles the findings into a model of workplace learning. In addition to the knowledge and skills of medical practice, there was a set of emotional competences that students had to acquire. Those various learning outcomes were attained together in a complex amalgam. Attaining them reinforced the learning process, and failing to acquire them weakened it. Practitioners - nurses as well as doctors - had great power to enable or disable the workplace participation that brought students closer to their ultimate goal of helping patients. As they progressed through the curriculum, the outcomes students achieved and the activities through which they achieved them evolved. An effective workplace teacher was someone who could simultaneously support students and make demands of them in a way that built their emotional and technical competence.

\section{STRENGTHS AND WEAKNESSES OF THE STUDY}

One strength was the coherence of the interpretation that resulted from subjecting the narratives to lengthy and detailed grounded theory analysis by a deliberately mixed team of researchers, who teased out interactions between process and outcome and systematically sought coherence and incoherence in the data. Another strength was the potential for generalisability that resulted from asking students to narrate experiences spanning hospital wards, outpatient clinics, primary care and other settings. A third strength was the combination of observational research with experimental strengthening of some students' experiences. Whilst the sample of narratives was sufficient to achieve theoretical saturation, the students all came from one medical school and might not be representative of students elsewhere: For example, our curriculum is not vertically integrated. The balance and timing of practical and emotional competences might have been different if participants had been exposed to early practical experience ${ }^{19}$, and the applicability of our findings to a traditional curriculum cannot be taken 


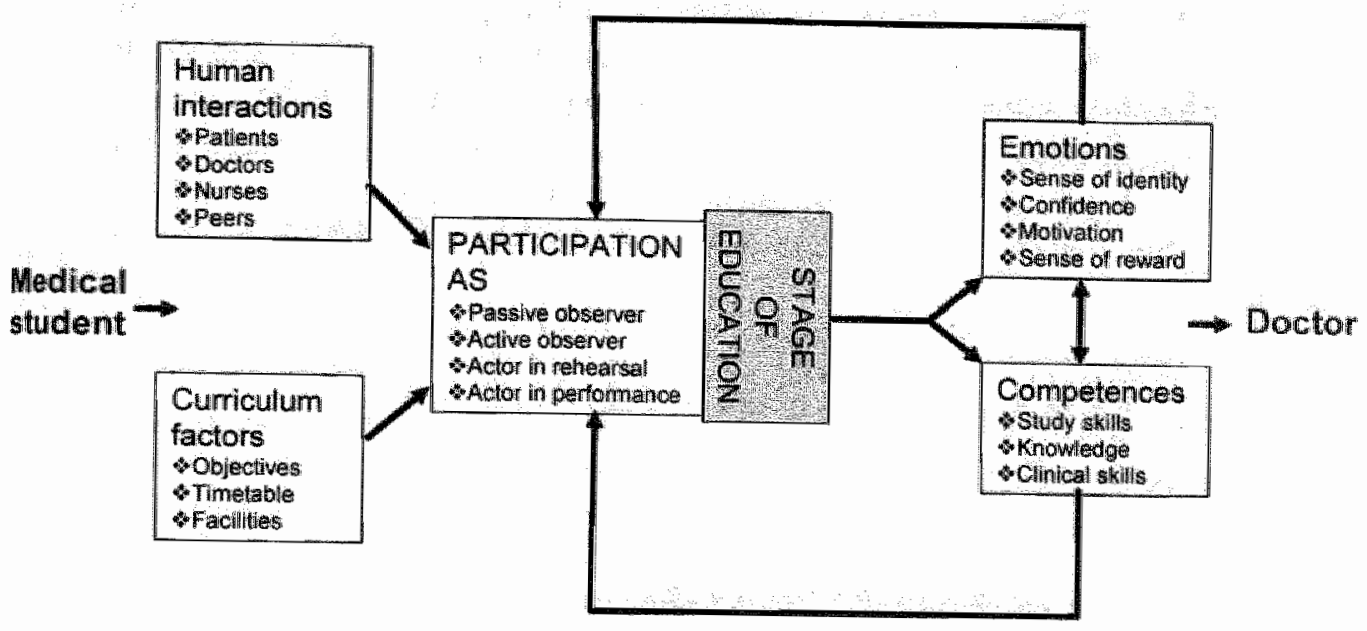

Figure 1 Progression from medical student to doctor through participation in practice The figure describes a model of how a medical student becones a doctor. Central to the model is participating in practice in a way that is appropriate to the student's stage of education. By participating, learners develop enrotions and compecences. Greater competence leads to more positive emotions and vice versa. Developing positive emotions and conpetence rakes it easier for leamers to participate, but the ability to participate is strongly modulated by the behaviour of people the learner meets in the workplace, and whether their experience is diluted by being part of a large group. The cycle can be virtuons (learning begets leaming) or wicions.

for granted. Another potential weakness is the assumption that students, as in Manchester, enter the clinical workplace having had basic training in a clinical skills laboratory.

Whilst our synthesis is novel, it is entirely consistent with previous research into clinical teaching and learning, which is spread across a large a number of publications reviewed elsewhere ${ }^{20}$. It is well described that students quickly become bored if they have to remain as passive observers overlong ${ }^{2122}$; the more actively they are involved and the closer their involvenent comes to caring for patients the more highly they value $i t^{89} 1223$. Students' discomfort at the harm they and their teachers can do to patients creates a tension between their feelings of empathy and need to acculturate to their new professional identity ${ }^{24} 25$. The highs of forming collegial relationships with practitioners and their clinical teans in a "teaching-learning alliance", and the lows of being taught by humiliation are well documented, though the dominant place of nurses in students" workplace 
experiences has received less attention" 122326 . According to a "relational" model of education, the teacher-learner relationship is important in just the same way as the doctor-patient relationship, and teachers can use that relationship to good effect if they couple demand with support ${ }^{27}$. The emotionally charged nature of dinical leaming is well reported, particularly in relation to student stress at times of transition. The constructive place of positive emotions ${ }^{5}$ is now receiving more attention through research into the effect of educational clinate 2830

\section{MEANING OF THE STUDY}

Our findings fit well with contemporary social theories of learning, according, to which expertise is not simply a property that passes from teacher to leamer; but a dynanic commodity that resides within communities of practice; learning, according to the theory, is a process of absorbing and being absorbed into the culture of such a community ${ }^{31-34}$. Developing a professional identity is so fundamental to the process of becoming a doctor ${ }^{35}$ that having to be credible in the eyes of practitioners causes young medical students more stress than encountering illness and death ${ }^{36}$. Stress levels peak when students first start learning in workplaces because they become acutely aware of their own incompetence and unimportance beside the practitioners they strive to emulate ${ }^{101337} 38$. They feel discomfort as they "try on" new professional identities that fit more or less well ${ }^{37}$. Their individuality can find expression through seeking out practitioner role models, developing relationships with them, and negotiating the right to participate in their practice ${ }^{12} 39$. So, relationships between practitioners and learners can both facilitate learning and generate high emotions. Learning medicine as a process of social enculturation has been very thoroughly explored in the important participant-observer research of Sinclair ${ }^{40}$, albeit in a more traditional system of teaching and learning than ours.

\section{UNANSWERED QUESTIONS AND FUTURE RESEARCH}

We suggest research to explore how curriculums can more explicitly acknowledge the emotional dimension of workplace learning and help learners and teachers learn reflectively from the significant events that arise there. Curriculum lleaders and individual teachers need to identify ways of helping students participate in workplace activities appropriate to their stage of training. "Task based learning" is one such pedagogy whose place in contemporary medical education needs to be more thoroughly explored ${ }^{41}$. As the education of doctors, nurses, and allied professionals responds to the conflicting pressures to make graduates more fit for practice, strengthen the academic content of curriculums, increase the output of health professionals, and respond to the pressure to treat large numbers of patients ${ }^{2}$, studies comparing the basic education of different 
health professionals would be informative. The contribution of traned nurses to the climate of basic medical education seems, also, to need further investigation. Finally, the model depicted in figure 1 needs to be turned into an instructional method, taught to learners and practitioners, field-tested, and evaluated.

\section{REFERENCES}

1. General Medical Council. Tomorrow's Doctors. London: General Medical Council, 1993.

2. General Medical Council. Tomorrow"s Doctors. Second edition. London: General Medical Council, 2002.

3. Doman T, Scherpbier A, King N, Boshuizen $H$. Clinical teachers and problem based learning: a phenomenological study. Med Educ 2005; 39:163-70.

4. ten Cate $O$. What happens to the student? "The neglected variable in educational outcome research. Evaluation and the Health Professions 2001; 6:81-8.

5. ten Cate $\mathrm{O}$, Snell L, Mann K, Vermunt J. Orienting teaching towards the learning process. Acad Med 2004; 79:219-28.

6. Fernald DH, Staudenmaier AC, Tressler CJ, Main DS, O'Brien-Gonzales A, Barley GE. Student perspectives on primary care preceptorships: enhancing the medical student preceptorship learning environment. "Teaching and Leaming in Medicine 2001; 13: $13-20$.

7. Howe A. Patient-centred medicine through student-centred teaching: a student perspective on the key impacts of community-based leaming in undergraduate medical education. Med Edac 2001; 35:666-72.

8. Stark $P$. Teaching and learning in the clinical setting: a qualitative study of the perceptions of students and teachers. Med Educ 2003; 37:975-82.

9. van der Hem-Stokroos HH, Daelmans HEM, van der Vleuten CPM, Haarman HJThM, Scherpbier AJJA. A qualitative study of constructive clinical learning experiences. Med Teach 2003; 25:120-6.

10. Seabrook MA. Clinical students' initial reports of the educational climate in a single medical school. Med Educ 2004; 38:659-69

11. Lempp $\mathrm{H}$, Seale $\mathrm{C}$. The hidden curriculum in undergraduate medical edacation: qualitative study of medical students" perceptions of teaching. BMJ 2004; 329:770-3.

12. Lyon P. A model of teaching and leaming in the operating theatre. Med Educ 2004; 38:1278-87.

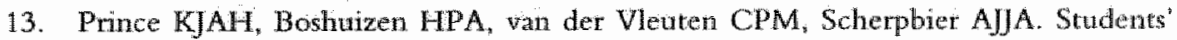
opinions about their preparation for climical practice. Med Educ 2005; 39:704-12.

14. Strauss A, Corbin I. Basics of qualitative research. Techniques and procedures for developing grounded theory. Second edition. Thousand Oaks: Sage, 1998.

15. O'Neill PA, Willis SC Jones A. A model of how students link problem-based learning. with chnical experience through "elaboration". Acad Med 2002; 77:552-61.

16. Macpherson R, Jones A, Whitehouse CR, O'Neill PA. Small group learning in the final year of a medical degree: a guarititative and qualitative study. Med Teach 2001; 23:494-9. 
17. Mulrow CD, Pugh J. Making sense of complex interventions. J Gen Intern Med 1995: 10:111-12.

18. Dornan T, Hadfeld J, Brown M, Boshuizen H, Scherpbier A. How can medical students learn in a self-directed way in the clinical environment? Design-based research. Med Educ 2005; 39.356-64.

19. Littlewood S, Ypinazar V, Margolis SA, Scherpbier A, Spencer J, Dornan T. Early practical experience and the social responsiveness of clinical education: systenatic rewiew. BM] $2005 ; 331: 387-91$.

20. Dorman TL. Experience based learning. Leaming clinical medicine in workplaces. Thesis submitted to Maastricht University.

21. Remmen R, Denekens J, Scherpbiet A et all. An evaluation study of the didactic quality of clerkships. Med Educ 2000:34:460-4.

22. Kachur EK. Observation during early dinical exposure - an effective instructional tool or a bore? Med Educ 2003; 37:88-9.

23. Ratanawongsa N, Teherani A, Hauer KE. Third-year Medical Students' Experiences with Dying Patients during the Iraternal Medicine Cleskship: A Qualitative Study of the Informal Curriculum. Acad Med 2005; 80:641-7.

24. Brewster A. A student"s view of a medical teaching exercise. N Eng J Med 1993; 329:1971-2.

25. Branch W, Pels RJ, Lawrence RS, Arky R. Becoming a doctor: critical-incident reports from third-year medical students. N EngJ Med 1993; 329:1130-1.

26. Yonke AM, Lemon M. First-year medical students and longitudinal primary care. Acad Med 1993; 68:779-80.

27. Tiberius RG, Sinai J, Flak EA. The role of teacher-leamer relationships in medical education. In: Norman GR, van der Vleuten CPM, Newble DI, Eds. International Handbook of research in medical education. Dordrecht: Kluwer, 2002: 463-97.

28. Roft S. New resources for measuring educational environment. Med Teach 2005; $27: 291-3$.

29. Roff S. The Dundee Ready Educational Environment Measure (DREEMI)-a generic instrument for measuring students' perceptions of undergraduate health professions curricula. Med Teach 2005; $27: 322-5$.

30. Roff S. Education enviromnent: a bibliography. Medical Teacher 2005; 27:353-7.

31. Wenger E. Communities of Practice. Leaming. Meaning and Identity. Cambridge: Cambridge University Press, 1998.

32. Woolliscroft JO. Medical Student Clinical Education. In: Norman GR, van der Vleuten CPM, Newble DI, Eds. Intemational Handbook of Research and Medical Education. Dordrecht: Kluwer, 2002: 365-80.

33. Bleakley A. Pre-registration house officers and ward-based learning: a "new apprenticeship' model. Med Educ 2002; 36:9-15.

34. Swanwick T. Informal learning in postgraduate medical education: from cognitivism to "culturism". Med Educ 2005; 39:859-65.

35. Niemi PM. Medical students professional identity: self-reflection during the preclinical years. Med Educ 1997; 31:408-15.

36. Moss F, McManus $\mathbb{C}$ C. The anxieties of new clinical students: Med Educ 1992; 26:17-20.

37. Prince $\mathrm{KJAH}$, Van de Wiel MWJ, Scherpbier AJA, Van der Vleuten CPM, Boshuizen HPA. A qualitative analysis of the transition fron theory to practice in undergraduate 
training in a PBL-medical school. Advances in Health Sciences Education 2000; 5:105-16.

38. Radcliffe $C$, Lester $H$. Perceived stress during undergraduate medical training: a qualitative study. Med Educ 2003; 37:32-8.

39. Mutha $S$, Takayama JI, O'Neil EH. Insights into medical students' career choices based on third-and fourth-year student focus group discussions. Acad Med 1997; 72,635-40.

40. Sinclair S. Making doctors. An institutional apprenticeship. Oxford: Berg, 1997.

41. Harden RM, Crosby J, Davis MH, Howne PW, Struthers AD. Task-based learing the answer to integration and problem-based learning in the clinical years. Med Ednc 2000; 34:391-7.

42. Dacre J. Clinical work and teaching. In. Jolly B, Rees L, Eds. Medical education in the millenium. Oxford: Oxford University Press, 1998. 
$\sqrt{1 / 2}$ 


\section{CHAPTER \\ Learning in clinical workplaces. Bringing teacher and learner together}

Published in Medical Education 2005; 39:356-364

How can medical students learn in a self-directed way in the clínical environment? Design-based research

Tim Dornan, Judy Hadfield, Martin Brown, Henny Boshuizen, and Albert Scherpbier 


\section{ABSTRACT}

Ain: 'This study amed to establish whether and under what conditions medical students can learn in a self-directed manner in the clinical environment.

Method: A web-based learning management system brought 66 placement students, in a problem-based learning (PBL) medical curriculum, into closer touch with their clinical learning objectives and ways of achieving them. Free response comments from 16 of them during the 7 weeks they used it, transcripts of group discussions before and after the period of use, and responses from all 66 students to a questionnaire were analysed qualitatively.

Results: Students were rarely fully autonomous or subservient. They valued affective and pedagogic support, and relied on teachers to manage their learning environment. With support, they were motivated and able to choose how and when to meet their learning needs. The new system was a useful adjunct.

Conclusions: Self-direction, interpreted literally, was a method of learning that students defaulted to when support and guidance were lacking. They found 'supported participation' more valuable. Leaming in the clinical environment was a social process with as many differences from, as similarities to, PBL. 


\section{INTRODUCTION}

The UK General Medical Council (GMC) set medical education off on a new track when it called for medical students to direct their own learning." "Adult learning principles', ${ }^{2}$ which underpin that recommendation, have 'served a useful role in putting the learner and his or her individual aspirations back in the teaching-learning equation. ${ }^{3}$ However, the term 'self-direction' does not have a single, generally agreed meaning. The GMC meant "organising and managing one's own learning needs. ' ${ }^{1}$ Knowles, who first articulated adult learning principles, meant finding one's own motivation and having a more equal relationship with teachers. ${ }^{2}$ Others might mean choosing the content or method of learning. Problem-based learning (PBL) fulfils all those meanings, although the content of learning is heavily cued. ${ }^{4,5}$ The limited transfer of self-directed behaviour from PBL to placement learning ${ }^{6}$ led us to hypothesise that:

- 1 unfamiliarity, complexity, power differentials and emotional factors make it hard for young learners to act autonomously, and

- 2 more external direction is needed in the clinical environment.

We use information technology ('Signup system" - SUS) to resource our students' clinical learning. ${ }^{7}$ We decided to make the software more 'directive' by displaying learning outcomes and suggesting how to achieve them, and used students' reactions as a lens through which to examine self-direction in the clinical environment.

\section{METHODS}

\section{SETTINGI}

Hope Hospital is 1 of 5 teaching hospitals for the University of Manchester, which has a horizontally integrated, problem-based curriculum. ${ }^{8,9}$ The nutrition, metabolism and excretion (NME) module starts Phase 2, when students first have sustained clinical experience. In groups of 8 , they apply 8 -step study skills ${ }^{10}$ to weekly PBL scenarios, formulating learning goals for borh placement and theoretical learning. To resource their learning, they undertake 7-week placements on a hospital firm (medical or surgical) with a specialty interest related to their current PBL cases. Simultaneously, a general practitioner (GP) clinical tutor provides access to relevant case-mix, and they choose 'signups' to fill any remaining gaps in their 'real patient learning' (Appendix 1). ${ }^{7}$

\section{RESEARCH METHODOLOGY}

We used design-based research, evaluated qualitatively. ${ }^{11}$ 


\section{"INTELLIGENT SIGNUP SYSTEM" - ISUS}

The learning management system, described in detail elsewhere, ${ }^{12}$ is intelligent in that it 'knows' the curriculum objectives, keeps track of each student's self-reported progress towards them, compares progress against the whole peer group, suggests signups or other relevant experiences, and helps access them. A student night, for example, see they need to learn more about renal / urological disease, particularly chronic renal failure, identify the predialysis clinic as a relevant learning opportunity, and reserve a place to attend it. That would take 7 mouse-clicks and a few seconds. iSUS would "know' there was space for only 1 student to attend, and restrict booking to someone who had no other timetabled activity. Feedback from previous students would be available online to guide the choice. The next time the student logged on, the system would ask for a free text comment about their experience at the clinic.

\section{STUDY DESIGN}

Groups 1 and 2 comprised 2 consecutive groups of 8 Year 3 students allocated by chance to the diabetes / endocrine firm for 7 weeks. They were briefed about iSUS, gave verbal consent to trial it, had 1 hour of hands-on training in pairs, had free access to technical support, and were supervised by TD, a consultant on the firm. Group 3 consisted of all 48 NME module students on 6 different firms in the next 14-week semester, who were given a 45 -minute introductory lecture and a 30-minute hands-on training session. Participants could choose between the SUS and iSUS interface at all times and had no obligation to book signups, although they had to use the system to read timetables.

\section{EVALUATION}

The 86 free text entries on 91 uses of iSUS by group 1 and 2 students were extracted, anonymously, for qualitative analysis. Anonymised textual responses from group 1,2 and 3 students in an end-of-module evaluation questionnaire ${ }^{13}$ were extracted. TD facilitated semistructured group discussions with group 1 and 2 students at the beginning and end of their placement, asking for their conceptions of self-direction and, in the exit discussions, their opinions on how iSUS had affected them. The discussions were audio-taped and transcribed verbatim.

\section{QUALITATIVE METHODS.}

T'extual materials were coded, back-referenced to the complete transcripts, assembled into an evolving interpretation, and reduced to a single narrative using NVivo software (QSR, Doncaster, Victoria, Australia). Three types of statement were identified: 
1 Statements describing the behawion of a student on a specific actasion in a prowtion sething, coded as "performing', "observing", "discussing' or 'being taught' and subcoded as active ("I did"), passive ('I was directed") or nutual ("We did").

2 General descriptions of learning were coded for the degree of autonomy expressed by the student, and sources of guidance or support.

3 Conceptualisations of self-direction.

One researcher carried out the primary coding. Three others read the material and sought bias in his coding, omissions, and disconfimatory statements. The final conclusions were arrived at by triangulation between the 3 categories of statement, representative examples of which are cited.

\section{RESULTS}

The statements referred to in this section are listed in Appendix 2.

\section{BEHAVIOUR OF STUDENTS IN THE CLINICAL ENVIRONMENT}

\section{1.a. Performing}

There were 27 such statements (1.a.1). Sometimes students created the conditions for learning (1.a.2); at other times, they were "allowed", "able to" or "given opportunities' to act (1,a.3). Five statements referred directly to a teacher's behaviour as a condition for action (1.a.4).

\section{1.b. Observing}

In 27 statements, the student was an observer. Sometimes circumstances made that inevitable, although teachers tried to involve students even in complex practice (1.b.1). Non-participation could be unproductive and frustrating $\left(1 . b_{2}\right)$

\section{1.c. Discussing}

There were 8 such statements. Sometimes the teacher took control (1.c.1); sometimes the discussion was more equal (1.c.2).

\section{1.d. Being taught}

Eleven statements described being taughe (1.d. 1, and 2). Participation in practice allowed students to be taught skills (1.d.3). Teachers gave impromptu tutorials during lulls in clinics (1.d.4). 


\section{GENERAL DESCRIPTIONS OF LEARNING}

\section{2.a. Learwing autonomowsly}

Statements describing autonomous behaviour were few (2.a.1).

\section{2.b. Learning with support}

Much more often, students learned with support. Even highly motivated people benefited from it (2. b. 1). There were a variety of sources of support.

\section{2.b.1a. Staff behaviours}

Staff helped students learn by being "friendly". They involved students in the process of care and tacitly gave permission for action. Students" motivation and clarity about their goals fed on teachers' supportive behaviour and vice versa (2.b.1a.1). One way of encouraging action was to be demanding (2.b.1a.2). Unhelpful behaviours were to ignore students' objectives, show indifference towards their leamng, be disorganised and be unavailable (2.b.1a.3-5). Sometimes, staff discouraged students from seeing patients (2.b.1a.6). They could also discourage action by spending undue time teaching theory. In discussions, they could demotivate by 'putting the onus back on ... students rather than giving .... the guidance ... you're asking for".

\section{2.b.16. Guidance}

Practical guidance about what to learn and how to learn was an important source of support, and iSUS was able to provide it (2.b.1b.1). Teachers, particularly PBL tutors, did not always give enough guidance. Clinical placements were more effective when there were clear objectives (2.6.1b.2).

\subsection{1c. Facilitation}

Even students with clear objectives needed help in achieving them. iSUS helped access appropriate experiences and manage time (2.b.1c.1 and 2). Staff were most effective as facilitators when they were sensitive to students' learning needs.

\section{2.b. 1d. Feedback}

There were many types of feedback. Debriefing on clinical skills was one. Seeing patients without feedback 'did not really teach much'. iSUS's capacity to give reedback on as student's accumulated real patient learning was valued (2.b.1d.1). Students were motivated by seeing what they had and had not yet leamed (2.b.1.2). Filling in the iSUS feedback screens could become an accepted routine, although not for all students (2.b.1d.3 and 4). Comparison with 
peers was seen as valid and motivating, particularly when it came to choosing experiences (2.b.1d.5). Feedback helped self-managenent (2.b.1d.6).

\section{2.c. Being told what to learn}

Most descriptions of external direction came from students' earlier experiences in other universities. Students who had learned basic sciences in another UK university were glad not to be 'spoon-fed' in Manchester, although a student who had experienced 'traditional clinical teaching' in another continent missed being told 'what you should see in medicine and what ... you should learn' by a consultant. Being 'made to come to clinics' could be beneficial. It was demotivating if nobody noticed whether you attended or not (2.c.1).

\section{CONCEPTUALISATIONS OF SELF-DIRECTION}

\section{3.a. Definition of self-direction}

Self-direction involved being in the driving seat, or being responsible for one's own learning. At times, it could be a compensation for deficiencies in the course, but that was seen as an inefficient way of learning (3.a.1). One respondent distinguished 'direction' - having clear objectives - from 'motivation" - for which direction was a prerequisite (3.a.2). Autonomy meant being able to choose how, rather than what, to learn (3.a.3). Whilst valuing diversity of learning, respondents were concerned to cover core objectives.

\section{3.b. The value of self-direction}

There was strong support for self-direction. It was seen as a feature of clinical practice (3.b.1). It fostered a sense of responsibility, lifelong learning skills and individuality. The main problem lay in establishing the level of detail to learn.

\section{3.c. Prerequisite conditions for self-direction}

Statements followed a remarkably consistent logical form, and included a rider about necessary conditions coupled to a statement of support for the principle or practice of self-direction $(3 . c .1)$.

\section{3.c.1a. Objectives}

Being given clear objectives at the right level of generality was the most frequently cited prerequisite (3.c.1a.1 and 2). Teachers, as well as students, needed to be clear (3.c.1a.3).

\section{3.c. 1b. Student attributes}

Self-direction worked best for motivated and organised people (3.c.1b.1). 


\section{3.c. 1c. The transition into self-direction}

To become self-directed, students had to be helped through a transition (3.c.1c.1). When students made the transition to the clinical environment, it was important that they learned how much of what type of experience was required.

\section{3.c.1d. Support by reachers}

Students often coupled statements about their need for senior support with their comments about self-direction. Teachers had to: trust students (3.c.1d.1); be accessible (3.c.1d.2); provide clarification (3.c.1d.3), and offer guidance (3.c.1. .4)

\section{DISCUSSION}

Curriculum evaluation has moved us from disappointment in students' behaviour to a more questioning attitude towards self-direction. Our students were active in their actions and conceptualisations of learning. However, they were most active and motivated when teachers supported them. Support took several forms:

- organisational: opening up learning opportunities, particularly those that involved students in patient care;

- pedagogic: suggesting objectives or methods, training skills, giving feedback, explaining concepts, and

- affective: giving permission, helping students through the transition to a more independent learning style, nurturing, and placing demands.

Only when teachers were completely apathetic did students learn fully autonomously, and that could be unproductive.

This study confirms and helps explain our previous observation that problem-based methods do not transfer automatically to the clinical environment. ${ }^{n}$ The sources of direction and motivation, and their interrelationship, are different in PBL and placement learning. Uncertainty in a tutored PBL group in a seminar roon motivates students by generating "epistemic curiosity" 14 and leads then to learning objectives. Placement learning does not have the same level of group interaction as a motivator and (at least without iSUS) no ready source of objectives. "The clinical environment is much more threatening than the seminar room. Thus, uncertainty is more of a demotivator than a motivator. Social interaction with a supportive practitioner gave our students the direction they needed to become motivated. Unfortunately, the lack of crossover between problem-based and placement leaming leaves our teachers and learners very un- 
clear about the intended learning outcomes of their clinical placements: ${ }^{6}$ iSUS, it seems, can provide the missing piece of the motivational jigsaw. We cannot, as yet, claim generalisability beyond the conditions of this study because the results could be explained in other ways. Longer term follow-up will tell if the students' positive attitudes towards iSUS represented a Hawthome effect. Likewise, follow-up will establish whether the first author's position as researcher, curriculum developer and teacher, which gave him unusual access to the students' learning world, led them to "buy in" out of loyalty.

Our own and others' research leads us to suggest that 'self-direction", as literally applied by many of our teachers, is inapplicable to basic professional education in the clinical environment. It is noteworthy that Knowles himself re-emphasised the place of affective support in late publications. ${ }^{15}$ Other writers have emphasised the interaction between self-directed behaviour and contextual factors, ${ }^{16}$ which are less emphasised in cognitive conceptions of education ${ }^{17}$ than new social theories. ${ }^{18}$ Miflin and colleagues found, like us, that the teacher is a vital condition for clinical learning. ${ }^{5}$ Their analysis anticipated, and has strong similarities with, our own critique of self-direction. Schmidr, who gave problem-based method its cognitive foundation, later reaffirmed its benefits but recognised how difficult it is to develop truly self-directed behaviours and transfer them from PBL to the clinical environment. ${ }^{19}$

We conclude that placement learning should be seen as separate from, although complementary to, PBL. Whereas autonomy (albeit within a peer group) is key to PBL, supported participation is a core condition for placement learning. Appropriately supported, medical students are very active learners. Harden et al. approached the same problem from a different angle when they devised 'task-based learning'. Whatever the name, these methods conform to a new, social theory of learning, according to which active participation builds the professional identity that changes novices to masters of professional practice. ${ }^{18}$

Contributors: TD conceived the idea of iSUS and led educational aspects of its development. He planned and conducted the study, analysed the data and wrote the paper. JH led the implementation of iSUS, second-coded the qualitative data and contributed to each draft of the paper. MB developed the design concept of iSUS, led its technical development and commented on each draft of the paper. $\mathrm{HB}$ reviewed the evolving qualitative interpretation against the original transcripts and helped shape the data interpretation. AS suggested drawing on students" expertise to critique the concept of self-directed learning, checked the data interpretation against the original transcripts and contributed to each draft. Acknowledgements: we thank our ever-willing students for their insightful and 
enthusiastic support of this project. Dan Powley, Stephen Brown and Stuart Clark have had pivotal roles in developing and implementing iSUS.

Funding: iSUS was developed under the anspices of Salford Royall Hospitals NHS Trust; incidental research expenses were met from Tim Dornan's research. funds.

Conflicts of interest: none.

Ethical approval this programme of research was cleared by both the University of Manchester Senate Ethics Committee and Salford and Trafford Ethics Committee as a quality improvement initiative that did not require formal ethical approval.

\section{REFEREN CES}

1. Generall Medical Council. Tomorrow's Doctors. London: GMC 1993.

2. Knowles MS. Self-directed Leaming. A Guide for Learners and Teachers. New York: New York Association Press 1975.

3. Noman GR. The adult leamer: a mythical species. Acad Med 1999;74:886-9.

4. Schmidt HG. Foundations of problem-based learning: some explanatory notes. Med Educ 1993;27:422-32.

5. Miflin BM, Campbell CB, Price DA. A conceptual framework to guide the development of self-directed, lifelong learning in problem-based medical curricula. Med Educ $2000 ; 34: 299-306$.

6. Doman T, Scherpbier A, King N, Boshuizen H. Clinical teachers and problem-based learning. Phenomenological study. Med Educ 2005;39:163-70.

7. Foster M, Dornan T. Self-directed, integrated clinical learning through a signup system. Med Educ 2003;37:656-9.

8. O'Neill PA. Problem-based learning alongside clinical experience: reform of the Manchestet curriculum. Educ Health 1998;11:37-48.

9. Doman T, Scherpbier A, Boshuizen H. Towards walid measures of self-directed clinical leatming. Med Educ 2003;37:983-91.

10. Dorman TL, Baxter CM, Lee C. ParaBLe. A web-based instructional guide to problen-bised learning. 2000. http://www. ParaBLeman.ac.uk.

11. Design -Based Research Collective. Design-based research: an emerging paradigm for educational inquiry. Educational Reser 2003,32:5-8.

12. Dornan 'T, Brown M, Powley D. Hopkins M. A technology using feedback to manage experience-based learning. Med Teach 2004;26:736-8.

13. Dornan T, Boshuizen H, Cordingley L, Hider S, Hadfield J, Scherpbier A. Evalluation of self-directed clinical education: validation of an instmument. Med Educ $2004 ; 38: 670-8$.

14. Lowry $N$, Johnson DW. Effects of controversy on epistemic curiosity, achievement and atritudes, J Soc Psychol 1981;115:31-43.

15. Knowles MS, Holton EF, Swanson RA. The Adult Learner. Houston: Gulf Publishing 1998. 
16. Hammond M, Collins $\mathbb{R}$. Self-directed Leaning. Critical Practice. New York: Nichols / GP Publishing 1991.

17. Ertmer PA, Newby TJ. Behaviourism, cognitivism, constructivism. Comparing critical features from an instructional design perspective. Performance Improventent $Q$ $1993 ; 6: 50-72$.

18. Wenger E. Communities of Practice. Leaming, Meaning and Identicy. Cambridge: Cambridge University Press 1998.

19. Schmidt $\mathrm{H}$. Assumptions underlying self-directed leaming may be false. Med Educ $2000,34: 243-5$.

20. Harden RM, Laidlaw JM, Ker JS, Mitchell HE. AMEE Medical Education Guide No. 7. Task-based learning: an educational strategy for undergraduate, postgraduate and continuing medical education. Part 2. Med Teach 1996;18:91-8. 


\section{APPENDIX}

This form of words was used in both iSUS and the end of module questionnaire to explain ro students their leaming task.

\section{Definition of 'real patient learning'}

As distinct from simulated patient learning, PBL scenarios, seninars / tutoridls about the theory of medicine, or private study away from the bedside, this means learning from real parients:

- on your own or with a teacher;

- in any setting, from $\mathrm{A} \& \mathrm{E}$ in the middle of the night to a business or teaching round, to a clinical demonstration provided by a teacher, or to a postmortem, or

- in the flesh, under an anaestlietic, or seeing the images, Jaboratory results or pathological materials of a patient with whose case you are pessonally faniliar: 


\section{PENDIX 2}

\section{Excerpts from transcripts}

\section{Behaviour of students in the clinical environment}

\section{1.a. Performing}

1.a.1.

II performed a rectal examination and felt a bilaterally enlarged benign prostate. I also learned about the "prostate symptom score" and its application in such a clinic. This was a brilliant signup.'

\section{1.a.2.}

"I performed venepunture on any patient who needed it. Greatly increased my confidence about sticking needles into people!'

\section{1.a.3.}

"Going to the diabetes clinic allowed me to see a patient suffering from type 2 diabetes. 1 . examined the foot pulses."

1.a.4.

"Dr A was very helpful, involving me in pacient care and allowing me to practise... ophthalmoscopy.'

\section{1.b. Obsenving}

1.b.1.

'Angiography techniques. How to remove a catheter whose balloon cannot be deflated ... Dr B was very helpful."

\section{1.b.2.}

"Not very informative. Was a good signup to watch; little participation occurted, although reasoning for $\mathrm{CAPD}$ insert was $\mathrm{ex}-$ plained well.'

\section{1.c. Discussing}

1.c.1.

"I did Aexible cystoscopy and there were a lot of long gaps in ... the middle; the consultants were saying, "Tell me the predisposing facu tors for bladder cancer." Aaagh.'
"Worked with Dr C concentrating on correcting divergent squints and tear duct lavage. We also talked about different ways to get into ophthalmology."

\section{1.d. Being lawght}

1.d.1.

"Excellent teaching in dinics. Everyone very friendly and approachable and happy for us to attend.'

\section{1.d.2.}

"Sat in with SpR (Dr D) who was more than willing to teach.'

\section{1.d.3.}

"Taught and practised PR and prostate examination, testicular examination and venepuncture on 2 patients."

\section{1.d.4.}

"Only 1 of the 5 new patients turned up. This was a very disappointing gession. The doctor present did give me some teaching. however.'

\section{General descriptions of learning}

\section{2.a. Learning autonowously}

2.a.1

'I ... thought of going allong to a clinic and not sitting in with a doctor. I sat there and took blood for a while.'

\subsection{Learning with support}

\section{2.b.1.}

We could not have found the oppotinities without the GP, but it needed us to instigate the learning experience."

\section{2.b.1a. Staff behaviours}

2.b.1a.1.

"I think it is a 2-way thing that, on our behalf we knew what we wanted to do ... and on his behalf it's the way he organises it, allows us to see for example a dietician, the community nurse, and the notes, etc.' 
2.b.1a.2.

"When you are told that you have to have a history to present next week, you will get one!"

\section{2.b.1a.3.}

"I"ve mentioned to him before that we are doing a diabetes case ... but he just says, "I'll just teach you what comes through the door."

\section{2.b.1a.4.}

"Because it is really difficult to be self-motivated when you really are trying and nobody is responding."

\section{2.b. 1 a. 5 .}

'I basically spent a week being very motivated wery enthusiastic, and that soon got killed off, by $\mathrm{Dr} E$, and it was rejuvenated by DrF.

\section{2.b. 1a.6.}

I have been on a ward and wanted to take histories and do examinations, and the staff have said, "They're all pretty old, they are all pretty confused, there is really nobody you can speak to today." ... it does not take much discouragement to put you off. You just say, "Well, I will go home again."

\section{2.b.1b. Guidance}

\section{2.b.1b. 1 .}

[iSUS] has helped a lot because it gives you the minimum threshold of guidance which I think is also required for self-directed learning."

\section{2.b.lb.2.}

"Q: So what is the message in that?" "A: That you need to be more explicit (about objectives) at the beginning.'

\section{2.b.1c. Facilitation}

\section{$2 . b .1 c .1$}

'Using iSUS allowed us to choose signups nost able to facilitate our learming.'

2.b. 1c. 2. "[SUS] aids co-ordination of all aspects of learning, allowing beter use of time."

\section{2.b.1d. Feedback}

2.b.1d.1.

"iSUS is ... well set out and gives feedback."

\section{2.b.1d.2.}

'I think the graphs and histograms [in iSUS] are really good because it motivates you more. If you can visualise what you have done and why you lack experiences then you can go away and look into it."

\section{$2 \mathrm{~b} .1 \mathrm{~d} .3$}

Using the charts to monitor your progress was not appropriate as it grossly overestimates your comparative experience."

\section{2.b. $1 \mathrm{~d} .4$}

"iSUS is far too in-depth and time-consuming."

\section{2.b.1d.5}

"iSUS really helped to keep me motivated the slightly competitive element of the "profile" plus being able to find out at a glance what I should be aiming to achieve meant I was better able to choose an appropriate signup.'

\section{2.b. $1 \mathrm{~d} .6$}

"...feedback analysis to allow "rating" of signups from previous students to allow planning of appropriate leaming."

\section{2.c. Being told what to learn}

2.c.1.

"I used not to turn up to things and no one knew the difference, no one said " $G$, where were you?"'

\section{Conceptualisations of self-direction 3.a. Deftintions of self-divection:}

3.a.1.

'When we didn't have any timetable at all, I just thought, "Well, I don't know what I need to do," sol put more hours in, but they weren't productive, effective hours, because I was casting around trying to kind of get hold of something that I needed to know.'

\section{3.a.2.}


"I think you really need to make a differentiation between self-direction and self-motivation. The objectives for this particular module [are] ... our direction, but it is up to us to pursue that."

\section{3.}

'Okay, now, you know where you are going, ... you can get on with it.'

\subsection{The walwe of self-direction}

3.b.1.

"Q: So one definition of self-directed learning is something that doctors have to be able to do?'

\section{'A: Yes."}

\section{3.c. Prevequisite conditions for self-divection 3.c.ll.}

'I think as long as you've got a set of leaming objectives, along with some sort of agenda, then you can be self-directed."

\section{3.c.1a. Objectives}

3.c.la.l.

'I don't think we could do without a list of objectives because at least we need a framework to know where we are going because we are adjusting to clinical medicine and it is so vast that we do not really know what we have got to learn or what we have to get out of this semester."

\section{0 .1 a. 2.}

"It is like being provided with a map. Suddenly you are able to take some control, which is a big change."

\section{3.c. 1a 3 .}

"It makes things a lot easier if you go into a session and the people who are teaching you know what you're supposed to ger out of it as well."

\section{3.c.1b. Student attributes}

3.c. 1 b. 1 .

"I think you need a lot of intrinsic motivation for that, though."

\section{3.c. $1 c$. The transition into self-ditection}

3.c.1c.1.
"It"s difficult because we"ve all come from a similar background through A-levels and GCSEs and we"ve all, pretry mucli, one way or another ${ }^{\text {been }}$ spoonfed and when you come from that kind of background to a PBL course where you are doing self-directed learning, you can"t really expect the students to, um, adjust straightaway so, from the start of the first and second year, you need a teacher to help the student cross the bridge and then once they" te over the bridge that's when you can set them loose and they will be more happy."

\section{3.c.11. Support by teachers}

3.c. 1 d.1.

"I think mutual trust as well, I think that's important, especially in PBL, because we need to trust the tutors to help us if we get into difficulty, and they need to trust is that we are going to be self-directed learners."

\section{3.c.1d.2.}

"I think the emphasis is on the students themselves learning during the course but the tutors are always there to ask then where you are going wrong or what shall 1 learn."

\section{3.c.1di3.}

'I think it can be self-directed up to the point where, um, you start misunderstanding things and you need things clarified, and that's where teaching sessions come in."

\section{3.c.1d.4.}

And also guidance to know where we should, and when to lean tach thing." 
n 


\section{CHAPTER 7}

\section{Measuring learning. Methodology}

Published in Medical Education 2004; 38: 670-678

Evaluation of self-directed clinical education: validation of an instrument Tim Dornan, Henny Boshuizen, Lis Cordingley, Sam Hider, Judy Hadfield, and Albert Scherpbier 


\section{ABSTRACT}

Aim: To explore the evaluation of self-directed, integrated clinical education. Methods: We delivered a quantitative and qualitative, self-report questionnaire to students through their web-based learning management system. The questionnaire was distributed 4 times over 1 year, each time in 2 parts. A generic part evaluated boundary conditions for learning, teaching activities and 'real patient learning'. Factor analysis with varimax rotation was used to validate the constructs that made up the scale and to stimulate hypotheses about how they interrelated. A module-specific part evalluated real patient learning of the subject matter in the curriculurn.

Results: A total of 101 students gave 380 of a possible 404 responses (94\%). The generic data loaded onto 4 factors, corresponding to: firm quality; hospital-based teaching and learning; community and out-patient learning, and problem-based learning (PBL). A 5-item quality index had content, construct and criterion validity. Quality differed greatly between firms. Self-evaluation of module-specific, real patient learning was also valid. It was strongly influenced by the specialty interests of hospital firms.

Conclusions: Quality is a multidimensional construct. Self-report evaluation of real patient learning is feasible, and could be capitalised on to promote reflective self-direction. The social and material context of learning is an important dimension of educational quality. 


\section{INTRODUCTION}

To 'evaluate' is to measure the quality of a curriculum. North American usage, in which the word 'evaluate' also means assess summatively, implies that students' perfomance in examinations is synonymous with educational quality. However, students preparing for examinations seek every possible way of surmounting weaknesses in their training programmes. ${ }^{1}$ Moreover, examinations have the greatest difficulty in testing those qualities that patients value most: humanistic behaviour; performance in real practice, as opposed to competence in test situations; and the capacity to learn when not under examination pressure. An alternative approach is to evaluate educational process rather than outcome, on the assumption that valid processes lead to valid outcomes. However, the constructs measured by 'process scales' often reflect satisfaction, and may be invalid. For example, we found a deterioration in students' numerical ratings of satisfaction when their own free text comments showed a change in their education for the better. The satisfaction measure, we concluded, was more sensitive to the 'pain' than the 'gain' of self-directed learning. ${ }^{2}$ In the study reported here, we sought insight into self-directed, integrated clinical education by developing and establishing the psychometric properties of another scale.

Before starting the empirical phase, we identified and made explicit the value system on which our concept of evaluation was based. Following the theoretical arguments of Miller, ${ }^{3}$ and the recommendations of the UK General Medical. Council (GMC), our first proposition was that effective behaviour in authentic clinical situations should be the ultimate goal of medical education. A second, generally accepted, proposition was that students must learn experientially in the workplace in order to develop that behaviour. Despite a lack of empirical evidence, the GMC (which accredits UK curricula) holds that integrated education will make medical graduates perform better: Therefore, our third proposition was that clinical learning should be horizontally integrated. 4,5 It would be at odds with the principle of integration for the case-mix of a discipline or the interests of its practitioners to dictate learning, so our fourth proposition was that learning should be guided by a set of objectives; such objectives exist in our school, and represent the competences required of graduates. ${ }^{6}$

The thinking behind our fifth proposition follows from integration. If they are to cross the disciplinary boundaries that constrain their teachers, students must take at least some responsibility for their learning. 'Self-directed' or 'adult learning theory" sets out to explain why and how they should do so. Although very popular, the theory has been criticised because professional learners need help to identify their learning needs, and must acquire much of their learning interac- 
tively through role modelling and the tacit transfer of knowledge from more experienced people. ${ }^{B .9}$ So, the relationship between teacher and learner is complex. Apprenticeship theory recognises that complexity, and sees participation in practice and support from practitioners ${ }^{10}$ as factors that help novices become masters of their profession. Our sixth proposition, then, is that workplace learning is a social process that must be supported and sometimes instructed by senior practitioners. Our seventh proposition derives from cognitive psychology, according to which expert clinicians work from schemata built up from prior experience and have a meta-cognitive ability to know what they know. ${ }^{11}$ They must have plenty of experience to build up their repertoire of clinical prototypes. Our eighth proposition derives from reflective learning theories, according to which experience 'triggers' learning, and does so best when students consciously interpret their experiences. Learning, then, is internal to the learner, but explicit. These considerations led us to hypothesise that learners are able (and perhaps best able) to evaluate learning.

\section{METHODS}

\section{SETTING}

The research was conducted at 1 of the 3 teaching hospitals of the University of Manchester Medical School, Hope Hospital, which provides secondary care to a population of 230,000 people, along with many tertiary services. The approximately 100 students who enter the hospital each year are based in it and its linked district hospitals and general practices for their 3 final years of basic medical training.

\section{CURRICULUM}

Manchester has a self-directed, horizontally integrated, problem-based learning (PBL), community-orientated curriculum. Phase 1 lasts 4 semesters (2 years), is systems-based, and offers little direct clinical contact. Phase 2 likewise lasts 2 years and has 4 systems-based, integrative semesters, but provides plentiful clinical contact. During Phase 3, which lasts 1 year, students round off their practical training and prepare for practice. This research was performed in the first year of Phase 2, in which 214-week modules - Nutrition, Metabolism and Excretion (NME), and Heart, Lungs and Blood (HLB) - take place. The content of the former is gastrointestinal, renal/urological and metabolic/endocrine disease. The latter concerns diseases of the respiratory, cardiovascular and haematological systems. 
There is a rotation between and within modules. For example, NME students have attachments in renal medicine, urology or endocrinology while they are working on renal/urological and metabolic/endocrine PBL cases, and gastrointestinal surgical or medical attachments during their gastrointestinal set of PBL cases. The cases serve as educational 'pacenakers', and students set practical as well as theoretical objectives. They can achieve them on their firms, through a computerised learning management ("signup") system that allows them to identify and attend wirtually any relevant inpatient or outpatient activity in the hospi$\mathrm{tal}_{x}{ }^{12}$ or during the whole day each week they spend out of hospital with a general practitioner.

\section{STUDY DESIGN}

We incorporated a quantitative and qualitative evaluation instrument within the computer system that our students use to manage their learning. As the primary aum was to improve the learning experience of future students, and the data would be invalid without a high response rate, we promoted the system strongly by e-mail and verbally at seminars and reserved the right to debar students who did not respond from using the system. We never did so. We made public any major conclusions that could be drawn from the evaluation, and the actions we planned to take. Ten days before the end of each firm, the learning management system prompted the students to complete a web-based questionnaire. Students who did not respond were reminded, if necessary, repeatedly. The instrument was administered 4 times in 1 whole academic year.

\section{STUDENTS}

Student participation involved the entire 2001 cohort of 101 students entering Salford Phase 2.

\section{EVALUATION}

\section{Instmment}

The instrument had 2 parts, one of which was generic to both modules, while the other was module-specific.

\section{Generic sechion}

This had 13 items, each using a Likert scale of $1-7$. Seven of the items were positively worded and 6 were negatively worded. Positive and negatively worded items were interspersed. Each item was set to a default value of 0 (missing) until a student completed it. The items were in a standard form:

- Heading: e.g. 'leadership" 
- Definition: e.g. "There is leadership if 1 or more senior doctors fron the firm (consultant or registrar) take responsibility for your teaching and learning"

- Stem: "There was leadership of this firm"

- Pull-down rating scale, values of 1-7 anchored as: $1=$ strongly disagree, $4=$ neither agree nor disagree, and $7=$ strongly agree.

Negatively worded items were identical, except for the stem: e.g. "The firm did not prowide appropriate teaching' (underlined in the original). In every case, 'leaming' was included in the response framework in a way that emphasised it (e.g. "How far did the PBL contribute to your learning?"). After each Likert item, there were 2 boxes for optional free text comments; above the first was an unfinished sentence (e.g. "Strengths of clinical teaching were ...') and above the second another (e.g. "Weaknesses, and ways in which clinical teaching could be improved ... $)$.

The first 5 of the 13 items related to aspects of firms that we predicted from apprenticeship theory and a previous student survey would enhance learning:

- the quality of leadership;

- reception to the firm;

- the people students met;

- the learning environment (facilities, equipment, books, etc.), and

- dinical teaching.

Item 6 referred to PBL and items $7-9$ concerned teaching and learning outside the firm:

- hospital teaching outside the firm (e.g. seminars and skills training);

- community teaching, and

- the signup (learning management) system. ${ }^{12}$

Items $10-12$ asked students to rate their real patient learning from:

- hospital inpatients;

- Lospital outpatients, and

- the community.

Item 13 referred to a rating of overall real patient learning.

\section{Module-specific section}

For brevity, this description and the data analysis are restricted to the NME module, although the HLB data support the same conclusions. The module specific part of the questionnaire asked students to rate their real patient leaming of the relevant system(s), and skills, altemating positively and negatively worded items, and using the same format as the generic part. Thus, the items that were relevant to the gastrointestinal half of NME (NME-gastro), referred to real patient learning of:

- the upper gastrointestinal tract; 
- the lower gastrointestinal tract;

- the liver, and

- acute surgical situations.

They also referred to acquisition, through real patients, of these skills:

- examination of the abdomen;

- rectal examination;

- interpretation of abdominal radiographs;

- proctoscopy, and

- nasogastric intubation.

For the renal / urological and metabolic / endocrine part of NME (NME-renal $/$ endocrine), the items related to:

- diseases of the kidneys and urinary tract;

- endocrine disease / diabetes, and

skills:

- testicular examination;

- urethral catheterisation;

- near-patient glucose measurement;

- examination of the neck;

- rectal examination, and

- interpretation of abdominal radiographs.

\section{Assessment results}

Objective, structured clinical examination (OSCE) and progress test results were linked to students' ratings using anonymous, unique identity numbers.

\section{Analysis}

After reversal of negatively worded items, a 5-item quality index was calculated by subtracting 1 from the ratings of leadership, reception, people, learning environment and clinical teaching (so the scale started at 0 ), calculating a mean of each student's ratings, and expressing the mean as a percentage (0-100\% scale); a higher percentage signified higher quality.

Free text responses to the generic questions were coded to maintain student anonymity and prevent any bias caused by the researchers knowing which firm they referred to. We used the extremely conservative technique, described in a previous publication, ${ }^{2}$ of rating free text comments on ordinal scales of 0 and 1. Two researchers independently coded each as positive (describing a strength of the firm), negative (a weakness, or suggestion for change), neither, or both. Coding discrepancies were identified and resolved by discussion. 


\section{Statistical andysis}

Data were analysed using SPSS (Release 10). The Likert data were treated as continuous variables once we had checked that they were normally distributed. We also analysed the dataset by dichotomising the scales around their midpoints; with similar results. Factor analysis with varimax rotation was used to reduce the individual scale items in the generic section of the instrument to discrete factors. One-and 2-way analysis of variance (ANOVA) was used to compare group means, and results are expressed as means \pm 1 standard deviation $(\mathrm{SD})$ or, where group comparisons are shown in tables, 95\% confidence limits (95\% CIs). Speaman coefficients were calculated to test bivariate relationships.

\section{RESULTS}

In all, $100(99 \%), 90(89 \%), 101(100 \%)$ and 89 students $(88 \%)$ responded at the 4 timepoints, yielding 380 of a possible 404 (94\%) responses.

\section{GENERIC SECTION: QUALITY OF TEACHING AND LEARNING}

\section{Factor analysis}

The factor analysis converged after 5 iterations onto a 4-factor solution, accounting for $60 \%$ of the variance in the correlation matrix. The factor loadings are shown in Table 1 . The components of the 5 -item quality index loaded onto factor 1. (firm quality). Factor 2 (hospital teaching and learning) included hospital teaching, real patient learning from inpatients, overall real patient learning and the signup learning management system. Factor 3 (community and outpatient learning) included community teaching, real patient learning in the comm munity, and outpatient real patient learning. Problembased learning alone lovaded onto factor 4 .

Firm quality: walidy of the 5-iten quality index

The index had content validity because the items were selected a prion to represent favourable conditions for learning. Loading of the 5 itens onto a single factor was evidence of construct validity. As evidence of the index's ability to discriminate, we selected 2 frrms for comparison. Firm B (Fig. 1) was led by 1 of us, who aimed consistently to model the values discussed in this paper. It 5 -item quality index did not vary significantly over the year $(86 \pm 6,89 \pm 9,83 \pm 16$ and $95 \pm 4)$. It was higher, averaged over the whole year $(88 \pm 11)$, than that of Firm A (61 \pm 19 ; Fig. 1), whose consultant stafl were not a coherent single subspecialty group. During the second 7 weeks of semester 1, 1 Firm A clinician 
Table 1

Factor loadings

\begin{tabular}{|c|c|c|c|c|c|}
\hline \multirow{3}{*}{ 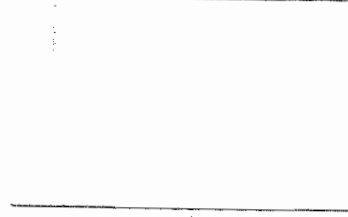 } & & \multicolumn{4}{|l|}{ Factors } \\
\hline & & 1 & 2 & 3 & 4 \\
\hline & & Firm qualiry & $\begin{array}{l}\text { Hospital teaching } \\
\text { and learning }\end{array}$ & $\begin{array}{l}\text { Community } \\
\text { and outpatient } \\
\text { leaming }\end{array}$ & $\mathrm{PBC}$ \\
\hline \multirow{5}{*}{$\begin{array}{l}\text { Components of the } \\
\text { S-item quality index. }\end{array}$} & Leadership & $0.779^{*}$ & 0.14 & 0.07 & -0.05 \\
\hline & Reception & $0.759 \star$ & 0.08 & -0.04 & 0.00 \\
\hline & People & $0.784^{\star}$ & 0.12 & -0.14 & 0.16 \\
\hline & Leaming environment & $0.724^{\star}$ & 0.05 & 0.18 & -0.08 \\
\hline & Clinical teaching & $0.539 \star$ & 0.19 & -0.08 & 0.26 \\
\hline \multirow[t]{4}{*}{$\begin{array}{l}\text { Other activities to 'trigger' } \\
\text { or stappont learning }\end{array}$} & $\begin{array}{l}\text { Problen-based } \\
\text { learnmg tutorials }\end{array}$ & 0.06 & 0.01 & 0.09 & $0.91 *$ \\
\hline & Hospital teaching & 0.20 & $0.44^{\star}$ & 0.14 & -0.05 \\
\hline & Community teaching & 0.01 & 0.01 & $0.92 *$ & -0.08 \\
\hline & $\begin{array}{l}\text { Signup learning } \\
\text { management system }\end{array}$ & -0.06 & $0.64 \star$ & -0.15 & -0.08 \\
\hline \multirow[t]{4}{*}{ Real patient learning } & From inpatients & 0.26 & $0.75 *$ & 0.14 & 0.17 \\
\hline & From outpatients & 0.09 & 0.59 & $0.78 *$ & 0.36 \\
\hline & In community & -0.04 & 0.25 & $0.78 *$ & 0.32 \\
\hline & Overall & 0.11 & $0.75^{\star}$ & 0.15 & 0.01 \\
\hline
\end{tabular}

assumed leadership on behalf of all of them, but only for those 7 weeks. The index rose from $57 \pm 11$ to $79 \pm 19$, then reverted to previous levels ( $57 \pm 17$ and $51 \pm 21$, respectively). Two-way between-groups ANOVA for the quality index of these 2 firms showed a statistically significant main effect for firm $(\mathrm{F}[1,49]$ $=63.1 ; \mathrm{P}<0.001$ ); the effect was large (partial eta squared $=0.563$ ). The main effect for block was also significant $(\mathbb{F}[3,49]=3.28 ; p<0.05)$ and large (partial eta squared $=0.17)$. The effect for interaction $(\mathrm{F}[3,49]=4.22 ; \mathrm{P}=0.01)$ was significant.

Evidence of criterion-related validity is summarised in Fig. 2. An experienced teaching administrator's ranking of the fims based on informal student opinion correlated significantly with the 5-item quality index (Fig $2 \mathrm{~A}$ i $=0.81$; $\mathrm{P}<$ $0.01)$. Students made 1550 free text statements relating to the 5 items of the quality index, 976 of which coded positive and 620 of which coded negative (46 coded both positive and negative). The firms" mean scores on the 5 -item quality index correlated significandy with the number of positive comments about them (Fig $2 \mathrm{C} \mathrm{r}=0.74 ; \mathrm{P}<0.01$ ), the number of negative comments $(r=-$ 


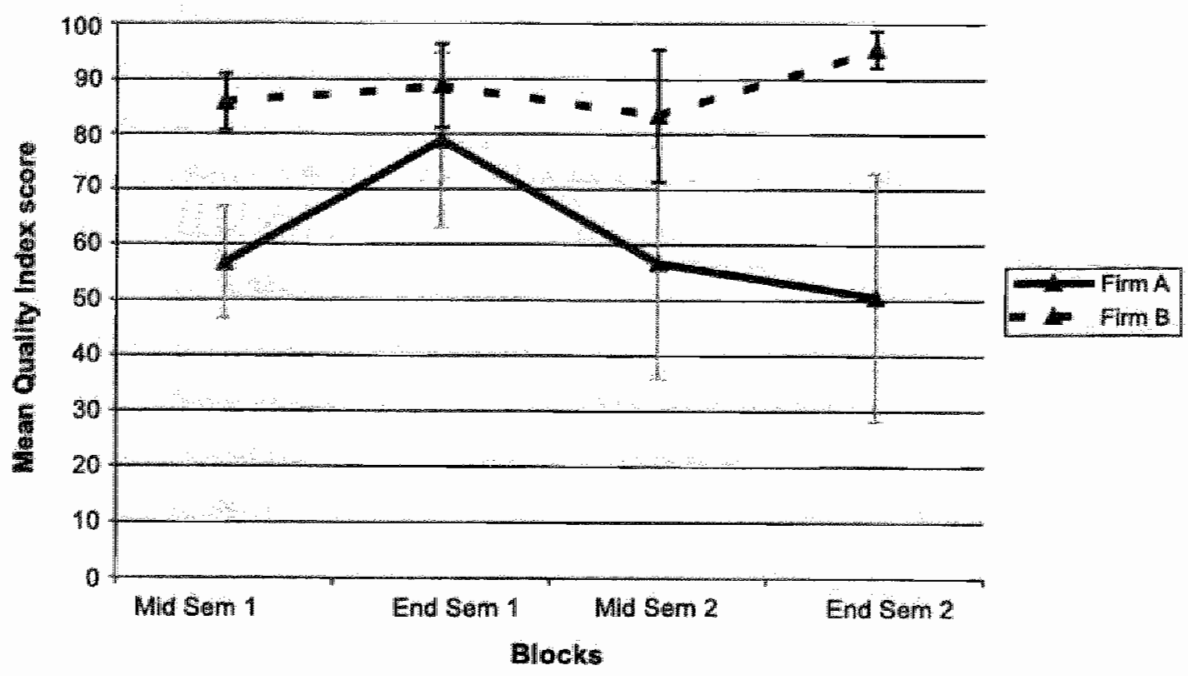

Figure 1 The 5-iten quality index is shown for firm $\mathrm{B}$, which performed successfully throughout 1 acadenic year, and firm $A$, which was less successful except when 1 clinician provided leadership for the second half of semester 1 (sem = semester).

$0.772 ; \mathrm{P}<0.01)$, and the ratio of positive to negative comments $(\mathrm{r}=0.77 ; \mathrm{P}<$ $0.01)$.

\section{COMPARISON BETWEEN FIRMS}

Figure $2 B$ shows substantial differences between firms in the quality index averaged over the whole academic year $(\mathrm{F}[11,350]=11.0 ; \mathrm{P}<0.001)$. The free text comments (Fig. 2C) showed similar differences. Firms attracted a certain mininum number of comments ( 60 positive and 30 negative ones). Higher ranked firms received higher numbers of positive comments, rising to twice the minimum. Lower ranked firms receiwed higher numbers of negative comments, rising to 3 times the minimum. Accordingly, the ratio of positive to negative comments declined from the highest to the lowest ranked firm, with a nearly 4 -fold differential between the 2 extremes.

Results of assessments

Neither OSCE $(\mathrm{F}[11,167]=0.9 ; \mathrm{P}>0.5)$ nor progress test results $(\mathrm{F}[11,167]=$ $0.3 ; \mathrm{P}>0.5$ ) differed between firms, suggesting that student rather than firm is the variable that determines examination success. 

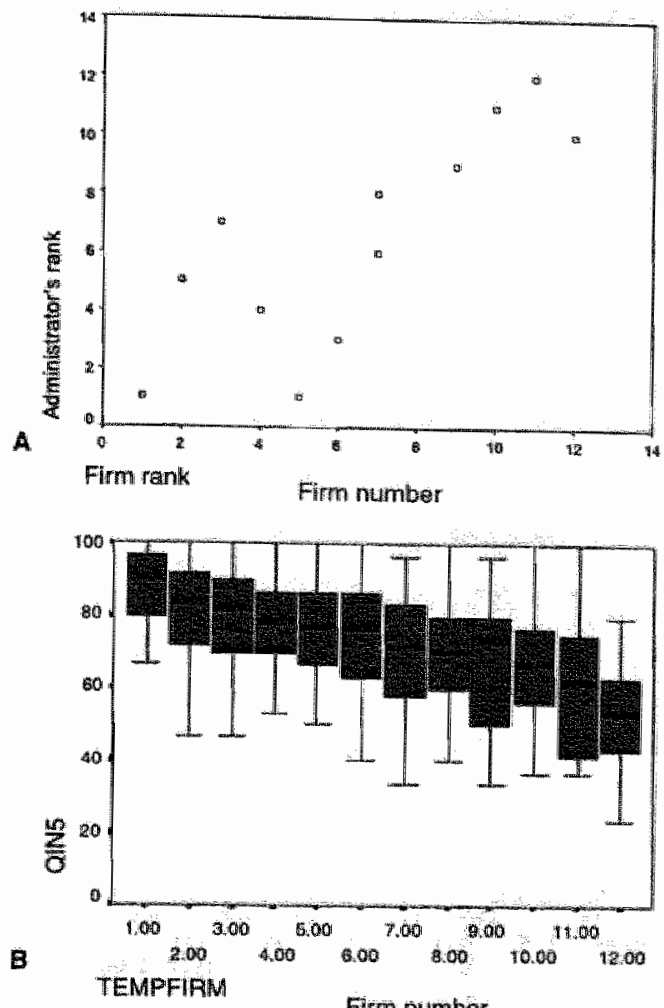

Firm number

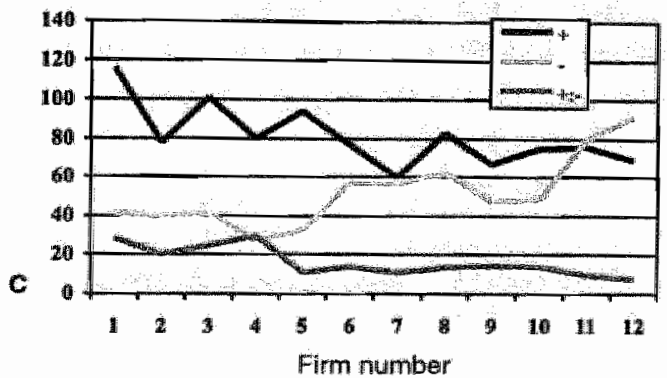

Figure 2 (A) Scatter plot of experienced administrator's ranking of firm quality (wertical axis) against ranking by the 5-item quality index (hortcontal axis); $\mathrm{x}=0.81, \mathrm{p}<0.01$. (B) Box and whisker plot of the 5-item quality iridex for all 12 firms, ranked according to their quality aweraged over 1. whole academic year. (C) Line plots correlating ranking on the 5-item quality index with numbers of positive comments about a firm (keyed as + ; $5=0.74$; $P<0.01$ ), the number of negative comments (keyed as $-; r=-0.772 ; \mathrm{P}<0.01$ ), and the ratio of posicive to negative comments (keyed as $+;-; r=0.77 ; \mathrm{P}<0.01$ ). The borizontal axis - representing the fims numbered $1-12$ - is the same in all 3 panels. 
Table 2 Students' mean ratings $(95 \% \mathrm{CD}$ ) of real patient learning

1) NME-renal/endocrine

Objectives

\begin{tabular}{|c|c|c|c|}
\hline & & Endocrine/diabetes ** & Renal-/urological* \\
\hline \multirow[t]{3}{*}{ Firm } & Endocrine/diabietes & $6.1[5.7-6.5]$ & $4.6[4.2-5.0]$ \\
\hline & Renal medicine & $4.7[4.1-5.2]$ & $5.1[4.6-5.6]$ \\
\hline & Urological surgery & $4.3[3.8-4.8]$ & $5.6[5.11-6.0]$ \\
\hline
\end{tabular}

1b) NME-gastro

\section{Objectives}

\begin{tabular}{|c|c|c|c|c|c|}
\hline & & $\begin{array}{l}\text { Upper GI } \\
\text { disease } \star \star \star\end{array}$ & $\begin{array}{l}\text { Lower GI } \\
\text { disease }^{\text {NS }}\end{array}$ & Liver disease ${ }^{\star \star}$ & $\begin{array}{l}\text { Acute surgical } \\
\text { situations } k \star k\end{array}$ \\
\hline \multirow[t]{3}{*}{ Firmu } & Upper GI surgery & $5.6[5.1-6.2]$ & $5.1[4.5-5.6]$ & $4.0[3.5-4.5]$ & $5.1[4.6-5.6]$ \\
\hline & $\begin{array}{l}\text { Lower GI/breast/ } \\
\text { endocrine surgery }\end{array}$ & $4.1[3.4-4.8]$ & $4.8[4.0-5.5]$ & $4.2[3.5-4.9]$ & $3.8[3.1-4.5]$ \\
\hline & Medical gastroenterology & $4.8[4.1-5.4]$ & $5.2[4.6-5.8]$ & $5.3[4.6-6.0]$ & $3.9[3.2-4.5]$ \\
\hline
\end{tabular}

Mean ratings $(95 \% \mathrm{CI})$, averaged over the whole year, of real patient learning of six major curriculum objectives. $\star \star \star * p<0.001, * \star p<0.01,{ }^{\star} p<0.05$ comparing ratings in the three forms by one-way ANOVA

\section{ATTAINMENT OF MODULE-SPECIFIC OBIECTIVES}

Content validity was assured by the source of the items, all of which were curriculum objectives that were implicit in PBL cases and/ or made explicit in module books, the skills curriculum and the curriculum web site.

The fact that 5 of the 6 NME real patient learning objectives differed significantly between firms, as shown in Table 2 , is evidence of the scale's construct validity.

Criterion-related walidity derived from the match of real patient learning to the specialty interest of the firms; specifically, endocrine / diabetes students learned more endocrinology / diabetes $(\mathrm{P}<0.001)$, renal medicine / surgery firm stu dents learned more renal disease $(\mathrm{P}<0.05)$, medical gastroenterology students learned more liver disease $(P=0.001)$, and upper gastrointestinal (GI) surgery firm students learned more upper $G I$ disease $(\mathrm{P}=0.001)$. Whilst those differences are unsurprising, the key point is that the instrument was sensitive to them. Lower GI learning was similar in all gastrointestinal firms. One surgical 
firm had a lower rating for acute surgical situations than the other, perhaps because the emphases of their clinical teaching and learning differed.

\section{DISCUSSION}

This evaluation was conducted within the value system of self-directed, integrated clinical education. We developed a measure of educational context and process that was valid, allowed us to make summative measurements of quality, and provided formative guidance on how to improve our students' learning. Delivery of the instrument through an on-line learning management system made the process easy to manage without, as has been done in our school in the past, ${ }^{13}$ using the duress of surnmative assessments to achieve a high response rate. As predicted from theory, students' ratings of firms' success at making them welcome and instructing them clustered together in factor analysis and contributed to a summary index of quality. As students spend more time in hospital than in the community, it is unsurprising that hospital teaching and learning correlated with overall real patient learning, whilst community teaching and learning did not. It is of note that ratings of PBL did not correlate with ratings of real patient learning, suggesting a separation between theory and practice. Despite all our efforts to provide an integrated education, students' learning was strongly influenced by the specialty interest of their hospital firm.

A major limitation was the expected 'generosity error' 14 , placing most ratings in the upper half of the scale and limiting its discriminant value due to a ceiling effect. We made the system anonymous, but students may nevertheless have been reluctant to give low ratings or make unfavourable comments for fear of repercussions. Whilst we triangulated the quality ratings against free text comments, we have not yet triangulated the self-report of real patient learning against other subjective or objective data. In common with many evaluation studies, we do not yet have data on utilisation of the results. ${ }^{15}$

Early in the adult learning era, Brookfield discussed the fit of various evaluation methods with adult learning theory. ${ }^{16}$ He classified summative assessment among the 'predetermined objectives' approaches, which he considered ats authoritarian and failing to take account of different students' experiences, interests and abilities. He commended 'goalfree' and 'naturalistic' evaluation because they are sensitive to unexpected as well as intended effects, and operate within the learner's rather than the teacher's frame of reference. Evaluation, he considered, should acknowledge what matters to learners, be led by them, be informal and tlexible, and be carried out against valid criteria. 
A person setting up an evaluation system thas to decide at what stage the evaluation should be carried out, and what methods should be used. Ultimately curricula should be judged by learning outcomes at or after graduation, ${ }^{17,18}$ preferably at the level of practitioner performance or impact on health, rather than competence in test situations. ${ }^{3}$ However, such an evaluation is expensive and takes many years to produce results. Moreover, it may shed little light on how to inprove the educational process, even when there is summative evidence of a need to do so. Another approach, implemented successfully with information technology at the University of Sydney. 19 is not to attempt summative judgements, but ser up a formative quality development loop based entirely on free text feedback, in line with Brookfield's recommendations. 16

Evaluators wishing to make short-to-medium term summative judgements can choose to evaluate resources, educational processes and/or outcomes. Shipengrover and James ${ }^{20}$ called the recent shift from evaluation of inputs and outputs to evaluation of educational process "looking into the black box", and that is what we did in the present study. Of the 15 within-course empirical evaluations of basic medical education we identified in a literature review, all 7 of those published in the last 5 years measured process (some also measuring outcome), whereas 5 of 8 evaluations in earlier years measured knowledge, attitude or skills learning outcomes. Not one of the 15 studies made explicit the theoretical assumptions on which the evalulation was based, and only 2 even commented on the reliability of the measure, a third using a modification of a previously validated instrument. Thus, studies that are well theorised and psychometrically validated seem to be ware.

One group of researchers has develloped a measure of educational process and used it widely, with the gon of developing benchmarks that can be applied across institutions. 21 Bowen and colleagues argued that quality should be regarded as multidimensional, and evaluated as such; ${ }^{22}$ this is in line with our own findings, although it is not universally accepted. ${ }^{23}$ It has been suggested that descriptive as opposed to graded numerical ratings ${ }^{24}$ could be used in evaluation instruments.

Out summative assessments did not discriminate between firms. They were designed to be reliable, but seemed to measure student attributes such as ability and hard work rather than educational quality. In contrast, students' evaluations of teaching and learning were valid, and tended to support our theoretical analysis of quality. Combining quantitative and qualitative evaluation of learning shows promise as a formative and summative measure of self-directed clinical educa- 
tion. The validity of our 5-item index tends to confrim that contextual factors, particularly social ones, are very important to self-directed clinical learners.

Contributors. TD conceived of the project, conducted it, and wrote the paper. HB helped design the project, advised on the evaulation of learning, and commented on each draft of the paper. LC advised on statistical aspects of the paper, and commented on the drafts. SH second coded the qualitative data, and commented on the drafts. JH managed the project, and commented on the drafts. AS advised on the study design, and commented on each draft of the paper.

Acknowledgements. We thank Sally Hollis for advice about statistical aspects of the study in the early stages of analysis.

Funding: This study was funded out of Tim Dornan's endowment funds, and the running expenses of Salford Undergtaduate Education.

Ethical approval. After consultation with the University of Manchester Senate Ethics Committee, ethical approval was not sought.

\section{REFERENCES}

1. ten Cate $O$. What happens to the student? The neglected variable in educational outcone research. Eval Health Prof $2001 ; 6: 81-8$.

2. Doman $T$, Scherpbier $A$, Boshuizen H. Towards valid measures of self-directed clinical learning. Med Educ 2003;37:983-91.

3. Miller GE. The assessment of clinical skillis / competence / performance. Acad Med $1990 ; 65: 63-7$.

4. Harden RM. Integrated teaching - what do we mean? A proposed taxonomy. Med Educ 1998;32:216-7.

5. Benor DE. Interdisciplinary integration in medical education: theory and method. Med Educ 1982;16: 355-61.

6. ONeill PA, Metcalte $D$, David T]. The core content of the undergraduate curriculum in Manchester. Med Educ 1999;33:121-9.

7. Knowles MS. Self-directed learning. A Guide for Leamers and Teachers. New York: New York Association Press 1975.

8. Noman GR. The adult learner: a mythical species. Acad Med 1999,74:886-9.

9. Brookfield $S$, ed. Self-Directed Learning: From Theory to Practice. New Directions for Continuing Education No. 25. San Francisco: Jossey-Bass 1985.

10. Choi J, Hannafin M. Situated cognition and learning environments: roles, structures and implications for design. Educational Technol Res Dev 1995;43:53-69.

11. Schmidt HG, Noman GR, Boshuizen HPA. A cognitive perspective on medical expertise: theory and implications. Acad Med 1990;65:611-21.

12. Foster $M$, Dornan T. Selif-directed, imtegrated clinical leaming through a signup system. Med Educ 2003;37:656-9.

13. Whitehouse $C R, O$ Neill $P$, Dornan T'. Building confidence for work as house officers. Student experience in the final year of a new problem-based curriculum. Med Educ $2002 ; 36: 718-27$. 
14. Albanese M. Rating educational quality: factors in the erosion of professional standards. Acad Med 1999:74:652-8.

15. Holzener W. A protocol for programme evaluation. J Med Educ 1976;51:101-8.

16. Brookfield S. Evaluating leaming and its facilitation. In: Brookfield S, ed. Understanding and Facilitating Adult Leaming. Milton Keynes: Open Universicy Press 1986.

17. Friedman $C_{x}$ de Bliek $R$, Greer $D$ et al Charting the winds of change: evaluating innovative medical curricula. Acad Med 1990;65:8-15.

18. ONeill PA, Willis SC, Jones A. A model of how students link problem-based learning with clinical experience through 'elaboration'. Acad Med 2002;77.552-61.

19. Hendry GD, Cumming RG, Lyon PM, Gordon J. Student-centred course evaluation in a four-year, problem-based medical programme: issues in collection and management of feedback. Assess Evall Higher Educ 2001,26:327-39.

20. Shipengrover JA, James $P$. Measuring instructional quality in community-oriented medical education: looking into the black box. Med Educ 1999;33:846-53.

21. James $\mathrm{P}$, Shipengrover J. Developing benchmarks to measure instructional quality for ambulatory education. Acad Med 2001;76:571-2.

22. Bowen JL, Stearns JA, Dohner C, Blackman J, Simpson D. Defining and evaluating quality for ambulatory care educational programmes. Acad Med 1997;72:506-10.

23. Janes $P$, Schwartz D, Jaen $C$. Shipengrover J, Graham RP, Osbone J Model still needed for defining and evaluating quality of ambulatory care education. Acad Med $1997,72: 831-2$.

24. Battistone MJ, Pendleton B, Milne $\mathrm{C}$ et al. Global descriptive evaluations are more responsive than global numeric ratings in detecting students' progress during the inpatient: portion of an inpatient medicine clerkship. Acad Med 2001;76 (Suppl):105-7. 
CHAPTER 8

\section{Measuring learning. \\ Conditions and outcomes}

In press, in revised form, Medical Education Evaluation of the clinical "curriculum in action" Tim Dornan, Arno Muijtjens, Judy Hadfield, Albert Scherpbier, and Henny Boshuizen 


\section{ABSTRACT}

Aim: Examine how students' evaluations of the environment, process, and outcome of clinical learning interrelated and correlated with assessment results.

Method: A post-hoc study in the third of five years in a student-centred, horzontally integrated, objective-based, medical curriculum. In the last week of each module, students evaluated what they had learned and how they had learned it using a previously validated, web-based scale. The interrelationships between scale variables and their relationships with summative assessment results were tested using factor analysis, correlation analysis ${ }_{\text {, }}$ and stepwise multiple regression analysis.

Results: Student evaluation yielded four measures: Two reflected learning outcomes ("real patient learning" and "curriculum coverage"), one reflected process ("instruction") and one reflected environment ("conditions for learning"). They fitted a causal model according to which instruction, conditions for learning, and curriculum coverage favoured real patient learning. Real patient learnirig was rated higher, and the measures were more strongly associated, in women than men. Performance in end of year summative assessments was strongly predicted by mid year performance but by no other measure.

Conclusions: Students" evaluations of their learning environment and instructional processes correlated with two outcomes of the curriculum in action: Curriculum coverage and real patient learning. There was little shared variance between those measures and students' performance in summative assessments. Given its formative potential, students' evaluation of their curriculum in action could play a useful part in learner-centred clinical education. There is a possibility, which needs further research, that women's evaluations have greater predictive validity than men's. Assessment performance should be regarded not as a solitary gold standard but as just one measure of educational outcome. 


\section{INTRODUCTION}

Curricula can be thought of as having several elements: A curriculum on paper (objectives), a curriculum in action (teaching), and a curriculum as experienced by students (learning), all of which are tested by summative assessments (examinations). ${ }^{1}$ According to traditional, behaviourist educational principles, assessment performance quality-controls the curriculum because the amount of learning candidates demonstrate is a product of their teaching. In reality, assessment performance is mostly determined by students' ability and effort because they "learn to the test" irrespective of the quality of their teaching. ${ }^{2}$ It is becoming ever more important to find out "what happens to the student" contemporary educational theory gives students considerable responsibility for managing their own leaming. Moreover, their performance as qualified doctors reflects aspects of learning that are hard to detect in summative assessments such as their depth and breadth of practical experience and the impact of patients, practitioners, and learning environments on their humanistic qualities. The importance of students" learning activities to their future "fitness for purpose", the lack of impact of teaching quality on assessment performance, and the recognised gap between curriculum leaders', teachers', and students" understandings of the curriculum led us to believe that the workplace curriculum in action should be evaluated directly, as well as indirectly through assessment performance. That would provide a quality management process which more directly addressed students' learning. Moreover, the effort they put into evaluating their learning would support their educational self management and perhaps motivate them to take the evaluation seriously. We developed an evaluation scale and showed that it was sensitive to the quality of students' workplace learning and the supportiveness of their educational environment. ${ }^{45}$ The aim of the present study was to build a model of how those learner-centred measures of educational environment, process, and outcome interrelated and related to the results of summative assessments.

\section{METHODS}

\section{CONTEXT}

The research was conducted within the University of Manchester's predominantly undergraduate entry, five-year medical curriculum. Described in cletail elsewhere, ${ }^{4}$ the curriculum is learner-centred, objective-based, and horizontally integrated. ${ }^{5}$ It was not vertically integrated when this research was done. 


\section{SUBJECTS}

All students entering Hope Hospital, Salford, at the start of Phase 2 in the academic years 2001-2, 2002-3, and 2003-4 took part. About three quarters had completed Phase 1 in Manchester (two years, PBL), and one quarter at St Andrews University (three years, non-PBL). A small number came from other UR or overseas universities.

\section{STUDY DESIGN}

The study had a post hoc design, illustrated in figure 1. Students rotated through four seven week modules, each with its own set of integrative clinical learning objectives embedded in six PBL cases. Groups of up to ten students were attached to a hospital fim with a specialty interest that was relevant to the objectives of the current module, where they learned from real patients, received clinical teaching, and participated in PBL tutorials. Concurrent with those hospital placements, they spent one day per week in general practice and received instruction in seminars and a clinical skills laboratory. During the second half of 2002-3 and the whole of 2003-4, students also used the novel isUS web-based learning management system ${ }^{67}$ to record their learning and access real patient learning opportunities that were appropriate to the objectives of their current module.

\section{ASSESSMENTS}

Students sat biennial 14-station Objective Structured Clinical Examinations (OSCEs) and Progress Tests. ${ }^{9}$ OSCEs tested the objectives of the preceding modules and their results were criterion referenced. Progress Tests assessed knowledge of the entire curriculum. They were norm referenced and expressed as difference from the peer group mean. OSCE performance correlated significantly with progress test performance and there was no systematic difference in their correlations with the other variables under study, so they were aggregated as "mid year assessment performance" and "end of year assessment performance"."

\section{MODULE QUESTIONNAIRE}

In the last week of each module, concurrent with the assessments but before their results were known, students completed a web based evaluation questionnaire, whose design and psychometric properties have been reported in a previous publication. ${ }^{5}$

\section{Generic iterws}

13 items that were generic to all four modules were rated on $1-7$ Likert scales (with an option to add free text comments). These were: The quality ofleader- 
Gender

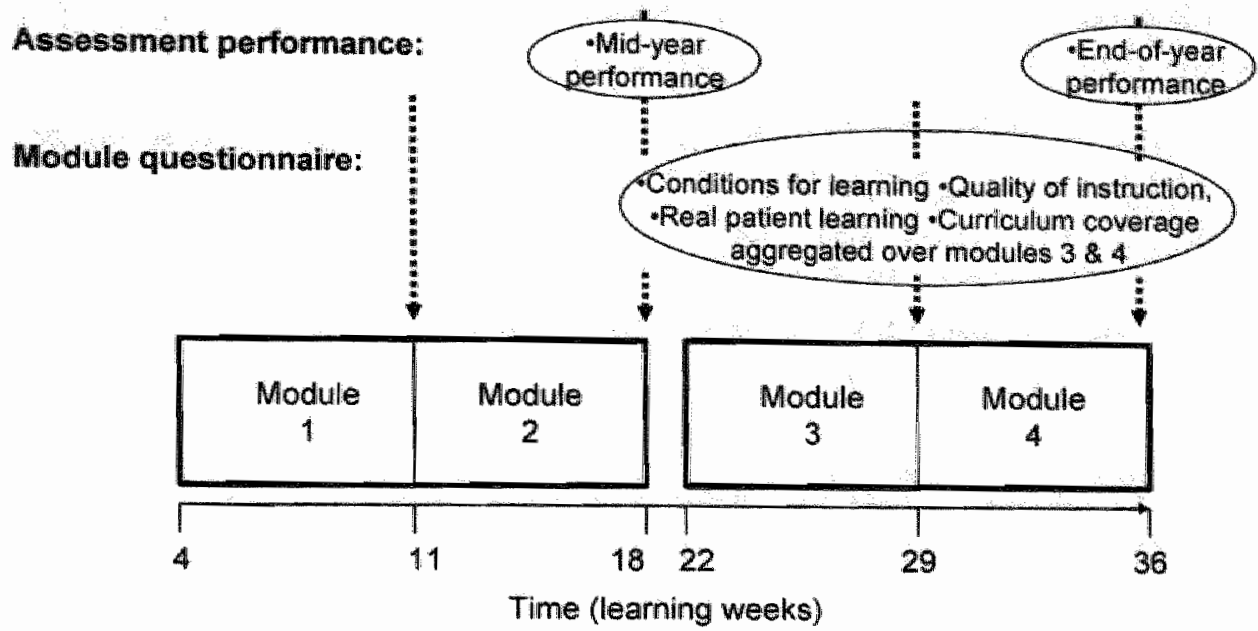

Figure 1 Study design and variables in the correlation analysis

During the course of an academic year, a student completed two semesters, each with two modules. They took an OSCE and Progress Test mid-year and at the end of year, from which the items "mid-year assessment performance" and "end-of-year assessment performance" were computed. They completed a module questionnaire at the end of each modale, from which four items were computed: "conditions for learning" "instruction", "learning", and "curriculum coverage". The variables that were entered into the correlation analysis are ringed.

ship of the firm; students' reception when they started the firm; the supportiveness of the people they met during it; the quality of the facilities and resources provided by the firm; the clinical teaching they received on it; the quality of PBL tutorials, hospital seminars and skills laboratory training; the teaching and learning during the one day per week in community; the extent to which students had learned from real patients in the hospital in-patient setting; in outpatients; from real patients overall; and their learning from the iSUS real patient learning management system.

\section{Module-specific items}

Each module had its own set of clinical learning objectives ${ }_{x}$ and the number differed in different modules. Participants' Likert-ratings of their attainment of each objective of each module were aggregated by student and divided by the number of objectives in the module to reduce them to a single measure of "curriculum coverage". 


\section{ANALYSIS}

Statistical analysis was with SPSS, $11^{\text {th }}$ release (SPSS, Chicago, USA). The modwe questionnaire data were factor analysed and aggregated, using oblique rotation to allow for intercorrelation between the summary items. There were two modules between each set of assessments and there was no way of knowing how each module affected assesment performance, so the summary measures were aggregated over the two modules. End of year assessment performance, mid year perfomance, gender, and the four summary measures derived from the module questionmaire were entered into a Pearson correlation matrix to examine bivariate relationships. A model was constructed by logical consideration of concepts and time relationships. It was simplified after the results of the bivariate correlation analysis were known and stepwise regression was performed. For ease of interpretation and to enhance numerical stability of the estimation procedure, the independent variables of the regression procedure were centred at their mean value (new variable = old variable - mean (old variable)).

\section{RESULTS}

There were 308 students distributed roughly equally between the three cohorts. Despite failure to respond and dropout from the course, the average response tate to the module questionnaire was over $90 \%$. Failure to respond to just one of as many as 36 questions would invalidate a data item, so the aggregated measures were avallable for $87 \%$ of students (conditions for learning), $83 \%$ (instruction), $79 \%$ (curriculum coverage) and $91 \%$ (learning). Both mid-year and end-of-year assessment performance were available for almost every student.

\section{FACTOR STRUCTURE}

The factor analysis converged after nine iterations onto a 3 -factor solution which accounted for $53 \%$ of the variance in the correlation matrix. Factor loadings are shown in table 1 . The items that loaded onto factor 1 represented the conditions for learning on at student's firm: The quality of leadership of the firm; students" reception when they started it; the supportiveness of the people they met during it; the quality of the facilities and resources provided by the firm; and the clinical teaching they received on it. The items that loaded onto factor 2 represented the quality of instruction: The quality of PBL tutorials, hospital seminars and skills laboratory training; and the teaching and learning during the one day per week in community. The items that loaded onto factor 3 represented students' real patient leaming: The extent to which they had learned from real patients in the hospital in patient setting; in outpatients; from real patients overall; and their learning from the iSUS real patient learning management system. 
Table 1 Factor loadings in the rotated component matrix (Oblimin rotation with Kaiser normalisation)

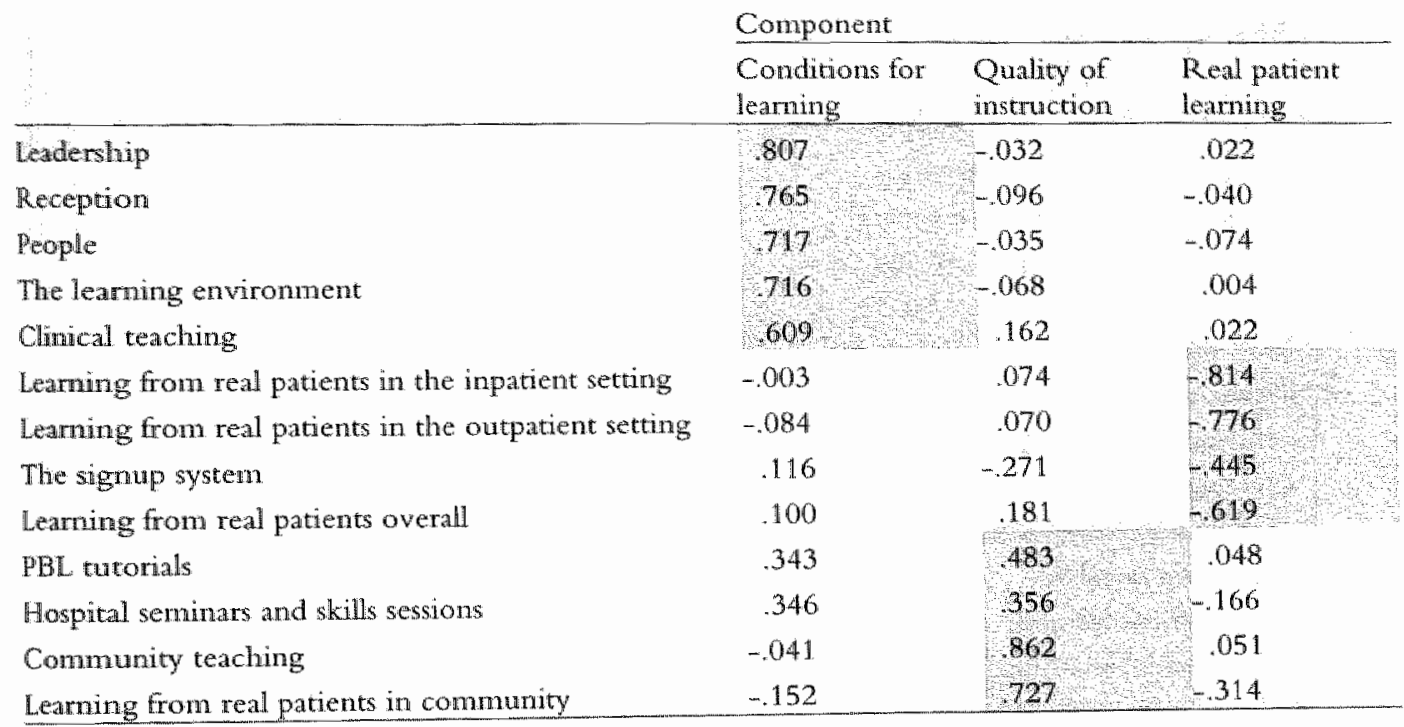

Those three factors and curriculum coverage were the four meastres that were entered into correlation and regression analysis.

\section{BIVARUATE ANALYSIS}

End of year assessment performance correlated significantly and positively with mid year assessment performance $(r=0.64 ; \mathrm{P}<0.001)$, real patient leaming $(r=0.20 ; p=0.001)$ and gender $(r=-0.13$ [higher scores in women]; $<<0.05)$ but not quality of instruction, conditions for learning, or curriculum coverage. Mid year assessment performance correlated with real patient learning $(r=0,18$; $p<0.01)$ and gender $(r=-0.17 ; p<0.01)$. Real patient learning correlated significantly and positively with curriculum coverage $(r=0.45)$, conditions for learning $(x=0.38)$, and quality of instruction $(r=0.37 ; p<0.001$ for all three correlations). Curriculum coverage correlated significantly with conditions for learning $(r=0.30 ; p<0.001)$ and quality of instruction $(r=0.31 ; p<0.001)$. Conditions for leaming correlated significantly with quality of instruction $(r=0.33$; $p<0.001$ ).

\section{MULTIVARIATE ANALYSIS}

Table 2 shows the variables that were entered into multivariate analysis and figure 2 shows a model developed using the following reasoning: Quality of instruction, conditions for learning, and curriculum coverage might all be ex- 
Table 2 Variables and seales

First multivaniate analysis

Variable

Scale

Independent variables

- Mid year assessment performance

$0-200 \%$ *

- Conditions for leaming

$0-100 \%$

- Quallicy of instruction

a-100\%

- Curriculum coverage

$0-100 \%$

- Gender

$-0.5(\mathrm{~F})$ to $0.5(\mathrm{M})$

Moderator variables

- Interaction of mid year assessment performance with gender

$-100 \%$ to $+100 \%$

- Wnteraction of conditions for learning with gender

$-50 \%$ to $+50 \%$

- Interaction of quality of instruction with gender

$-50 \%$ to $+50 \%$

- Interaction of curriculum coverage with gender

$-50 \%$ to $+50 \%$

Dependent variable

- Real patient learning

$0-100 \%$

Second multivariate analysis

Independent variables

- Mid year assessment performance

$0-200 \%$

- Conditions for learning

$0-100 \%$

- Quality of instruction

$0-100 \%$

- Corriculum coverage

$0-100 \%$

- Real patient learning

$0-100 \%$

- Gender

$-0.5(\mathbb{F})$ to $0.5(\mathrm{M})$

Moderator variables

- Interaction of nuid year assessment perfomance with gender

$-100 \%$ to $+100 \%$

- Interaction of conditions for learning with gender

$-50 \%$ to $+50 \%$

- Interaction of quality of instruction with gender

$-50 \%$ to $+50 \%$

- Interaction of curriculum coverage with gender

$-50 \%$ to $+50 \%$

- Interaction of ral patient learning with gender

$-50 \%$ to $+50 \%$

Dependent variable

- End of year assessment performance

$0-200 \%$

"Assessment performance totals up to $200 \%$ because OSCE and progress test perfomance, each on a $0-100 \%$ scale, were aggregated. 
Table 3 Standardised regression coefficients ( $\beta$ ) for all subjects and separately for men and wometr

\begin{tabular}{|c|c|c|c|}
\hline & All subjecs & Women & Men \\
\hline \multicolumn{4}{|c|}{ Real patient learning as dependent variable } \\
\hline - Curriculum coverage & $0.34 * *$ & $0.39 * \star *$ & $0.27 * *$ \\
\hline - Quality of instruction & $0.21 * * *$ & $0.25 * *$ & \\
\hline - Mid year assessment performance & $0.17 * * *$ & $0.20 * * *$ & \\
\hline - Conditions for learning & $0.18 * * *$ & $0.15 *$ & $0.30 * \star$ \\
\hline - Gender & $-0.11^{*}$ & & \\
\hline
\end{tabular}

End of year assessment performance as dependent variable
- Mid year assessment performance

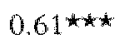
$0.57 \star \star \star$
$0.67 * \star *$
- Real patient learning

${ }^{\star} \mathrm{p}<0.05 ;{ }^{\star \star} \mathrm{p}<0.01 ;{ }^{\star \star \star} \mathrm{p}<0.001 ;$, non-significant otherwise

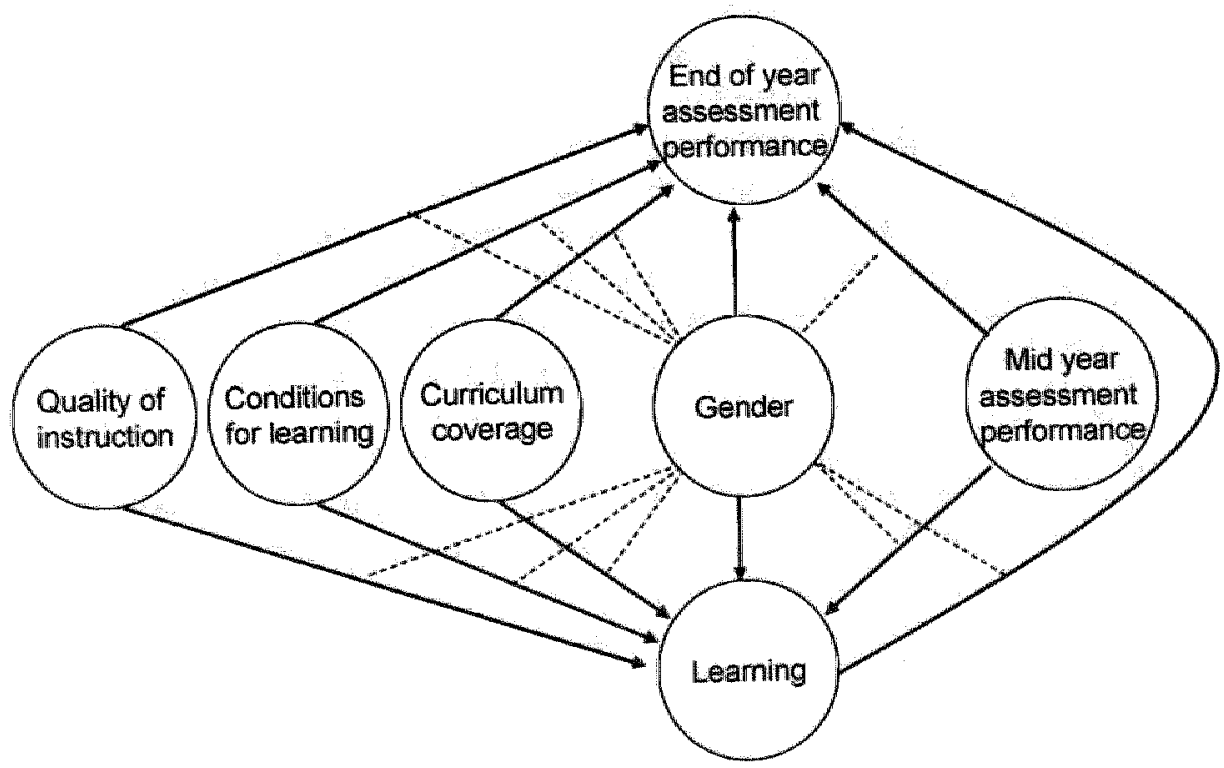

Figure 2 Model for stepwise regression procedures

Solid line arrows represent independent-dependent relationslips and dashed lintes represent gender acting as a moderator of independent-dependent relationslips. 
pected conceptually to affect real pationt learning. Mid year assessment performance might also affect real patient learning because it immediately preceded the period under scrutiny. All of the above variables might be predicted to affect performance in end of year assessments because they antedated it. Gender might affect the dependent variables through the intercept (main effect, indicated by a solid arrow) or through moderating the relationship between the independent and dependent variables (slope, broken line). In a first stepwise multiple regression analysis, real patient leaming was the dependent variable with mid-year assessment performance, conditions for learning, quality of instruction, curriculum coverage, and gender as independent wariables, and the product of gender and each of the three module questionnaire items as interaction variables. In a second analysis, end of year assessment performance was the dependent variable with real patient learning and the same variables as in the furst analysis as independent variables, and the same interaction terms as in the forst analysis together with the product of real patient learning and gender.

\section{Real patient learning as dependent variable}

The model as a whole was significant $(F \mid 5,271]=26.9 ; p<0.001)$. There were significant, positive effects on real patient leaning of curriculun coverage (standardised $\beta$ coefficient $=0.34 ; p<0.001)$, quality of instruction $(\beta=0.21$; $p<0.001)$, mid year assessment performance $(\beta=0.17 ; p=0.001)$, and conditions for learning $(\beta=0.18 ; p=0.001)$. There was also a significant effect of gender $(\beta=-0.11, p<0.05)$, women rating their real patient learning higher than men. Table 3 shows those results and secondary analyses for women and men separately. Associations were less strong in men than women.

\section{End of year assessment performance as dependent variable}

The model as a whole was significant $(F[1,273 \rrbracket=180.7 ; p<0.001)$. There was only a significant effect of mid year assessment performance $(\beta=0.61 ; p<0.001)$.

\section{DISCUSSION}

We used a type of factor analysis that minimised spurious intercorrelations but nevertheless our conceptual model of the relationships between the environment, process, and outcome of clinical learning was supported by statistically significant correlations. The scale asked students to judge teaching and learning activities according to their effect on real patient learning but the study had a post hoc design so we cannot conclude that a better educational environment caused better real patient learning. A more conservative interpretation would be that the data support our previous assertion that it is valid to evaluate the curricu- 
Ium in action in student centred, objective based chinical education. ${ }^{4}$ It is, noreover, entirely logical that a supportive firm backed up by good seminars, skills laboratory training, and PBL tatorials encourages students to cover the theoretical and practical components of their clinical curriculum and learn well from real patients. Indirect support for our emphasis on patient learning comes from contemporary theories of the nature of climical expertise ${ }^{10}$ and the acquisition of clinical skills, " which predict that new doctors who have had richer real patient experiences will be more clinically competent.

We found no significant association between real patient learning and assessment performance in multivariate analysis. If assessment performance were regarded as the solitary "gold standard" of curriculum evaluation, that would question the validity of students' evaluations of the curriculum in action. However, the validity of summative assessment as a measure of curriculum quality is itself a matter of debate. ${ }^{3} 60 \%$ of the variance in assessment performance was unexplained by any measure including gender, prior assessment perfornance, and those teaching and learning activities we were able to measure. Measurement error, one possible explanation, would be unlikely to leave quite so much variance unexplained. There may have been effects of the educational programme that we did not measure; there may also have been compensation by students for deficiencies in their own prior assessment performance and/or the qualicy of their teaching ${ }^{3}$. These and other explanations for variance in assessment performance need to be explored in future research. Women performed better in assessments and evaluated their real patient learning higher than men, indicating that gender differences need to be considered when evaluating the curriculum in action in a mixed gender cohort. It raises the interesting possibility that women are more reliable self evaluators as well as better performers, and perhaps the two are causally related.

Previous authors have described the curriculum in action in much the sanne terms as ourselves ${ }^{12-14}$ and used students' itiability to perform authentic tasks in summative assessments to identify flaws in it. ${ }^{15}$ Rigorously conducted studies from North America have shown that teaching quality and curriculum change can improve performance in knowledge tests; ${ }^{16-22}$ however, publications from the UK do not find that more positive learning experiences predict better assessment performance, ${ }^{23-27}$ and one author has gone as far as to suggest that the re-verse might be expected because of compensation for poor teaching. ${ }^{3}$ Perhaps international differences exist because psychometric evaluation is conducted more rigorously in the USA. Another possibility is that the difference is genuine and that the whole US system of clinical education is attuned to obtaining good results in a national licensing examination, which is the "gold standard" of rigor- 
ous psychometric studies. Our observation that a positive leaming environment favours learning is consistent with many previous studies, ${ }^{28-32}$ including our own qualitative research. ${ }^{33}$ The demonstration by researchers from McMaster that self-assessment has very poor predictive validity might seem to challenge our assertion that students can usefully evaluate the curriculum in action. ${ }^{34}$ However, there were major methodological differences between their research design, where students attempted to predict their perfornance in summative assessments, and our evaluation scale, which calls on students retrospectively to evaluate their clinical exposure and attainment of prescribed learming outcomes.

We present these findings as evidence that the curriculum in action is evaluable. Just how useful it is to evaluate it has yet to be proven, calling as it does for long term studies to demonstrate predictive validity. We have not yet proved that this form of evaluation helps students manage their learning, but double benefit of that sort seems possible because contemporary educational theory predicts that reflective evaluation of competence will enhance learning.

\section{REFERENCES}

1. Coles C. How students learn. In: Jolly B, Rees L, Eds. Medical education in the millennium. Oxford: Oxford Universicy Press, 1998.

2. Jolly BC, Jones A, Dacre JE, Elzubeir M, Kopelman P, Hitman G. Relationship between students' clinical experiences in introductory clinical courses and their performance on an objective structured clinical examination (OSCE). Acad Med 1996; $71: 909-16$.

3. ten Cate $O$. What happens to the student? The neglected variable in educational outcome nesearch. Adv Health Sci Educ Theory Pract. 2001; 6:81-8.

4. Dornan T, Scherpbier A, Boshuizen H. Towards valid measures of self-directed clinical learning. Med Educ 2003; 37:983-91.

5. Doman T, Boshuizen $H$, Cordingley L, Hider S, Hadfeld J, Scherpbier A. Evaluation of selfodirected clinical education: validation of an instrument Med Educ 2004; $38: 670 m 8$.

6. Doman T, Brown M, Powley D, Hopkins M. A technology using feedback to manage experience based leaming. Med Teach 2004; 26:736-8.

7. Doman $T$, Hadfield J, Brown M, Boshuizen $H$, Scherpbier A. How can medical stum dents learn in a self-directed way in the clinical environment? Design-based research. Med Educ 2005; 39:356-64.

8. Harden RM, Gleeson FA. Assessment of dinical competence using an objective structured clincal examination (OSCE). Med Educ 1979; 13:41-54.

9. van der Vleuten CPM, Verwijnen GM, Wijnen WHFN. Fifteen years of experience with progress testing in a problem-based learning cumiculum. Med Teach 1996; $18: 103-8$.

10. Schnidv HG, Noman GR, Boshuizen HPA. A cognitive perspective on medical expertise: theory and implications. Acad Med 1990; 65:611-21. 
11. Patrick J. Training Research and Practice. London: Acadenic Press, 1992.

12. Remmen R, Denekens J, Scherpbier AfA tet at. Evaluation of skills training during clerkships using student focus groups. Med Teach 1998; 20:428-32.

13. van der Hem-Stokroos HH, Schetpbier AJA, wan der Vlewten CPPM, de Vuies H, Haarman HJTHM. How effective is a clerkship as a learning environment. Med Teach $2001 ; 23: 599-604$.

14. Worley P, Prideaux D, Strasser R, March R, Worley E. What do medical students actually do on clinical rotations? Med Teach 2004; 26:594-8.

15. McGaghe WC, Winter $\mathrm{RJ}$. Critique of a clinical curiculum from examination performance. Acad Med 1996; 71:552.

16. Griffith III $\mathrm{CH}$, Wilson JF, Haist SA, Rambbortom-Lucier M. Relationships of how well attending physicians teach to their students" performances and residency choices. Acad Med 1997; 72 (Suppl 1):S118-20.

17. Blue AV, Griffith III CH, Wilson J, Sloan DA, Schwartz RW. Surgical teaching quality makes a difference. Am J Surg 1999; 177:86-9.

18. Griffith CH, Georgesen JC. Wilson JF. Six-year documentation of the association between excellent clinical teaching and mproved students" examination performances. Acad Med 2000; 75 (10 Suppl):S62-S64.

19. Stem DT, Williams BC, Gill A, Gruppen L, Woolliscroft JO, Grum CM. Is there a relitionship between attending physicians" and residents" teaching skills and students" exammation scores? Acad Med 2000; 75:1144-6.

20. Roop SA, Pangaro L. Effect of clinical teaching on student performance during a niedicine clerkship. Am J Med 2001; 110:205-9.

21. Wood DF. Evaluating the outcomes of undergraduate medical education. Med Educ $2003 ; 37: 580-1$.

22. Fitzgerald JT, White CB, Gruppen LD. A longitudimal study of self-assessment accuracy. Med Educ 2003; 37:645-9.

23. McManus IC, Richards P, Winder BC, Sproston KA. Clinical experience, performance in final examinations, and learning style in medical students: prospective study. BMJ 1998; 316:345-50.

24. McManas IC, Richards P, Winder BC. Clinical experience of UK medical students. Lancet 1998; 351:802-3.

25. Seabrook MA, Lawson M, Malster M, Solly J, Rennie J, Baskerville PA. Teachng nuedical students in a day surgery unit: adapting nedical education to changes in dinical practice. Med Teach 1998; 20:222-6.

26. Seabrook MA, Lawson M, Woodfield $S$, Baskerville PA. Undergraduate teaching in a day surgery unit: A 2-year evaluation. Med Educ 1998; 32:298-303.

27. Seabrook MA. Woodfield SJ, Papagrigoriadis S, Rennie JA, Atherton A, Lawson M. Consistency of teaching in parallel surgical firms: an audit of student experience at one medical school. Med Educ 2000; 34:292-8.

28. van der Hem-Stokroos. HH, Datmans HEM, van der Vleuten CPM, Haarman HJThM, Scherpbiet AJJA. A qualitative scudy of constructive dimicall learnirg experiences. Med Teach 2003; 25:120-6.

29. Lempp H, Seale $\mathrm{C}$. The hidden curriculum in undergraduate medical education: qualitative study of medical students' perceptions of teaching. BMJ $2004 ; 329: 770-3$

30. Seabrook MA. Clinical students' initial reponts of the educational chimate in an single medical school. Med Edue 2004: 38:659-69. 
31. Roff $\mathrm{S}$. New resources for measuring educational enviromment. Med Teach 2005; $27: 291-3$.

32. Stewart CL, Preece PE, Dent JA. Can a dedicated teaching and learning enviromment in ambulatory care improve the acquisition of learning outcomes? Med Teach 2005; $27: 358-63$.

33. Dornan $T$, Boshuizen $H$, King $N$, Scherpbier A. Medical students' learning in clinical workplaces. Grounded theory analysis. Submitted 2005.

34. Eva KW, Cunnington JPW, Reiter HI, Keane DR, Norman GR. How can I know what I don't know? Poor self-assessment in a well-defined domain. Adv Health Sci Educ Theory Pract 2004; 9:211-24. 


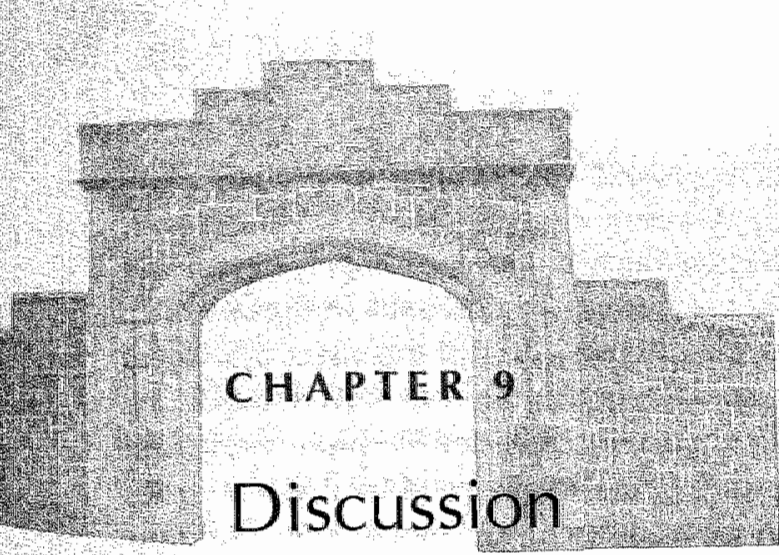




\section{BACKGROUND}

In the 1990s, a change to PBL in the preclinical curriculum and changes in the UK healthcare system led Manchester Unwersity to revise the later years of its undergraduate medical curriculum. The people who led the change assumed that students learn in clinical environments in much the same way as in PBL tutorial rooms. The old clinical curriculum was a rotation through specialties, where students were supposed to learn by participating in clinical achivities. In the new curriculum, specialties were given more of a secondary role. Students were expected to use them, like their books, to resource their learning. The new curriculum left at least sone teachers and learners confused about their roles and responsibilities. A publication from another innovative medical school showed that it, also, had found it hard to transfer responsibility for learning onto its students, which led to the premises explored in this thesis: There are important differences between the conditions for successful PBL and clinical workplace learning, and the learning processes are also different. Accordingly the term "experience based learning (ExBL) is used from here on to describe workplace learning.

Assumptions about PBL and clinical workplace learning that underlie the premise can be summarised as follows: PBL is a new educational method that was conceived of as a whole and is well supported by theory and empirical re search. ${ }^{2-4}$ The PBL leaming enviromment is quite a regulated and stable one. Its actors have clearly dafined responsibilities and the material that triggers leaming is within their control. ${ }^{5-8}$ ExBL has grown over centuries. There are plenty of publications about it but the authors have started from different perspectives. They have, for example, been interested in either primary or secondary care education rather than the similarities between the two Often, they have not stated their theorites and assumptions. In contrast to PBL, the ExBL learning environment is a very complex one. Students piece together their learning by meeting different people behaving in different ways in different settings. Fxpressed in the language of complexity theory, clinical learning is an "emergent property" of the "complex adaptive systems" that operate within a whole variety of workplaces."

In recognition of that complexity, the research question investigated in this thesis was very broadly framed: What should students in today"s learner centred clinical curricula learn in workplaces and how should they learn there? "To make as few assumptions as possible, "the workplace" was defined as an environment in which patients, practitioners, and students come together for the dual purpose of delivering medical care and learning. So, the wards, outpatient departments, 
and GP surgeries of Manchester are different forms of a common learning environment, where students gain experience. To make sense out of complexity, the research set out to identify important features of this learning environment. It explored qualities of doctors and students and the interactions between them. It examined the outcomes of clinical learning. This chapter synthesises the results into a whole, weighs up their strengths and limitations, and considers their implications for instructional design. Quite simple changes can make big differences to the outputs of complex adaptive systems so this chapter assembles a tentative model of ExBL that could be manipulated in future curriculun development and research.

\section{SUMMARY OF RESEARCH FINDINGS}

\section{EXBL IS DIFFERENT FROM PBL}

This section summarises ways in which the research supports the assumptions from which it started. There is support for the assumption that there are important differences between the conditions for and processes of PBL and ExBL in the finding that "problem-based method lacks some important conditions for professional teaching and leaming" and that there is a need for "new educational methods that help the learner to build a professional identity through social interaction with practitioners". Further support comes from the finding that learning in the clinical environment is "a sociall process with as many differences from, as similarities to, PBL". Those conclusions are supported by the research of other authors, who have interpreted clinical learning as a process of socialisation within a community of practice. ${ }^{10-14}$ The suggestion that early experience can support additional emotional learning in a $\mathrm{PBL}$ curriculum is further evidence that ExBL is different from PBL. The next section clarifies the difference by discussing some distinctive features of ExBL: The stimulus to learn is of a particular nature; the processes and products of ExBL are closely interrelated; clinical workplaces are complex learning environments; horizontal integration of ExBL poses special problems; the concept of "self direction" does not fit well with what happens in workplaces.

\section{Stimulus to learn}

In PBL, "cognitive and social congruence" between student and teacher around a neutral description of a problematic situation stimulates "epistemic curiosity" , which motivates studients to study privately and achieve learning outcomes set by curriculum leaders. ${ }^{1516}$ In ExBL, the stimulus is "experience", defined in the early experience studies as: "Authentic (real as opposed to simulated) human 
contact in a social or clinical context that enhances learning of health, illness and/for disease, and the role of the health professional."

\section{Process, product, and relationships}

Social interaction with practitioners in workplaces is found in many different parts of the thesis to help students construct a professional identity and help patients. The fact that these and other outcomes of ExBL are more to do with emotions than logical processes highlights a difference from PBL. The relationship between student and clinician is not just congruence with someone who knows the subject matter and is supportive, as in PBL, ${ }^{16}$ but an interaction with a model of what the student aspires to be. It is an interaction with a person who can help students build relationships with the patients they are leaming to care for. So ExBL transforms today's apprentices into tomorrow"s nuasters in a way that has been found true of interactions between surgeons and students in the operating theatre. ${ }^{17}$ The processes and products of ExBL are embedded in the triangular relationship between student, practitioner, and patient in a way that is distinct from PBL.

\section{Complexity of the clinical learning environment}

PBL focuses learning by abstracting some of the facts of a problematic situation from the complex environment in which it is enacted. ExBL does not remove situations from their contexts so students are exposed to their full complexity. ${ }^{10}$

\section{Clinical disciplines and horizontal integration}

Clinical teachers quoted in the thesis support its starting assumptions that "changes in clinical practice put pressures on traditional apprenticeship" and that teachers are confused about their roles and responsibilities. Through the eyes of clinical teachers, the official curriculum is divorced from the leaming they are keenest to offer. That might be dismissed as a problem to be overcome by training them better, or an argument for learners to spend more time in general practice, were it not that students value the mastery of clinicians, including specialists like surgeons. ${ }^{19}$ Perhaps it is because there is a gap between the official curriculum and teachers' clinical mastery that they hold onto outdated representations of clinical practice represented by rarities, surprise, and exotic physical signs, not the holism that a least some of them practice. The thesis and other research not included in it ${ }^{20}$ report the success of a technology and evaluation process that draw the integrative objectives of the official curriculum closer to what students and teachers do in the workplace, suggesting that the gap can be bridged. 


\section{Self directed learning}

In common with earlier writers, ${ }^{21}$ this thesis finds limitations in Knowles" original concept of self directed learning, ${ }^{22}$ which was influential in the early years of PBL. ${ }^{23}$ However, even PBL is not truly self directed because it has clear objectives for students" learning, though they are "buried" in scenarios. ExBL, the research finds, is only "self directed" when students are left without support and guidance. Having explicit objectives, they say, helps their learning. One of them (extract 3.a.2) criticises the term "self directed learning" because it confuses "direction" with "motivation". Given direction, as they are by a PBL scenario or iSUS, ${ }^{20}$ students are motivated and make choices. The relationship between teacher and student in the workplace is so "asymmetrical" 24 that students' need for support is a continuing one. So, "supported participation" is the core condition for ExBL.

\section{Difference or incompatibility}

To say ExBL is different from PBL is not to say the two are incompatible. Part of the novelty of this research has been to identify aspects of learning that do not fit the PBL model so well. The following section frames then and seeks to answer the question "how should students learn in workplaces?" in a way that might help curriculum designers.

\section{FURTHER ANALYSIS AND IMPLICATIONS FOR CURRICULUM DESIGN}

\section{The clinical curriculum as a continum}

Like earlier publications, this thesis identifies progression from preclinical to clinical learning as a transition whose abruptness can have adverse effects on students' emotions. ${ }^{1314}{ }^{25-27}$ The finding that the processes and products of medical education evolve even within the clinical curriculum years is further evidence that the clinical curriculum should be thought of as a continuum. A related finding is that what a student learns in the workplace one day helps them learn better in the workplace the next day. Just as clinical skills learned through early experience help students make the transition from preclinical to clinical learning, supported participation within the workplace makes them better learners. A medical curriculum, the research suggests, should be designed as a continuum. Students should be "titred" into workplace learning. Experience should be distributed through the curriculum and opportunities for participation sequenced in a way that sustains students' motrvation, builds their confidence, clinical skills, and professional identity, and allows them to acquire competences appropriate to their stage of training. A particularly important implication is that curriculum 
designers should seek opportunities for students to participate actively in their early clinical exposure.

\section{Continuty of experience versus "teachable moments"}

A starting point for the thesis was the assumption that increased sub-specialisation inakes it difficult for students to encounter all the clinical disciplines that could resource their learning. There is a "trade-off" between the number of specialties they are attached to and the time they can spend attached to each of them. A novel instructional design reported in this thesis and elsewhere ${ }^{28}$ is to provide the flexible structure of a "signup system" (instrumented with information technology 20 y to help students attached to one specialty learn simultaneotisly from others. This is an important feature of ExBL because it helps students achieve their PBL learning goals by having brief exposures to specialist practice. Student respondents describe in the thesis how signups help them reconcile continuity and variety. To help them learn from these brief encounters, clinicians must recognise and respond to "teachable moments". ${ }^{29}$ The research has not addressed in detail how such moments should be handled other than to identify one-minute preceptorship as a practical solution supported by empirical research that is worth further exploration in the context of ExBL ${ }^{30-33}$

\section{Outromes of ExBL}

Table 9.1 synthesises a set of outcomes that is intended not to be specific to any particular clinical workplace though the research is open to bias because it was conducted in a hospital setting. They change in character as students progress through the curriculun. Early objectives include the basic emotions that will sustain them through the long process of medical training and the knowledge and skills that will provide a foundation for their workplace learning. The thesis supports previous research showing that students have to restructure those foundation competences to make them more relevant to practice and acquire new. more applied competences as they progress through the curriculum. ${ }^{131426}$ "They have to sustain their altruism and motivation, and develop confidence in settings that becoming increasingly close to the context of practice. They have to build study skills that evolve from those of the freshman science student to participant in practice, as lhas been reported by others. 12 . 34 They have to broaden their perspective on life and learn about diseases, clinical situations, and the attributes of practitioners that they see represented in authentic practice. They have to build a sense of identity that evolves, eventually, into the professional identity of a doctor. "They have to acquire, through contact with "real patients", the curriculum coverage that will make them fit for practice. One distinctive feature of ExBL is the interrelatedness of its emotional, social, cognitive, and psychomotor outcomes, a point that has received little attention in earlier publications. An- 


\section{Table 9.1 Outcomes of ExBL}

\section{Knowledge}

Broader and stronger knowledge of foundation disciplines

Knowledge of how foundation disciplines apply in practice

Applied knowledge of, for example:

- Professional roles and responsibilities

- How diseases impact on people

- Public health

\section{Higher order intellecrual skills}

For example:

- Clinical information gathering

- Diagnostic logic

- Appraisal and application of research evidence

- Application of ethical principles to practice

\section{Emotions/atitudes tourards oneself}

Motivation

Self confidence

Reward

Feeling of comfort and usefulness in clinical settings

Sense of:

- Vocation

- Professional identity

Self awareness and ability to handle strong emotions

\section{Attitudes towards others and practice}

Altruism

Enpathy

Positive atcitudes towards practice

\section{Clinical skills}

Communication and clinical skills as detailed in the official curriculum

\section{Study skills}

Knowledge of, for example:

- What to learn

- What to attend

- How to access clinical experience

- Etiquette

Ability to choose appropriate learning experiences

Reflective skills

Self regulation and time management

\section{Cumiculum coverage}

An appropriate quantity and quality of authentic (real clinical) experience of the diseases, situations, and skills detailed in the official curriculum. 
other is the sher complexity of the leaming outcomes and their almost inextricable linkage to the learning enviroment. An effective curriculum design would make explicit this breadth of outcomes and sequence them as discussed in the last section. From the assessment perspective, the thesis shows that summative assessment can be regarded as, at best, 35 only one measure of students" learning.

\section{Conditions for learning}

Atributes and roles of students and teachers - The research has not examined the role of students other than the requirement that they respond actively to conditions created by curriculum planners and teachers. It has assumed that students will be stimulated to learn reflectively ${ }^{36}$ by interacting with peers and teachers ${ }^{37}$ though published research shows that they vary in their capacity to do so. ${ }^{1038}$ The research indicates that students need just enough "external guidance" to motivate them to learn, developing over time a capacity for "internal guidance" that has been described by other researchers. ${ }^{39}$ The research supports previous publications showing that effective clinical teachers are well disposed towards students and enjoy teaching them. They are good clinicians who like being stimulated to reflect on their practice. They are supportive colleagues, effective supervisors, and good role models, who are open minded, and humane. 4041 Table 9.2 lists important roles of clinical teachers in ExBL, which they fulfil by developing what has been described as a "teaching-learning alliance" with students. ${ }^{25}$ The research finds that they do so by being receptive, encouraging, and enthusiastic. They inspire students' self-confidence and build a mutual sense of trust and respect. They ensure that students are able to access the workplace. They help them interpret their experiences and feel part of the clinical team. They advocate students' learning needs to patients. They role model, guide, facilitate, explain. question sensitively, and coach. "They help students become involved in practice, observe their performance, and give feedback.

Those observations have implication for the recruitment of teachers and for teacher training: Clinicians, in general, are ready to teach and readien to support ExBL than PBL. They might benefit from faculty development that shows them how to help students achieve curriculum coverage by participating in practice as fully as their current level of experience permits. Activities that are integral to clinical practice provide ready opportunities, though teachers in training might learn from skilled teachers how to turn a wider variety of workplace interactions into experiences of supported participation. They might learn how to make their students ${ }^{3}$ role increasingly close in nature to the role of a doctor as they progress through the course, the two merging when they graduate. It has been said that, in fostering self directed learning, Manchester "forgot about its teach- 
Table 9.2 The role of clinical teachers in ExBL

\section{Create a good leaming enviroment}

Lead and/or contribute to a community of practice within a learing onganisation

Model excellent clinical practice

\section{Know the curriculum}

Subject matter

Educationai processes

Curriculum structure

\section{Be a supportive person}

Be interested in learners and their learning

Get to know them as individuals

Be welcoming, accessible, friendly, and enthusiastic

Give time to education

Take an interest in learners" career aspirations

\section{Promote active participation}

Advocate students' needs to patients

Help students express their learning needs

Assess their abilities

Make it possible for them to attend clinical activities

Explain and coach

Make opportunities to rehearse or perform tasks

Be prepared to share your expertise

Use students as assistants

\section{Help students learn from experience}

Bries

Observe performance

Give constructive feedback

promote reflection

\section{Be demanding}

Ask questions, particularly concerning patient management

Allocate realistic tasks and ensure they are accomplished

ers". The research shows how students" fitness for practice could have suffered as a result. Hence, an important conclusion of the research is that a medical curriculum should actively support clinicians and value their mastery.

Leaming enviroments - A basic assumption of this thesis is that ExBL takes place in a complex and variable learning environment. The research consistently shows that supportive interactions with practitioners surrounding "experience" help students attain the learning outcomes in table 9.1. In other words, a cardinal 
feature of the learning environment is its social nature. Environment, process, and product are tightly interrelated. The implication for instructional design is that ExBL should take place within supportive learning environments. Table 9.2 suggests how clinical teachers can create a good learning environment. The thesis instruments and evaluates a method of evaluating what is described elsewhere in the medical education research literature as "educational climate. ${ }^{42-45}$ Whether in a pathology department, ward, outpatient clinic, or general practice, the research shows that favourable ratios of students to staff and students to patients is an important condition for learning.

\section{Instrumentation}

Since the traditional clinical curriculum was one and the same as the activities of the workplace, no instrumentation was needed beyond the instrumentation of practice. However, there needs to be some way of guiding and registering learning in a curriculum guided by a set of objectives. Log books are widely used but they have a disappointing impact on clinical learning. ${ }^{46}$ Research described here and elsewhere 2028 shows how educational technology can support ExBL by presenting students with their objectives and:

- Managing attendance at compulsory and voluntary learning events

- Managing the reflective feedback cycle and maintaining individual portfolios of learning experiences

- Providing those and other supports to the students' learning in a single, comprehensive, virtual managed learning enviromment.

\section{Evaluation and assessment}

ExBL requires both evaluation and assessment instruments that, in the hands of students and teachers, help shape the clinical teaching and learning process. Together with carlier research by the author, ${ }^{47}$ the thesis presents evidence that summative assessment should be regarded not as a solitary gold standard but as just one measure of educational outcome. It identifies various aspects of students' curriculum in action: Their real patient learning; curriculum coverage; conditions for leaming; and instructional quality. It develops and validates a measure of them. By making explicit students' workplace teaching and learning, and relating them to the objectives of the official curriculum, this measure could be of formative value in ExBL.

\section{Experience based learning model}

The two explanatory models that were developed in the thesis are amalgamated, presented as a single model, and explained in figure 9.1. 


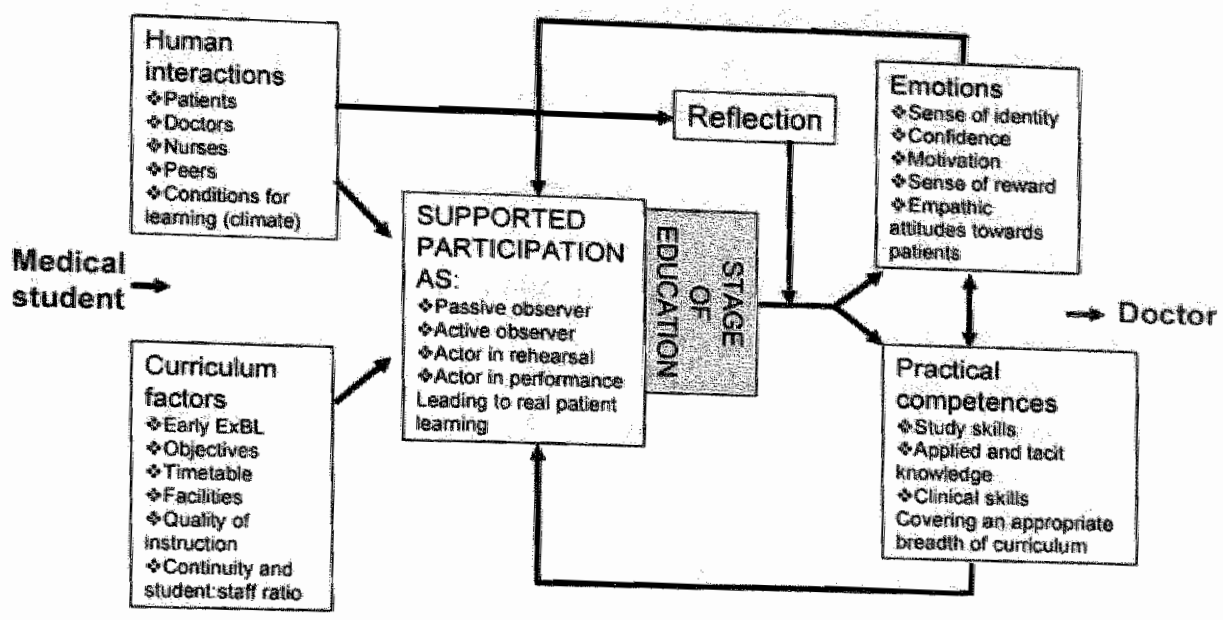

\section{Context \\ Process \\ Outcome}

Figure 9.1 The ExBL model

Interaction with other actors in the wotkplace, together with various organisational and material features of the curriculum, lead students to participate, with support, in clinical activities and reflect on their learning. The nature of those activities ewolves as students go throngh the various stages of medical training. Supported participation helps students develop a range of enotional and practical competences, which thersselves serve to make it easier for students to learn in workplaces in the future.

\section{STRENGTHS AND LIMITATIONS OF THE RESEARCH}

\section{STRENGTHS}

The strengths of the research are its inportance, originality, and methodological rigour. It is important because clinical students in every medical school in the world spend about half their curriculum learning in workplaces and yet there has been less innovative research in workplace learning than, for example, preclinical learning, skills training, or assessment. The author"s position as co-lead of an innovative medical curriculum, education researcher, clinical teacher, and practising doctor, gave him a rather unique entrée to the worlds of clinician and student, creating rich opportunities to conduct relevant research. Schmidt, a leading education researcher, recently classified education research into three types: "This is how we do it" research, "justification", and "clarification" research. Most of the research in this thesis falls into the clarification category, on which he suggested education researchers should concentrate their efforts. ${ }^{\text {* }}$ 
There are several ways in which the research is onginal. The novelty of Manchester"s curriculum made possible design based research ${ }^{49}$ that would have been difficult, at least on such arge scale, elsewhere. The bread th of the research is also original; whereas previous research has been bound to specific workplaces like ambulatory clinics, clerkships, or family practice, this research set its scope wide enough to include all such learning environments. By overarching such diverse workplaces, it has been possible to avoid pre-suppositions that bind the conclusions to any single clinical context. Another original feature is the development of a novel educational technology, iSUS, whose design specification arose from the early stages of the research. Later, iSUS became able to bind education delivery and research into a single exercise. The signups concept itself and Module Questionnaire are other original products of this research.

The research was rigorom both because individual pieces of research were rigorous and because topics were researched using more than one methodology, permitting triangulation between them. For example, the two different studies of early experience were mutually supportive, as were the two design based research studies into students' workplace learning. Another strength was the application of a similar method to more than one stakeholder group; for example, the thesis reports qualitative research into both teachers and learners' experiences of workplace learning. The research as a whole represents a coherent corpus of work centred on one specific topic. Having framed the topic, the author made conscious efforts to step aside from this presuppositions about clinicall learning

and ask broad questions. The mixture of qualitative and quantitative research, both within and between chapters, is another strength because it allows cross-comparison between results obtained in the two different research traditions.

\section{IIMITATIONS}

There are important limitations in the generalisability of the research, the lack of information on effect sizes, the susceptibility of the research to bias, its observational nature, and some assumptions that had to be made to draw conclusions from it. Its generalisability is limited by the extensive use of qualitative method, which is also responsible for the lack of quantified effect sizes. So, for example, the research into teachers' and students' experiences of workplace learning did not set out to be generalisable across all possible curricula and stakeholder groups, but to identify conditions for learning that prevailed in one curriculum at one point of time. Whilst a question mark hangs over the generalisability of the findings, the research has generated causal models that can be tested empirically in the future, which goes some way to offset that limitation. Moreover, many of 
the research findings are supported by earlier publications on clinical workplace learning.

There are various sources of bias. One is exemplified by the systematic review of early experience, whose conclusions may be unduly positive because it is easier to publish positive than negative findings. Even within individual publications included in the systematic review, the methodology may have been more sensitive to positive than negative effects. Most chapters report their outcomes qualitatively and may therefore be more sensitive to positive than negative findings. Even the design based research was uncontrolled, making it susceptible to a Haw thone effect. The author's participant observer status may have introduced a bias and his perspective as a specialist hospital practitioner may have made him insensitive to, or even prejudiced him against, primary care aspects of the research. However, there were co-researchers from different professional backgrounds in each study who were tasked, notably in the study of clinical teachers, to help him identify and make explicit his biases.

The obserwational natwe of much of the research leaves it for future research to demonstrate whether or not the causal models are valid. Moreover, some of the observations (for example, the study of the curriculum in action) were made over quite short time periods so it cannot be assumed their results will be born out by longer term studies.

Numerous assumptions have been made in interpreting this research. For example, the definition of experience applied to all 5 years of the curriculum was derived from studies in Phase 1 without evidence of its transferability to the other years. The intended learning outcomes of ExBL proposed earlier in this chapter were arrived at by analysing the opinions and reactions of clinical learners, making the assumption that learners know the outcomes that will make them competent practitioners. Throughout the thesis, the assumption is made that stakeholders" interpretations of their experiences constitute a type of "fact", an assumption that is firmly rooted in constructivist epistemology.

\section{Future researd}

The research reported here has arrived at some pedagogic principles for ExBL; now they and the various assumptions made in arriving at them need to be explored empirically. There is an argument that education is simply too complex to be subjected to justification research (what have been described disparagingly, elsewhere, as "grand educational experiments" 50 ) so there is a need for clarification research that can further inform instructional design. 


\section{DEFUNITION OF EXPERIENCE}

Research in the Phase 1 curriculum produced a working definition of experience" $^{*}$, which was tentatively applied to the clinicall curriculum years. With hindsight, the research findings suggest that the definition is incomplete. Exploratory research could test the relevance of a definition such as." "Authentic (real as opposed to simulated) human contact in a social or clinical context that enthances leaming of health, illness and/or disease, and the role of the health professional, and helps the learner construct a professional identity that makes them fit for practice". Not only would a working definition be practically useful, but it would be informative to test the assumption in this thesis that early and late experiences have fundamentally the same goal and nature. Such research would entail developing a measure of identity construction, which could be a useful measure of the outcome of ExBL. It would be valuable to research in more detail the microdynamics of the vicious and virtuous cycles of ExBL.

\section{THE CLINICAL TEACHER AND EXBL}

A conclusion of this chapter is that curricula that forget about the mastery of their teachers do so at the peril of their students. "There is a need for research into faculty development for ExBL. The thesis presents evidence that horizontal integration disempowers clinical teachers and is therefore not practicable. That nay have been the experience of research to date, but is it an inevitable conclusion? iSUS helped empower students to attain an integrative set of clinical learning objectives. To date, the functionality of iSUS to support teachers is very limited, perhaps another example of "forgetting the teacher". It could be hypothesised that extending iSUS to support teachers better could draw their curriculum in action closer to the official curriculum as it does for students.

\section{SUPPORTED PARTICIPATION AND PBL}

The research suggests that "supported participation" is a core condition for ExBL, which an ealier section of this chapter contrasts with the core conditions for PBL. It seems very complicated to suggest that clinicians must apply different conditions in their roles as PBL and ExBL teachers. Is it possible that the condition of supported participation could be introduced to PBL to draw the two pedagogies closer together?

\section{PAT\|ENTS AND EXBL}

The literature review concludes that it is ethically justifiable for patients to be involved in medical education and there may be potential for them to take on more expert roles. This thesis scarcely touches on the role of the patient, which is an important topic for future research. 


\section{REAL PATIENT LEARNING}

There is nothing particularly original about saying that students must learn from real patients although the measure of real patient learning developed in this research is novel. However, its exact nature and its relationship to curriculum coverage is conceptually unclear. Real patient learning could be an affective outcome, transfer of cognitive learning to the clinical context, integration of conceptual leaming, or the acquisition of practical skills. For the construct to be a very useful measure of learning outcome, its nature needs to be clarified. This research has assumed that students learn reflectively, but it is unknown exactly how that occurs, what conditions favour it, and whether even it is the most important aspect of workplace learning at this stage of professional development. Clarification research into reflective clinicall learning would be valuable.

\section{PREDICTIVE VALIDITY OF THE LEARNING OUTCOMES}

The research arrives at an inventory of intended learning outcomes and a validated measure of the curriculum in action. However, their predictive validity is unknown. The methods used to arrive at the inventory could do no more than put them forward as candidates. To have greater confidence in their validity, they need to be tested against the "gold standard" of undergraduate medical education, fitness for practice as a postgraduate learner. Likewise, there is a need for longer term observational research to test the predictive validity of the measures of the curriculum in action.

\section{INSTRUCTIONAL DESIGN}

The research concludes that new methods are needed to help students learn through participation in practice, but the thesis describes many obstacles to their participation. A useful exercise in instructional design would be to characterise those obstacles more thoroughly and find ways of overcoming them. The one instructional technique proposed here to help teachers make the most of "teachable moments" is one minute preceptorship. It was devised for intern or tesident education and its applicability to junior medical students is doubtful. An alternative set of microskills would be valuable.

\section{REFERENCES}

1. Millin BM, Campbell CB, Price DA. A conceptual framework to guide the development of self-directed, lifelong learning in problem-based medical curricula. Med Educ $2000 ; 34: 299-306$

2. Dolmans DHJM, Wolfhagen HAP, Van der Wleuten CPM. Motivational and cognitive processes influencing tutorial groups. Acad Med 1998; 22-4. 
3. Dachy ${ }^{*}$, Segers M, van den Bossche P. Gijbels D. Effects of problem-based learning: a meta-analysis. Learn Inst 2003; 13:533-68.

4. Dolnans DHJM, De Grave W, Wolfhagen IHAP, vari der Veuten CPM. Problem-based leaming: future challenges for educational practice and research. Med Educ $2005 ; 39: 732-41$.

5. McGrew MC, Skipper B, Palley $T$, Kaufman A. Student and faculty perceptions of problembased learning on a family medicine clerkship. Fam Med 1999; 31:171-6.

6. Dammers J, Spencer J, Thomas M. Using real patients in problem-based learaing: students' comments on the value of using real, as opposed to paper cases, in a problem-based leaming module in general practice. Med Educ 2001; 35:27-34.

7. van de Wiel MWJ, Schaper NC, Scherpbier AJJA, van der Vleuten CPM, Boshuizen HPA. Students" experiences with real-patient tutorials in a problem-based curriculum. Teach Learn Med 1999; 11:12-20.

8. Whitehouse CR, $O$ Neill $P$, Dornan $T$. Building confidence for work as house officers. Student experience in the final year of a new problem-based curriculum. Med Educ $2002 ; 36: 718-27$.

9. Sweeney $K$, Griffiths F, Eds. Complexity and healthcare. An introduction. Abingdon: Radcliffe Medical Press, 2002.

10. Niemi PM. Medical students professional identity: self-reflection during the preclinical years. Med Edtic 1997; 31:408-15.

11. Woolliscroft JO. Medical Student Clinical Education. In: Noman GR, wan der Vleuten CPM, Newble DI, Eds. International Handbook of Research and Medical Education. Dordrecht: Kluwer, 2002: 365-80.

12. Lyon PMA. Making the most of leaming in the operating the atre: student strategies and curricular initiatives. Med Educ 2003; 37:680-8.

13. Prince KJAH, Boshuizen HPA, van der Vleuten CPM, Scherpbier AJJA Students' opinions about their preparation for clinical practice. Med Educ 2005; 39:704-12.

14. Ratanawongsa $N$, Teherani A, Hauer KE. Third-year Medical Students' Experiences with Dying Patients during the Internal Medicine Clerkship: A Qualitative Study of the Informal Curriculum. Acad Med 2005; 80:641-7.

15. Schmidt HG. Foundations of problem-based leaming: some explanatory notes. Med Educ 1993; 27:422-32.

16. Schmidt HG, Moust JH. What makes a tutor effective? A structural-equations modelling approach to leaming in problem-based curricula. Acad Med 1995; 70:708-14.

17. Lyon P. A model of teaching and learning in the operating theatre. Med Educ 2004; 38:1278-87.

18. Fernald DH "Staudenmaier AC, Tressler CJ, Main DS, O'Brien-Gonzales A, Barley GE. Student perspectives on primary care preceptorships: enhancing the medical student preceptorship learning environment. Teach Learn Medicine 200 b; 1.3:13-20.

19. Mutha $\$$, Takayama JI, ONeil EH. Insights into medical students' career choices based on third and fourth-year student focus group discussions. Acad Med 1997; 72:635-40.

20. Doman T, Brown M, Powley D, Hopkins M. A technology using feedback to manage expentence based learning. Med 'Teach 2004; 26:736-8'.

21. Sohmidt H. Assumptions underlying self-directed leaming may be false. Med Educ $2000 ; 34: 243-5$.

22. Knowles MS. Self-directed learning. A guide for leamers and teachers. New York: New York Association Press, 1975. 
23. David TJ, Patel L. Adult learning theory, problem based learning, and paediatrics. Arch Dis Child 1995; 73:357-63.

24. Tiberius RG, Sinai J, Flak EA. The role of teacher-learner relationships in medicall education. In: Noman GR, van der Vleuten CPM, Newble DL, Eds. Intemational Handbook of research in medical education. Dordrecht: Kluwer, 2002: 463-97.

25. Yonke AM, Lemon M. First-year medical students and longitudinal prinary care. Acad Med 1993; 68:779-80.

26. Prince KJAH, Van de Wiel MWJ, Scherpbier AJA, Van der Vleuten CPM, Boshuizen. HPA. A qualitative analysis of the transition from theory to pratice in undergraduate training in a PBL-medical school. Adv Health Sci Educ Theory Pract 2000; 5:105-16.

27. Radclifte C. Lester H. Perceived stress during undergraduate medical training a quallitative study. Med Educ 2003; 37:32-8.

28. Foster M, Dornan $T$. Self-directed, integrated clinical learning through a signup system. Med Educ 2003; 37:656-9.

29. Branch WT, Paranjape A. Feedback and relection: teaching methods for clinical settings. Acad Med 2002; 77:1185-8.

30. Neher $\mathrm{OO}$, Gordon KC, Meyer B, Stevens N. A five-step "microskills" model of clinical teaching. J Am Board Fam Pract 1992; 5:419-24.

31. Ferenchick $G$, Simpson D, Blackman J, DaRosa D, Dumington $G$. Strategies for Efticient and Effective Teaching in the Ambulatory Care Setting. Acad Med 1997; $72: 277-280$.

32. Aagaard $E_{\text {, Teheran }} A$, Irby $D M$. Effectiveness of the one-minute preceptor model for diagnosing the patient and the learner: proof of concept. Acad Med 2004; 79:42-9

33. Irby DM, Aagaard E, Teherani A. Teaching points identified by preceptors observing one-minute preceptor and traditional preceptor encounters. Acad Med 2004; 79:50-5.

34. Seabrook MA. Clinical students' initial reports of the educational climate in a single medical school. Med Educ 2004; 38:659-69.

35. ten Cate $O$. What happens to the student? The neglected wariable in educational outcome research. Eval Health Prof 2001; 6:81-8.

36. Moon JA. Reflection in learning and professional development. London: Kogan Page, 1999.

37. Grant A, Doman TL, What is a learning portfolio? Diaber Med 2001; 18 (Suppl 1):1-4.

38. Epstein RM, Cole DR, Gawinski BA, Pootrowski-Lee S, Ruddy NB. How students learn fron community-based preceptors. Arch Fan Med 1998; 7:149-54.

39. ten Cate $O$, Snell $L$, Mann $K$, Vemunt J. Orienting teaching towards the learning process. Acad Med 2004; 79:219-28.

40. Prideaux $\mathrm{D}$, Alexander $\mathrm{H}$, Bower A ct al. Clinical teaching: maintaining an eduational role for doctors in the new health care environment. Med Educ 2000; 34:820-6.

41. Mann KV, Holmes DB, Hayes VM, Burge FI, Weld Viscount P. Community fanily medicine teachers ${ }^{3}$ perceptions of their teaching role. Med Educ 2001; 35:278-85.

42. Roff $\mathrm{S}$. New resources for measuring educational environunent. Med Teach 2005 ; 27:291-3.

43. Roff $S$. The Dundee Ready Educational Environment Measure (DREEM)-a generic instrument for measuring students' perceptions of undergraduate health professions cur ricula. Med Teach 2005; 27:322-5.

44. Roff $S$, McAleer $S$, Skinner A. Development and validation of an instrument to meamsure the postgraduate dinical learning and teaching educational caviroment for hospital-based junior doctors in the UK. Med Teach 2005; 27:326-31. 
45. Roff S. Education enviromment: a bibliography. Med Teach 2005; $27: 353-7$.

46. Jolly B. Clinical Jogbooks: recording clinical experiences may not be enough. Med Educ 1999: 33:86-8.

47. Doman T, Sicherpbier A, Boshuizen H. Towards vallid measures of self-directed clinical leaning. Med Educ 2003; 37:983-91.

48. Schmidr $H_{G}$. Plenary lecture. Education Research. Amsterdam: Association for the Study of Medical Education Conference, 2005.

49. The Design-Based Research Collective. Design-Based Research: An Emerging Para digm for Educational Inquiry. Educ Res 2003; 32:5-8.

50. Norman $\mathrm{G} . \mathrm{RCT}=$ results confounded and trivial: the perils of grand educational experiments Med Educ 2003; 37:582-4. 


\section{Summary}

This thesis concerns those parts of undergraduate medical education that are conducted in practice settings. Nearly a century ago, Abraham Flexner"s reforms established an education design that prevailed throughout the 20 th century. The Flexnerian medical curriculum had a preparatory preclinical phase then progressed to apprenticeship learning from clinician scientists in hospitals, where practice and theory were integrated. However, the wind of change began to blow in the last decades of the 20th century. In the UK, the GMC publication Tomorrow's Doctors mandated a national move towards "the new medical education". The University of Manchester Medical School responded by changing to a spiral, $\mathrm{PBL}$ curriculum, albeit one that was not vertically integrated. The subject matter was horizontally integrated and clinical experience was offered within a thematic structure. Scenario based PBL was continued into the clinical years and clinical disciplines changed from being the organising principle of the curriculum to a resource within which students could fulfil their study agendas. "The Manchester experiment" had some unexpected results: Clinicians wanted to be apprentice masters and teach their disciplinary expertise, not facilitate integrative learning. Students did not show the expected self directed learning behaviour. Students and teachers seemed uncertain how to relate to one another.

Chapter 1 suggests that the conditions for clinical workplace learning differ in important ways from the conditions for PBL. It reviews published literature from an instructional design perspective. It concludes that clinical workplace learning takes place in a relatively uncontrolled, complex, dynamic learning environment, at the centre of which lies the triadic relationship between patient, practitioner and student. However, the literature is fragmentary and framed more in terms of specific contexts than any underpinning theory. Chapter 1 ends by posing the research question: "What should students in today's learner centred curricula learn in workplaces and how should they learn there?"

Chapter 2 asks why the new medical education seeks to introduce early workplace experience and break Flexner's preclinical to clinical sequence. The research reported in it uses grounded theory methodology to find common ground between students and staff of all levels of seniority and persuasions. Respondents, particularly students, favour early experience, which is defined as "authentic (real as opposed to simulated) human contact in a social or clinical 
context that anhances learning of health, illness and/or disease, and the role of the health professional" in "what would traditionally have been regarded as the preclinical (preclerkship) phase, usually the frrst 2 years." Chapter 2 produces an. inventory of educational objectives that start to answer the research question. Early experience, according to respondents, can be expected to have social and emotional outcomes that prepare students for workplace learning and their fitture professional role. It can also be expected to have cognitive outcomes and teach skills, including the skill of being a workplace learner. It can teach subject matter that reflects the epistemology of the new medical education. Chapter 2 grves important insights into clinical education. The abrupt transition from preclinical to clinical learning can have adverse effects, which might be avoided if the clinical curriculum were more of a continuum. Clinical learning is a very complex entity with a strong emotional dimension as well as the cognitive dimension recognised by PBL. Chapter 2 suggests, but cannot prove, that early workplace experience will motivate students, make them less socially isolated, and make their studies more relevant to clinical practice. It highlights an important gap between the perceptions of students and teachers. Students have a much more vocational view of their learning than teachers; teachers do not realise that they and their curriculum are students" greatest source of stress.

Chapter 3 and a more complete version of the research published elsewhere and posted on the intemet address much the same question as Chapter 2 , moving now from consensus to empirical evidence. They report a systematic review of the effects of early experience. The research is novel, both in its content and its methodology, being the first publication from the Best Evidence Medical Education collaboration. It confirms many of the putative benefits of early experience reported in Chapter 2 , including the notion of medical education as an evolving continum rather than a sequence of discrete components. It shows, additionally, that early experience can foster a socially responsive career orientation. The research is successful in drawing conclusions from a fragmentary literature, but susceptible to several biases favouring a positive conclusion. Moreover, it cannot quantify the benefits, let alone balance them against cost.

Chapter 4 reports the phenomenological analysis of a qualitative study of all intemists in Hope Hospital, who give their narratives of clinical workplace teaching and learming in a PBL curriculum. In doing so, the chapter supports several of the fundamental premises of the thesis - that the Manchester experiment disenfranchised teachers, that there are important differences between PBL and clinical learning, and that apprenticeship learning is under strain in the UK. Manchester's clinical teachers are confused about their role. Their conceptions of teaching are divorced from both objective based education and contemporary 
clinical practice. Nevertheless, they have strongly positive affects towards learners and their learning and are ready to enter the relationships that Chapter 1 suggests are so important. Chapter 4 concludes that PBL lacks important conditions for workplace learning, which teachers see as very important. It concludes, also, that traditional apprenticeship is unsustainable under present day conditions of practice. There is a need for new ways for leamers to develop a professional identity through social interaction with practitioners and reachers themselves need support and guidance. Whether the uncontrolled qualitative method biased respondents towards positive attitudes, and whether they would take up support if it were offered, the chapter cannot answer.

Chapter 5 is another qualitative study, again using grounded theory methodology. It directly addresses the main research question of the thesis by asking what medical students learn in workplaces and how they learn it. Respondents are drawn from different stages of the clinical curriculum, and some are participants in a complex intervention. They learn by participation in practice along a continum from observation to involvement, and from relearsal to performance. The chapter analyses the concept of participation in terms of interaction with practitioners in the workplace and students" contribution to clinical care. Performing to the benefit of patients, the research finds, is a powerful motivator. Students are helped to learn by practitioners who couple support with demand, act as students' advocates with patients, foster a favourable climate, and know the curriculum. Having too many students for the number of patients and practitioners interferes with learning. The chapter provides an inventory of outcomes from clinical workplace learning, including emotional and practical competence. Each of those outcomes reinforces the other and successful learning creates favourable condicions for future learning, while unsuccessful learning sets up the conditions for a downwards spiral. Again, this chapter finds that clini cal learning is an evolving process, now within the clinical phase of the curricnlum. It illustrates the altruistic motivation of at least some students. It illustrates the importance of relationships between students and practitioners as a precondition for participation. It supports a fundamental premise of the thesis by illustrating that the concept of "self direction" does not describe very well how students learn in the clinical workplace.

Chapter 6 examines the same fundamental premise by asking whether, and under what conditions, medical students can learn in a self directed manner in the clinical environment. It uses iSUS, an educational technology that was developed in response to some of the early findings of the study. The methodology is design based research, evaluated qualitatively, involving student respondents. The chapter suggests that "supported participation" would be a more appropri- 
ate paradigm than self direction. Students are rarely fully autonomous or subservient. They agree that they should be partially autonomous, but autonomy has prerequisite conditions, one of the most important of which is being given clear objectives. They learn best when they have organisational, affective, and pedagogic support. They rely on teachers to manage the learning environment. Supported thus, they are motivated and able to make choices. By analysing the concept of self direction, the chapter draws an important distinction between motivation and direction. Unlike PBL, the chapter suggests that clinical workplace learning needs explicit objectives. The chapter provides some "proof of concept" for iSUS. Although there is rigour in the methodology, and some novelty in the way the research opens a window into the student lifeworld, the uncontrolled nature of the study makes it susceptible to a Hawthome effect.

Chapter 7 explores the evaluation of learner centred, integrated clinical education, seeking to find out what medical students learn in workplaces and how they do so. It uses a psychometric methodology, first articulating a value system. derived from first principles and elements of the new medical education, according to which: Effective behaviour in authentic clinical situations is the goal of medical education; to achieve that, students should learn experientially in workplaces; according to the new medical education, clinical learning should be horizontally integrated; for integrative learning to be possible, students should be guided by a set of objectives; they should take at least some responsibility for their learning; learning is a social process that must be supported and sometimes instructed by senior practitioners; learners need experience to build up schemata; learning is internal to the learner but should be explicit. Factor analysis of the results produces a four factor solution represents conditions for and outcomes of learning. The research examines the first factor, in particular, which represents boundary conditions for learning. Evidence is presented of the factor"s validity, particularly its ability to discriminate between firms.

Chapter 8 reports further psychometric research using the same questionnaire as Chapter 7 , conceptualising the research in terms of "the curriculum in action". With an expanded dataset, there has been a small change in the factor structure, but now it is possible to examine how students' evaluations of the environment, process, and outcome of workplace learning interrelate, and correlate with assessment results. The analysis produces several summary measures: "Instruction"; "conditions for learning"; "curriculum coverage"; and "real patient learning". It finds no significant correlation between those measures and the results of progress test and OSCE summative assessments. The data support a model according to which instruction, conditions for leaming, and curriculum coverage, favour real patient learning. Women report higher levels of real pa- 
tient leaming and the measures are more strongly associated in women than men. Because of the novelty of the research, there is no gold standard against which to compare the results. Further external evidence of validity is needed, and the constructs of curriculum coverage and real patient learning need to be further explored. However, the research suggests that direct evaluation of the curriculum in action could have some value in clinical workplace learning.

Chapter 9 summarises the research findings, returning to the instructional design perspective of Chapter 1 . It concludes that the thesis has found important differences in the conditions for PBL and clinical workplace learning, particularly concerning the stimulus to learn, the role of clinical disciplines, the desirability of horizontal integration, and the applicability of the construct of self directed learning. It gives clinical workplace learning the name "Experience based learning (ExBL)" and suggests that PBL and ExBL are complementary to one another. It proposes that clinical curricula should offer early experience and be conceived of as a continuum, whose process and product evolves over time. To reconcile breadth of learning with continuity, it finds proof of concept for "signups", with their attendant technology iSUS, and suggests that further research is needed to show how clinicians can make best use of "teachable moments". It proposes an inventory of outcomes of ExBL, emphasising the application of knowledge, higher order intellectual skills, emotional and attitudinal outcomes, study skills for workplace learning, and curriculum coverage. It supports the concept of the workplace as a learning environment, and lists roles that doctors can usefully take on there. It discusses instrumentation, evaluation, and assessment of ExBL. It synthesises a unitary model for ExBL from the analytical model of Chapter 8 and the interpretive model of Chapter 5 . According to the model, students learn through supported participation. Human interactions and features of the curriculum design and delivery make participation possible. A complex set of educational outcomes result from participation, and those out comes are themselves conditions for further learning. Chapter 9 discusses ways in which the research is important, original, and rigorous, acknowledging limits to its generalisability, a lack of information about effect sizes, important sources of bias, assumptions that were made in interpreting the research, and the limitations inherent in the largely observational nature of the research. Finally, it suggests directions for future research. 
n 


\section{Samenvatting}

Het onderwerp van dit proefschrift is medisch onderwijs in de klinische praktijk. Bijna een eeuw geleden introduceerde Abraham Flexner zijn vernieuwingen, die het gezicht van het medisch onderwijs in de twintigste eeuw bepaald hebben. Het Flexneriaanse medisch curriculum wordt gekenmerkt door een voorbereidende preklinische fase gevolgd door een klinische fase waarin studenten in de kliniek leren volgens een leermeester-gezelnodel en waarin praktijk en theorie geintegreerd zijn. In de laatste decennia van de twintigste eeuw ging de wind in her medisch onderwijs uit een andere hoek waaien. In het Verenigd Koninkrijk bracht de General Medical Council 'Tomorrow's Doctors" uit en dit vormde de aanzet tot onderwijsvernieuwingen volgens het stramien van 'modern medisch onderwijs.' Voor de Faculteit Geneeskunde van de Universiteit van Manchester was dit aanleiding om een curriculumvernieuwing in gang te zetten waarbij een spiraalvormig PGO-curriculum werd ingevoerd. Het nieuwe curriculum kende geen verticale integratie. De inhoud was horizontaal geintegreerd en klinische contacten werden gestructureerd rondom een thema. De PGO-structuur op basis van scenario's liep door in de klinische fase en de klinische vakken waren niet langer bepalend voor de structuur van het curriculum. Deze vakken waren nu leermiddel voor studenten om hun leerdoelen te kunnen verwezenlijken. Het 'Manchester experiment' leverde enkele onverwachte resultaten op. Clinici bleken de voorkeur te geven aan de rol van leermeester voor co-assistenten en wilden in het onderwijs hun vakkennis doorgeven an studenten in plaats van hen te stimuleren tot integrerend leren. De studenten bleken het verwachte zelfgestuurde leergedrag niet te vertonen. Studenten en docenten waren onzeker over hun onderlinge relatic.

In Hoofdstuk 1 wordt ingegaan op belangrijke verschillen tussen condities voor onderwijs in de klinische praktijk en voor PGO. Er is cen literatuuronderzoek gedaan vanuit de invalshoek van onderwijskundig ontwerpen ('educational design'). De conclusie is dat de leeromgeving in de klinische praktijk gekenmerkt wordt door gebrek aan structuur, complexiteit en dynamiek en dat de triade patiënt, clinicus, student centraal staat. De literatuur is echter fragmentarisch en meer gericht op specifieke contexten dan op onderliggende theorie. Aan het eind van Hoofdstuk 1 wordt de volgende onderzoeksvraag geformuleerd: Wat en hoe moet de student leren in de klinische praktijk in een modern studentgericht curriculumquestion 
In Hoofdstuk 2 wordt de vraag gesteld waarom in modern medisch onderwijs klinische contacten voeg in het curriculum worden gepropageerd en de Flexneriaanse volgorde preklinische, klinische fase wordt verlaten. Het onderzoek dat in dit hoofdstuk beschreven wordt, is aitgevoerd volgens de "grounded theory"-methode. Et wordt nagegaan welke inzichten gedeeld worden door studenten en stafleden van verschillende niveaus en met verschillende opvattingen. De deelnemers staan positief ten opzichte van vroege klinische contacten. Dit geldt met name voor de studenten. De volgende definitie van vroege klinische ervaringen wordt gehanteerd: "authentieke (d.w.z. met echte personen, niet gesimuleerd) contacten in een sociale of klinische omgeving die stimuleren tot leren over gezondheid, ziek zijn en/of ziekten en de rol van de professional in de gezondheidszorg' en die plaatsvinden in 'wat in een traditioneel curriculum de preklinische fase zou heten, meestal de eerste twee jaar van het curriculim.' Dit onderzoek levert een inventarisatie op van onderwijskundige doelstellingen die een aanzet geven tot een antwoord op de onderzoeksvraag. De deelnemers an het onderzoek verwachten dat vroege praktijkerwaringen leereffecten hebben op sociaal en emotioneel gebied waardoor studenten worden voorbereid op het leren in de klinische praktijk en hun toekomstige professie. Ze verwachten ook leereffecten betreffende kennis en vardigheden, waaronder de vaardigheid om te leren in de praktijk. Ook kan er aandacht besteed worden an onderwerpen die voortvloeien uit de igzichten over kennis die kenmerkend zijn voor modern medisch onderwijs. Hoofdstuk 2 biedt belangrijke inzichten in klinisch onderwijs. De abrupte overgang van preklinisch naar klinisch onderwijs kan een negatief effect hebben. Dit kan vermeden worden als. het klinisch onderwijs meer het karakter krijgt van een continuium. Klinisch onderwijs is complex en kent, maast de cognitieve dimensie die in PGO aan de orde lkomt, ook sterke emotionele dimensies. Hoofdstuk 2 geeft aanwijzingen, maar geen bewijs, dat vroege praktijkervaringen de motivatie van studenten verhogen, hun sociale isolement doorbreken en de ansluiting van het klinisch onderwijs op de praktijk verbeteren. In dit hoofdstuk komt een klloof tussen de visie van studenten en docenten aan het licht. Studenten zien het onderwijs veel meer als beroepswoorbereiding; de docenten realiseren zich niet dat zijzelf en het curriculum de voomaamste bron van spanningen voor studenten vormen.

Het onderzoek in Hoofdstuk 3, warvan een vollediger versie beschikbaar is op cd-rom, gat in op vrijwell dezelfde vraag als Hoofdstuk 2. De andacht verschuift evenwel van het zoeken naar consensus naar het zoeken naar empirisch bewijs. Err wordt een systematisch overzicht gepresenteerd van de effecten van vroege praktijkervaringen. Zowel het onderwerp als de methodologie van het onderzoek zijn innovatief. Dit onderzoek is de eerste publicatie van de onder- 
zoeksgroep Best Evidence Medical Education. Het onderzoek bevestigt veel van de in Hoofdstuk 2 beschreven veronderstelde voordelen van vroege praktijkervaringen, zoals de visie op medisch onderwijs als een continuim in plats van een opeenvolging van afzonderlijke delen. Daarnaast laat het zien dat studenten door vroege praktijkervaringen gestimuleerd worden om een maatschappelijk georiënteerde houding te ontwikkelen ten aanzien van hun toekomstige loopbaan. Er worden conclusies getrokken op basis van de fragmentarische literatuur, maar deze zijn mogelijk beinvloed door verschillende bromnen van bias ten gunste van een positieve conclusie. Bovendien was het niet mogelijk om de voordelen van vroege praktijkcontacten te kwantificeren, laat staan ze af te zetten tegen de kosten.

Hoofdstuk 4 beschrijft een fenomenologische analyse van een kwalitatief onderzoek onder internisten in het Hope Hospital, die hun ervaringen met klinisch onderwijs in een $\mathrm{PGO}$-curriculum beschrijven. De resultaten van dit onderzoek bevestigen verschillende vooronderstellingen die ten grondslag liggen aan dit proefschrift, namelijk dat het 'Manchester experiment' docenten buiten spel zet, dat er belangrijke verschillen zijn tussen $\mathrm{PGO}$ en klinisch onderwijs en dat het leermeester-gezelmodel wan klinisch onderwijs in het Verenigd Koninkrijk onder druk staat. Onder klinisch docenten in Manchester bestaat verwarring over hun rol in het onderwijs. Hun ideeën over onderwijs zijn los komen te staan van zowel het leerdoelgerichte onderwijs als van de hedendaagse klinische praktijk. Niettemin is hun houding ten anzien van studenten en onderwijs zeer positief en zijn zij bereid om hun aandeel te leveren an de relaties die in Hoofdstuk 1 als belangrijk beschreven worden.

Hoofdstuk 5 beschrijft een kwalitatief onderzoek met behulp van de 'grounded theory'-methode. Het onderzoek gaat in op de centrale vraag van dit proefschrift door studenten te ondervragen over praktijkcontacten en hoe zij daarvan leren. De deehemende studenten zijn in verschillende fases van het klinisch curriculum. Een deel van hen is betrokken bij een complexe interventie. De studenten leten door middel van participatie in de klinische praktijk wantbij zij een continuüm doorlopen van observatie tot actieve participatie en van oefening tot uitvoering. Om het concept participatie te analyseren is gekeken naar de interactie tussen studenten en clinici in de praktijk en de bijdrage van studenten aan de klinische zorg. Het onderzoek wijst wit dat iets kunnen doen voor patiënten een krachtige motivatie vormt voor studenten. Studenten leren van clinici die zowel steun geven als eisen stellen, die contact tussen studenten en patiënten bevorderen, een gunstig klimat creëren en bekend zijn met het curriculum. Het leren wordt belemmerd als er te veel studenten zijn in verhouding. tot het beschikbare aantal patienten en climici. Dit hoofdstuk inventariseert uit- 
komsten van leren in de praktijk, zoals emotionele en praktische competenties. De uitkomsten versterken elkaar en leerzame ervaringen scheppen gunstige voorwaarden voor volgende leerervaringen. Niet-leerzame ervaringen daarentegen bergen het gewar in zich van het inzetten van een neergaande spiraal. In dit hoofdstuk wordt opnieuw bevestigd dat klinisch onderwijs een geleidelijk ontwikkelingsproces is, maar nu binnen de klinische fase van het curriculum. Het onderzoek illustreert dat sociale overwegingen de motivatie vormen voor althans een deel van de studenten. Het illustreert dat de relatie tussen studenten en clinici een belangrijke voorwaarde is voor succesvolle participatie van studenten. Het bevestigt een van de vooronderstellingen die in dit proefschrift onderzocht zijn door te illustreren dat het concept zelfsturing geen goede beschrijving geeft van de het leren van studenten in de klinische praktijk.

Hoofdstuk 6 beschrijft een onderzoek naar dezelfde vooronderstelling. De vraag wordt onderzocht of en onder welke condities geneeskundestudenten in staat zijn tot zelfsturing bij het leren in de klinische praktijk. Hierbij wordt gebruik gemaakt van iSUS, een onderwijskundige technologie ontwikkeld naar aanleiding van eerdere bevindingen uit dit onderzoek. Het onderzoek wordt uitgevoerd onder studenten volgens de methode van ontwerpgestuurd onderzoek (design-based research) en de bevindingen worden kwalitatief geëvalueerd. Er wordt gesteld dat begeleide participatie een beter paradigma vormt dan het concept zelfsturing. Studenten zijn slechts zelden absoluut autonoom of ondergeschikt. De studenten zijn van mening dat gedeeltelijke autonomie belangrijk is, maar dat er wel aan bepaalde voorwaarden moet zijn voldaan. Een van de belangrijkste voorwaarden is dat er duidelijk omschreven doelen worden gesteld. Studenten leren het meest als zij organisatorisch, emotioneel en onderwijskundig begeleid worden. Zij hebben steun nodig van docenten om in de leeromgeving goed te kunnen functioneren. Door deze steun worden zij gemotiveerd en kunnen zij keuzes maken. Bij het analyseren van het concept zelfsturing wordt een belangrijk onderscheid gemaakt tussen motivatie en sturing. Anders dan in PGO wordt woorgesteld dat leren in de klinische praktijk uit moet gaan van heldere doelstellingen. Het onderzoek biedt enige ondersteuning voor het onderliggende concept van iSUS. Ondanks de degelijke onderzoeksmethodologie en de vernieuwende wijze warop een beeld van de leefwereld van studenten gegeven wordt, bestaat de kans dat de resultaten beinvloed zign door een Hawthorne-effect, omdat het onderzoek is uitgevoerd zonder controlegroep.

Hoofdstuk 7 betreft een evaluatie van studentgericht, geintegreerd klinisch onderwijs waarbij onderzocht wordt wat en hoe geneeskundestudenten leren in de klinische praktijk. Er worden psychometrische methoden toegepast. Om te 
beginnen wordt een waardensysteem opgesteld ontleend aan de basisprincipes en onderdelen van modern medisch onderwijs. Volgens dit systeem is effectief gedrag in authentieke klinische situaties het doel van medisch onderwijs en moeten studenten om dat te bereiken leren van praktijkervaringen; volgens modern medisch onderwijs moet klinisch onderwijs horizontaal geintegreerd zijm; vereist geintegreerd onderwijs dat studenten leren op basis van duidelijke leerdoelen; moeten studenten minimaal enige verantwoordeljkheid dragen voor hun leren; is leren een sociall proces dat begeleid en soms gestuurd moet worden door ervaren clinici; moeten studenten ervaringen kumen opdoen om schema's te ontwikkelen; en is leren een intem proces dat zich afspeelt binnen de student, en geexpliciteerd dient te worden. Uit de factoranalyse komen vier factoren naar voren die voorwaarden voor en uitkomsten van het leerproces vertegenwoordigen. Het onderzoek betreft met name de eerste factor die bestaat uit randvoorwaarden voor leren. Er wordt bewijs gepresenteerd voor de validiteit van de factor, met name het discriminerend vernogen van de factor bij vergelijkingen tussen klinische onderafdelingen.

Hoofdstuk 8 beschrijt een psychometrisch onderzoek met behulp van de viagenlijst die in het onderzoek in Hoofdstuk 7 is gebruikt. Er wordt gekeken naar het curriculum-in-actie. Door uitbreiding van de dataset is de factorstructuur enigszins gewrizigd. Het is nu mogelijk om de relatie te onderzoeken tussen het oordeel van studenten over omgeving, proces en uitkomst van het leren in de klinische praktijk en deze te comeleren met toetsresultaten. De analyse levert een aantal maten op: 'instructie', 'voorwaarden voor lexen', 'dekking wan curriculuminhoud' en 'leren van echte patienten'. De correlatie tussen deze maten en de resultaten van summatieve toetsen zoals de voortgangstoets en OSCES is niet significant. De data ondersteunen een model watrin instructie, voorwarden voor leren en dekking van curriculuminhoud gunstig beinvloed worden door leren van echte patiënten. Vrouwen rapporteren meer patièntgebonden leren en de samenhang tussen de uitkomsten van de verschillende factoren is bij de vrouwen sterker dan bij de mannen. Aangezien dit onderzoek erg nieuw is, is er geen gouden standaard waaraan de resultaten kunnem worden getoetst. Extern bewijs voor de validiteit moet nog worden geleverd en daamaast is er onderzoek nodig naar de constructen dekking van curriculluminhoud en leren van echte patienten. Het onderzoek geeft echter aanwijingen dat een rechtstreekse evaluatie van het curriculum-in-actie waardevolle resultaten kan opleveren voor onderwijs in de klinische praktijk.

Hoofdstuk 9 vat de onderzoeksbevindingen samen en keert terug naar het witgangspunt van Hoofdstuk 1, namelijk onderwijskundig ontwerpen. Er wordt geconcludeerd dat het onderzoek belangrijke verschillen aran het licht heeft ge 
bracht tussen de condities voor PGO en leren in de klinische praktijk, met name met betrekking tot de motivatie om te leren, de rol van de klinische disciplines, de wenselijkheid van horizontale integratie en de bruikbaarheid van het construct zelfsturing. Er wordt een nieuwe naam voor praktijkgebonden leren voorgesteld, 'ervaringsgestuurd onderwijs' (EGO) en PGO en EGO worden gezien als complementaire onderwijsvormen. Dit betekent dat vroege praktijkcontacten in klinische curricula moeten worden opgenomen en gezien moeten worden als een continuium waarin proces en uitkomst zich geleidelijk ontwikkelen. Als manier om breedte van leren te combineren met continuiteit is het concept 'sigmup' (onderwijsmomenten in de kliniek waarvoor de student zich kan inschrijven) met bijbehorende iSUS-technologie geschikt gebleken. Verder onderzoek is nodig om na te gaan hoe clinici geschikte onderwijsmomenten zo goed mogelijk kunnen benutten. Er wordt een inventarisatie van uitkomsten van $\mathbb{E G O}$ voorgesteld waarbij de nadruk ligt op toepassing van kennis, hogere cognitieve vaardigheden, uitkomsten gerelateerd aan emotionele en attitudegebonden aspecten, studievaardigheden voor leren in de praktijk en dekking van curriculuminhoud. Het concept de praktijk als leeromgeving wordt ondersteund en er wordt een overzicht gegeven van de rollen die de arts hierin kan vervullen. Er wordt ingegaan op een instrumentarium, evaluatie en toetsing voor EGO. Een duidelijk EGO-model wordt afgeleid uit het analytisch model in Hoofdstuk 8 en het interpretatiemodel uit Hoofdstuk 5 . Volgens dit model leren studenten door begeleide participatie. Menselijke interacties en aspecten van curriculumontwerp en -uitvoering maken participatie mogelijk. Participatie leidt tot een complex samenstel van onderwijsuitkomsten, die zelf weer voorwaarden zijn voor verder leren. Hoofdstuk 9 laat zien dat het uitgevoerde onderzoek belangrijk, origineel en gedegen is. Daarnaast wordt aangegeven dat er beperkingen zijn met betrekking tot generaliseerbaarheid, weinig informatie over effectgroottes, belangrijke potentiele bronnen van bias, aannames waarop de interpretatie van de resultaten is gebaseerd en de beperkingen van observationeel onderzoek. Tot slot worden aanbevelingen gedaan voor vervolgonderzoek. 


\section{Acknowledgements}

If I were to acknowledge all the influences on me and the support I have received, these acknowledgements would be even longer than the thesis. My parents and the Dornans of the last generation introduced me to medicine and humanism. Flistory and Philosophy of Science rescued me from the dreary, impersonal grind of Cambridge preclinical medicine which, perversely, fired my interest in medical education. The Radcliffe Infirmary socialised me to clinical medicine in a way that only a small, friendly, scholarly medical school could do. David Weatherall and John Ledingham showed me just how good doctors can be and the two Roberts (Tattersall and Turner) inspired me to be a researcher. David Anderson brought me to Salford, and ultimately to this thesis, in his own gloriously idiosyncratic way. Les Tumberg invited a fledgling consultant to be Hospital Dean, and the rest is history. I would like to acknowledge everyone involved in "the Manchester experiment". Les Tumberg, Robert Boyd, and David Metcalfe started it and Jan van Dalen, in his own characteristically modest and understated way, wrote a report that "launched 1000 ships". Tim David, John McClure, Steve Tomlinson, and Roger Green were important agents for change. My partners-in-arms in the 1990 s were too numerous to mention individually, though I would like to single out the pathologists, notably Tony Freemont, Emyr Benbow, and Ray McMahon, who arrived slightly late and inexplicably cheerful to the BISC Management Group at $5 \mathrm{pm}$ on Fridays. The influence of Carl Whitehouse, Paul O'Neill, and Mike Cheshire was huge. Since I did not know them so well, it is even more invidious to name people responsible for successfully introducing PBL to Years $1: 2$ but Maynard Case, Sigrid Rutishauser, Keith Burdett, and Ioan Davies were prominent amongst them. Roger Green deserves our thanks for being prepared to take the risk.

During the 1990s, Peter Foster, Bill Sang, Brenda Nuttall, and Karen Gwinnutt supported me in launching education development work in Salford. At the same time, the members of the now-defunct Salford Division of Medicine supported my move towards education. Helen Buckler, Pauline Lee, Louise Wong and "the girls", John New, and Martin Gibson never seemed to grudge my diminishing contribution to the clinical work of our Unit. Bob Young I thank, in particular, for being a fantastic doctor and companion for 17 years, who has carried much of my load, and whose support of my interest in education has never wavered. I thank Marcia Gowenlock and Carol. Cartwright and their fellow medi- 
cal secretaries for keeping my clinical service running when my interests were elsewhere. 1 thank. Felicity Stewart and Jon Shaffer for their support of my Hospital Deanship and then for tolerating patiently my audacities of the last five years. I thank Debbie Leadbetter for both personal and practical support; she responds to my every new idiosyncrasy with inexplicable enthusiasm. Most recently, Judy Hadfield, Carol Swindells, Raj Jain, Tim Johnson, Maggie Johnson, and all the staff of medical education in Salford deserve my thanks for standing shoulder-to-shoulder and keeping education development moving forwards. Salford's loss of Andy Garner was the Medical School's gain. I thank him for his personal support and for empowering education and educators so well that he has brought a whole spirit of renewal to the undergraduate curriculum.

Only a person who has experienced Maastricht can understand the friendship, inspiration, and high-quality scholarship one inhales with every breath of Limburg air. Henk Schmidt, Cees van der Vleuten, and Jan van Dalen inspired me in my Summer School days of the early 90s. MHPE is a masterpiece of instructional design that enhances the lives of students like me who enroll on it. My thanks to all its staff, above all Els Boshuizen who very literally was MHPE for us students. Again, the danger of naming single individuals, but I would like to thank Gerard Majoor for getting us to swallow raw herrings, Henk van Berkel for coping with international variations on the theme of punctuality, and Arno Muijtjens for taking the most heterogeneous bunch of students you could ever imagine through the t-test from first principles. Andy Grant and Michelle Elizov mobilised the entire richness of South America to create the sheer anarchy of Monday evenings in the guesthouse. Charlotte Ringsted added the Scandinavian flavour with her 21 Danes. Add a touch of Nepal, Thailand, Sudan, and Pakistan, give Jan van Dalen a piano to play, incubate in Geke Blok's flat or the Kruithuis, and $\mathrm{PhD}$ theses like this one are born.

In Manchester, Chris Bundy and Lis Cordingley were a source of inspiration and support, particularly over Early Experience. Sonia Littlewood is my only medical student co-author in this oeuvre but to the many who have researched with me and the thousands I have taught, my thanks for being such a source of inspiration. Sonia would, I an sure, agree with me that the Early Experience TRG (John Spencer, Albert Scherpbier, Valmae Ypinazar, Stephen Margolis) were wonderful co-workers; what a shame they only ever met one another over the Internet. Nigel King's expertise in qualitative research enriched our work in important ways. Judy Hadfield turned water into money and administrative staff into co-researchers; iSUS and the Module Questionnaire would have faded into obscurity were it not for her. To a person who can turn supertankers round 
without anyone noticing what has happened, my eternal thanks for steering me. Martin Brown's name appears on only one publication in the thesis, but that underestimates his contribution. He is not just the computing scientist behind iSUS but a friend who has led me and others with a rod of iron to perform beyond our own beliefs. Arno's arrival on the psychometrics scene in this research showed me just what qualities it took to explain that t-test. His critique and close engagement not just improwed our work, but transfomed it in a way that allowed me to make sense of it.

As for Albert Scherpbier and Els Boshuizen, this thesis is an emergent property of an academic relationship that has been very important to me. I had a hunch that doing a Maastricht PhD would unlock a treasure store but I had no idea just what riches I would find inside it. Thank you for your humanity and camaraderie, not just with me, but with one another and your colleagues. Thank you, Els, for the quizzical look which presages a monosyllabic question, then a short statement that incubates over the next year or so into a complete reorientation of my ideas. Thank you for your mind, and your breadth of perspective. Thank you, also, for your hospitality in Valkenburg. One day, I would like to observe you wearing that hard hat, helping Hein demolish part of your house. Albert, thank you for your equanimity, most clearly demonstrated by your calm reaction to the Dutch ban on smoking in public buildings. I thank you, also, for tolerating the discussions that went on a little too long before adjourning to the front steps of your Institute. I particularly appreciate your understanding of just how often coffee cups and beer glasses need to be refilled. Thank you for the one time you said something I wrote needed to be longer, and for being a polymath of medical education research with a mind like a rapier.

My "even greater woman" "Ceri, has kept me going by encouraging me, tolerating my excesses, sharing my core values, and not allowing me to take myself too seriously. I am only sorry the thesis has turned her into a workaholic too. To my children, Kate and Ben, my thanks for "daring to be what you are"; life is never dull in your company. To Olivia Dornan, my thanks for Northern Ireland and for reminding ne just how funny life can be. To Jan and Kate, thank you for agreeing to be nyy Paranimfs. If the thesis had done nothing more than get you two to meet one another, the effort would have been worthwhile. 
n 


\section{Curriculum vitae}

Tim Dornan was born in 1950. He was a scholar at Repton School and an exhibitioner at Corpus Christi College, Cambridge, where he read for his first degree in Medical Sciences and History and Philosophy of Science. He studied clinical medicine at Oxford University, qualifying with a BM degree in 1975. His early postgraduate training was in Stoke-on-Trent, Oxford, and Nottinghann. He obtained the MRCP diploma in 1977 and was later elected FRCP. He conducted research into the risk factors for diabetic retinopathy in Oxford and was awarded a clinical research doctorate (DM) in 1982. After a post-doctoral year in Seattle, USA, where he researched the immunogenetics of type 1 diabetes, he resumed his specialist training in general internal medicine, diabetes, and endocrinology in Nottingham. He has continued research in his clinical specialty to the present time, focusing increasingly on the patient experience of disease. He was appointed Consultant Physician to the Salford Royal Hospitals in 1988. His interest in education began with his appointment as Hospital Dean for Clinical Studies, continuing to work as a full-time clinician until 2000. After a decade's leadership of "the new medical education" in his own hospital and University, he registered with the University of Maastricht in 2000 for the MHPE degree, which he was awarded cum laude in 2002. During that time, he started work on this thesis. He became a substantive Senior Lecturer in the University of Manchester in 2000 and was promoted to Professor of Medicine and Clinical Education in 2005. He continues to practice general internal medicine, diabetes, and endocrinology and was appointed Director of Medical Education to the Salford Royal Hospitals in 2005 . He is married to Ceri, a general practitioner, and has two adult children, Kate and Ben. He plays the bassoon regularly in orchestras and chamber groups around Manchester and sails. 